\title{
MÉTODOS NÃO-CONVENCIONAIS PARA DETERMINAÇÃO DE CELULOSE COMO PARÂMETRO DE SELEÇÃO DE ÁRVORES MATRIZES VISANDO A PRODUÇÃO DE POLPA KRAFT-AQ
}

\section{CARLA RODRIGUES DOS SANTOS}

Bacharel em Química

Orientador: Prof. Dr. CLÁUDIO ANGELI SANSíGOLO

\begin{abstract}
Dissertação apresentada à Escola Superior de Agricultura 'Luiz de Queiroz", Universidade de São Paulo, para obtenção do título de Mestre em Ciências, Área de Concentração: Ciência e Tecnologia de Madeiras.
\end{abstract}

PIRACICABA

Estado de São Paulo - Brasil

Maio -2000 
Dados Internacionais de Catalogação na Publicação (CIP) DIVISÃO DE BIBLIOTECA E DOCUMENTAÇÃO - Campus “Luiz de Queiroz"/USP

Santos, Carla Rodrigues dos

Métodos não-convencionais para determinação de celulose como parâmetro de seleção de árvores matrizes visando a produção de polpa kraft-AQ / Carla Rodrigues dos Santos. - - Piracicaba, 2000.

$117 \mathrm{p}$.

Dissertação (mestrado) - - Escola Superior de Agricultura Luiz de Queiroz, 2000. Bibliografia.

1. Celulose kraft de eucalipto 2. Deslignificação 3. Fibra de madeira 4. Lignina 5. Polpa de celulose 6. Propriedade físico-química 7. Tecnologia de celulose e papel 8. Tecnologia de madeira I. Título 


\section{DEDICATOERYA}

"Você não sabe o quanto eu caminhei pra chegar até aqui.

Percorri milhas e milhas antes de dormir, en não cochilei.

Os mais belos montes escalei.

Mas noites escuras de frio en chorei..."

(Aestrada - Cidade Megra)

Dentro de cada um de nós existe uma força maior nos impulsionando, nos encornjando a prosseguir, nos fazendo crer no dia de amanhã. Judo sabe, tudo vê, tudo pode. Se não fosse por ela, eu não teria chegado até aqui.

A esta força maior, chamada Deus, en dedico este trabatho.

Muito obrigada. 


\section{AGR ADECOMENJOS}

A minha mãe pelo apoio e dedicação; não sei se te amo por sermos tão diferentes ou tão iguais.

A meu pai, cuja presença física infelizmente não gozamos mais, porém seu exemplo de dignidade e responsabilidade se faz presente em nosso dia-a-dia.

A minha irmã Sheila pela companhia e incentivo.

Aos meus irmãos Gefferson e Ćmerson, simplesmente porque o sño.

À Elaine Cristina, não hó expressão que traduza a intensidade de nossa amizade.

Aos amigos Lena e Elsinho: amigo é aquele que mesmo longe, a qualquer distância, compartitha de nossa alegria mas, principalmente, de nossas dificuldades e provas.

Ao professor Cláudio Angeli Sansigolo pela perfeita orientação, atenção, empenho pessoal, apoio, amizade e valorização do meu trabalho.

Aos amigos de Piracicaba - Luciany, Lucimary, Anna Cristina, Lourdes, Érica e Guitherme - pela amizade sincera. 


\section{Aos amigos da UMESP-Botucatu, especialmente Ricardo, Silvia, Sylvinha,}

Shirley, professor Paulo Zenner, professor Elias e professora Carmen, pela amizade, convivência agradável e colaboração inestimável.

Aos novos amigos da Votorantim Celulose e Papel - Unidade Luiz Antonio - pela acollida calorosa, incentivo e, principalmente, pela amizade imediata.

À Univesidade de São Paulo, através da Escola Superior de Agricultura "Luiz de Queiroz", pela oportunidade de realizar o curso de Pós-Graduação.

A Universidade Estadual Paulista, através do Departamento de Ciências Ilorestais, por ceder o laboratório de Quimica da Madeira.

À Coordenação de Aperfeiçoamento de Pessoal de Nivel Superior (Capes), pelo auxilio financeiro concedido que permitiu a realização deste curso e deste trabatho.

A Luarcel Celulose e Papel pela concessão do material necessário para a realização deste estudo.

A todos que, direta on indiretamente, contribuiram para a conclusão deste trabatho.

Muito obrigada. 


\section{SUMÁRIO}

Página

LISTA DE TABELAS............................................................................. viii

LISTA DE FIGURAS......................................................................

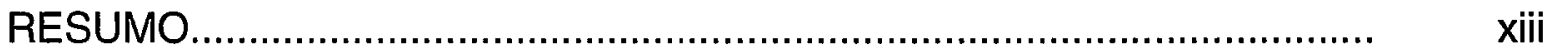

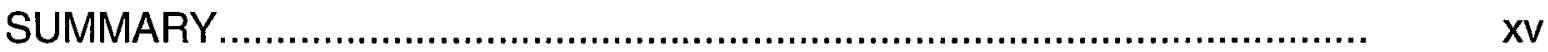

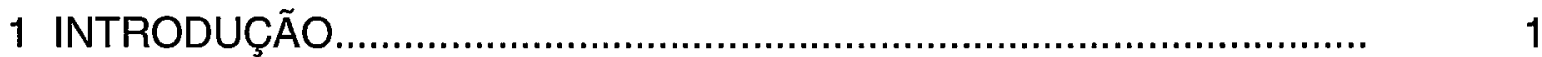

2 REVISÃO DE LITERATURA..............................................................

2.1 Máteria-prima............................................................................ 5

2.2 Propriedades físicas, químicas e anatômicas da madeira..................... 7

2.3 Densidade básica, composição química e rendimento em polpa kraft. 8

2.3.1 Relação entre densidade básica e composição química da madeira. $\quad 8$

2.3.2 Relação entre densidade básica e rendimento em polpa kraft.......... 11

2.3.3 Relação entre composição química e rendimento em polpa kraft..... 16

2.4 Conceitos químicos dos métodos não-convencionais para determinação de celulose................................................................ 21

3 MATERIAL E MÉTODOS.................................................................... 25

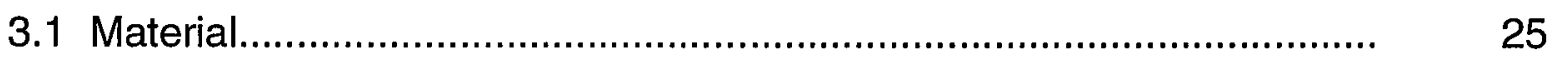

3.2 Métodos........................................................................................ 25

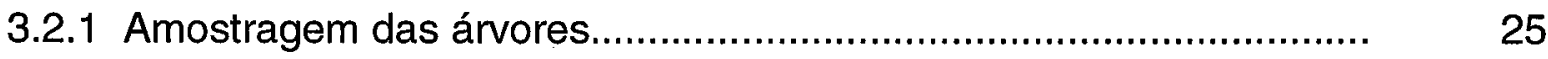

3.2.2 Densidade básica da madeira........................................................ 26

3.2.3 Volume e massa comercial da árvore.............................................. 26

3.2.4 Percentagem de casca em volume e massa de árvore.................... 27

3.2.5 Composição química da madeira........................................................ 28

3.2.6 Deslignificação kraft-AQ................................................................. 28

3.2.6.1 Lignina solubilizada na deslignificação kraft-AQ............................ 30

3.2.7 Métodos não-convencionais para determinação de celulose............. 31 
3.2.8 Determinação de $\alpha$-celulose como parâmetro de comparação para os métodos não-convencionais.

3.2.9 Análise do custo da deslignificação kraft-AQ para as árvores de Eucalyptus grandis.

4 RESULTADOS E DISCUSSÃO.

4.1 Relações entre propriedades da madeira.

4.1.1 Resultados dendrométricos.

4.1.2 Densidade básica. 36

4.1.3 Composição química tradicional da madeira.

4.1.4 Métodos não-convencionais para determinação de celulose.

4.1.4.1 Determinação de $\alpha$-celulose como parâmetro de comparação para os métodos não-convencionais.

4.1.4.2 Métodos não-convencionais de determinação de celulose e composição química tradicional da madeira.

4.1.5 Relação da densidade básica com a composição química tradicional da madeira e com os métodos não-convencionais de determinação de celulose.

4.1.5.1 Densidade básica e composição química tradicional da madeira...

4.1 5.2 Densidade básica e métodos não-convencionais de determinação de celulose na madeira.

4.2 Análise da deslignificação kraft-AQ.

4.3 Principais relações entre densidade básica e deslignificação kraft$A Q$.

4.3.1 Densidade básica e rendimento gravimétrico.

4.3.2 Densidade básica e número kappa

4.3.3 Densidade básica e consumo específico de madeira.

4.4 Principais relações entre componentes químicos da madeira e deslignificação kraft-AQ. 
4.5 Seleção tecnológica das árvores matrizes para produção de polpa kraft.

4.5.1 Análise do custo da deslignificação kraft-AQ para as árvores de Eucalyptus grandis.

5 CONCLUSÕES.

6 SUGESTÕES DE PROSSEGUIMENTO DA PESQUISA 93

7 REFERÊNCIAS BIBLIOGRÁFICAS. 94

ANEXO: Tabelas. 


\section{LISTA DE TABELAS}

Página

1 Dados dendrométricos médios para sessenta e quatro árvores de Eucalyptus grandis.

2 Densidade básica média para sessenta e quatro árvores de Eucalyptus grandis.

3 Composição química tradicional das árvores analisadas

4 Matriz de correlação dos componentes químicos da madeira de Eucalyptus grandis.

5 Análise da variância da regressão lignina versus holocelulose

6 Análise da variância da regressão extrativos totais versus holocelulose

7 Determinação de celulose por métodos não-convencionais para sessenta e quatro árvores de Eucalyptus grandis.

8 Matriz de correlação dos métodos não-convencionais para determinação de celulose.

9 Determinação de celulose por método normatizado e por métodos nãoconvencionais para quinze árvores de Eucalyptus grandis.

10 Matriz de correlação dos métodos não-convencionais e do método normatizado para determinação de celulose ...........................................

11 Matriz de correlação dos métodos não-convencionais e da composição química tradicional da madeira.

12 Matriz de correlação da densidade básica e da composição química tradicional da madeira.

13 Matriz de correlação da densidade básica e dos métodos nãoconvencionais de determinação de celulose na madeira

14 Valores de número kappa para as seis árvores testadas na deslignificação kraft-AQ. 
15 Valores médios da deslignificação kraft-AQ das sessenta e quatro árvores analisadas.

16 Matriz de correlação dos parâmetros da deslignificação kraft-AQ.........

17 Matriz de correlação da densidade básica e da deslignificação kraft$A Q$

18 Análise de variância da regressão número kappa versus densidade básica

19 Análise de variância da regressão lignina solubilizada versus densidade básica.

20 Análise de variância da regressão consumo específico versus densidade básica.

21 Matriz de correlação dos componentes químicos tradicionais da madeira e da deslignificação kraft-AQ.

22 Análise de variância da regressão número kappa versus holocelulose na madeira

23 Análise de variância da regressão número kappa versus lignina Klason na madeira

24 Análise de variância da regressão rendimento da deslignificação versus teor de lignina Klason na madeira.

25 Análise de variância da regressão rendimento da deslignificação versus teor de holocelulose na madeira.

26 Matriz de correlação dos métodos não-convencionais para determinação de celulose na madeira e da deslignificação kraft-AQ..

27 Análise de variância da regressão rendimento da deslignificação versus celulose na madeira pelo método do ácido peroxiacético

28 Resultados médios encontrados por Wright \& Wallis (1998) para os métodos não-convencionais de determinação de celulose.

29 Análise de variância da regressão número kappa versus celulose na madeira pelo método do ácido peroxiacético 
Página

30 Árvores selecionadas através dos critérios adotados nos resultados de rendimento e número kappa da deslignificação.................................

31 Densidade básica, composição química tradicional e determinação de celulose pelo método do ácido peroxiacético para as dezesseis árvores selecionadas quanto aos critérios da deslignificação..................

32 Árvores selecionadas quanto aos critérios de teor de celulose pelo

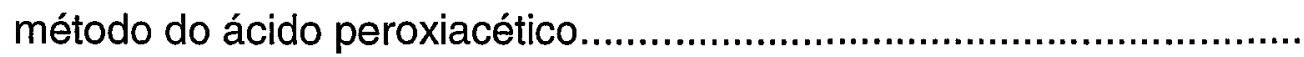

33 Árvores selecionadas através dos critérios adotados nos resultados de rendimento, número kappa e consumo específico de madeira da deslignificação.

34 Árvores selecionadas quanto ao critério adotado para determinação de celulose pelo método do ácido peroxiacético e suas respectivas densidades básicas.

35 Árvores selecionadas quanto ao critério adotado para determinação de celulose pelo método do ácido peroxiacético.

36 Análise do custo total da deslignificação kraft-AQ para as nove árvores de Eucalyptus grandis selecionadas tecnologicamente........... 


\section{LISTA DE FIGURAS}

Página

1 Relação entre teor de holocelulose e lignina na madeira de Eucalyptus grandis.

2 Relação entre teor de extrativos totais e holocelulose na madeira de Eucalyptus grandis.

3 Determinação de celulose na madeira por métodos não-convencionais.

4 Relação entre rendimento da deslignificação versus número kappa da polpa

5 Relação entre rendimento/número kappa versus número kappa da polpa

6 Relação logarítmica do rendimento/número kappa versus número kappa da polpa.

7 Relação entre número kappa da polpa e densidade básica da madeira.

8 Relação entre lignina solubilizada na deslignificação e densidade básica da madeira

9 Relação entre consumo específico de madeira/tonelada de polpa e densidade básica da madeira.

10 Relação entre número kappa da polpa e teor de holocelulose na madeira

11 Relação entre número kappa da polpa e teor de lignina Klason na madeira

12 Relação entre rendimento da deslignificação e teor de lignina Klason na madeira.

13 Relação entre rendimento da deslignificação e teor de holocelulose na madeira.

14 Relação entre rendimento da deslignificação e teor de celulose na madeira pelo método do ácido peroxiacético 
Página

15 Relação entre número kappa e celulose na madeira pelo método do

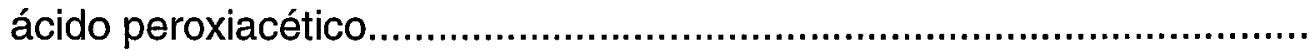




\title{
MÉTODOS NÃO-CONVENCIONAIS PARA DETERMINAÇÃO DE CELULOSE COMO PARÂMETRO DE SELEÇÃO DE ÁRVORES MATRIZES VISANDO A PRODUÇÃO DE POLPA KRAFT-AQ
}

\author{
Autora: CARLA RODRIGUES DOS SANTOS \\ Orientador: Prof. Dr. CLÁUDIO ANGELI SANSÍGOLO
}

\section{RESUMO}

O aumento da capacidade produtiva das indústrias de celulose e a crescente exigência do mercado consumidor, principalmente o externo, quanto à qualidade da polpa produzida, conduziu a um novo conceito de seleção das árvores para formação das florestas, buscando-se maior homogeneização da matéria-prima a ser utilizada pela indústria. A seleção por qualidade da madeira, atualmente, é realizada considerando-se os efeitos das propriedades físicas e químicas da madeira sobre o processo de deslignificação e na qualidade da polpa produzida. A densidade básica é considerada, na literatura correlata, como a principal propriedade física da madeira, influenciando diretamente o rendimento volumétrico do processo kraft. Componentes químicos da madeira, como a lignina e os extrativos, exercem considerável efeito sobre o consumo de álcali, ocasionando grande impacto sobre o custo e a produtividade da indústria de celulose kraft. Os polissacarídeos, principalmente a celulose, estão sendo considerados, com base nos estudos mais recentes, os melhores indicadores do rendimento da deslignificação kraft. Baseados neste fato, novas técnicas gravimétricas de determinação de celulose estão sendo investigadas. Tais técnicas se caracterizam por serem fáceis de 
executar, rápidas, econômicas e por possuírem correlações significativas com os parâmetros mais importantes da deslignificação. Com o objetivo de avaliar qual o parâmetro mais adequado para se selecionar árvores matrizes, foram realizadas análises tradicionais na madeira, tais como densidade básica e composição química, e não-convencionais para determinação do teor de celulose na mesma. Investigando-se isoladamente cada metodologia, os resultados indicaram que o teor de celulose na madeira pelo método do ácido peroxiacético (não-convencional) foi melhor parâmetro de seleção, ao se considerar rendimento da deslignificação e número kappa da polpa obtida, do que as técnicas tradicionalmente utilizadas. Árvores matrizes selecionadas a partir do teor de celulose na madeira e posteriormente para densidade básica permitiram otimizar o rendimento da deslignificação, número kappa e consumo específico de madeira, indicando uma nova e viável possibilidade de identificação das melhores árvores para produção de polpa kraft-AQ. 
NON-CONVENCIONAL METHODS FOR DETERMINATION OF CELLULOSE AS PARAMETER FOR PLUS TREES SELECTION AIMING AT KRAFT-AQ PULP PRODUCTION

\author{
Author: CARLA RODRIGUES DOS SANTOS \\ Adviser: Prof. Dr. CLÁUDIO ANGELI SANSÍGOLO
}

\title{
SUMMARY
}

The increase of the productive capacity of the pulp industries and the increasing requirement of the consuming market, mainly external, as for pulp quality, led to a new concept of selection of the trees for forest formation, searching homogeneous raw material to be used by the industry. The selection throught wood quality, currently, is carried through considering the effects of the physical and chemical properties of the wood on the delignification process and in the quality of the produced pulp. The basic density is considered, in current literature, as the main physical property of the wood, influencing directly the volumetric yield of the kraft process. Chemicals components of the wood, like lignin and extractives, exert considerable effect on the alcali consumption, causing great impact on the cost and productivity of the kraft pulp industry. The polysaccharides, mainly the cellulose, are being considered, in recent studies, the best pointers of the kraft delignification yield. Based in this fact, new gravimetrical techniques for cellulose determination have been developed. Such techniques are easy to execute, fast, economic and have significant correlation with the best parameters of the kraft delignification. With the purpose to evaluate the best parameter for plus trees selection, it was carried through traditional 
analyses in the wood, such as basic density and chemical composition, and non-conventional analyses for determination of cellulose content. Investigating separately each methodology, the results indicated that wood cellulose content for the peroxyacetic acid method was the best parameter of tree selection, when considering delignification yield and kappa number, other than traditional techniques. Selecting plus trees from wood cellulose content (peroxyacetic acid method) and later from basic density, allowed the optimization of the delignification yield, kappa number and wooden volumetric yield, indicating a new and viable possibility of identification of the best trees for kraft-AQ pulp production. 


\section{INTRODUÇÃO}

Atualmente o Eucalyptus grandis é uma das espécies que mais se destaca como matéria-prima para a produção de polpa no Brasil. Entre os fatores que contribuem para a adoção desta espécie, pode-se citar suas excelentes características silviculturais para plantios comerciais e altos níveis de produtividade em regiões subtropicais. Além do mais, oferece excelentes resultados na deslignificação, branqueamento e fabricação de papel.

No decorrer da década de 90 , especificamente na região sudeste do Brasil, iniciou-se a duplicação da capacidade produtiva das indústrias de celulose e papel. Esta expansão acarretou uma maior preocupação em um planejamento adequado de investimentos em reflorestamento por parte de algumas empresas, tendo em vista a possibilidade de se selecionar a madeira quanto aos seus aspectos de qualidade.

A competitividade da indústria de polpa kraft depende fortemente da possibilidade e habilidade de seleção das árvores matrizes mais adequadas para a formação das florestas. Neste contexto, a utilização da técnica de clonagem para formação de floresta possibilita maior rapidez na melhoria e maior homogeneização da matéria-prima a ser utilizada.

A avaliação e seleção da matéria-prima, no entanto, deve seguir alguns critérios de amostragem. É importante levar em consideração as variações que ocorrem com as propriedades da madeira em função da idade e da posição da amostra na árvore. Recomenda-se retirar os discos de 2,5 a $3,0 \mathrm{~cm}$ de espessura nas seguintes posições: 0, 25, 50, 75 e 100\% da altura comercial do 
tronco. As árvores devem ser cortadas em uma mesma idade e com iguais condições locais de crescimento, principalmente condições climáticas.

As condições laboratoriais para a prática da deslignificação deve se aproximar ao máximo daquela utilizada industrialmente, de forma a oferecer confiabilidade aos resultados.

Atualmente, para fins tecnológicos da madeira, as propriedades físicas e químicas da madeira têm sido consideradas no processo de avaliação da matéria-prima. Tem-se procurado avaliar os efeitos de tais propriedades no processo de deslignificação e na qualidade da polpa produzida.

A densidade básica tem sido considerada como um dos mais importantes parâmetros de qualidade da madeira. Sabe-se que o custo da madeira produzida, o rendimento do digestor (consumo específico de madeira) e a qualidade de polpa e papéis são influenciados por esta propriedade física.

Nos últimos anos, concretizada a importância da seleção das árvores matrizes mais apropriadas para formação das florestas, surgiu a preocupação em se reduzir ao máximo possível os gastos e tempo despendidos no processo de avaliação e seleção da matéria-prima a ser utilizada para a produção de polpas. A partir deste objetivo, acreditou-se que a inter-relação entre as propriedades da madeira (propriedades físicas e químicas) e, principalmente, destas com o rendimento do processo de deslignificação e número kappa da polpa, pudessem representar uma possibilidade viável. Mas os resultados observados têm afastado esta hipótese. Vale salientar que as propriedades da madeira, densidade básica, lignina, celulose, hemiceluloses e extrativos, constituem as características da madeira de maior impacto sobre o custo e a produtividade da indústria de polpa kraft de Eucalyptus, sendo que, os teores de lignina e extrativos são considerados como características químicas fundamentais, uma vez que influenciam diretamente o consumo de álcali, rendimento da deslignificação e o potencial de produção industrial. 
A observação da literatura correlata mais recente tem indicado que o comportamento do rendimento da deslignificação é quase que exclusivamente dependente do teor de polissacarídeos na madeira, principalmente da celulose. Este fato tem apoiado a investigação de métodos alternativos para a determinação do teor de celulose na madeira. O objetivo maior é desenvolver uma técnica de fácil execução, rápida e cujos resultados possuam relação direta com rendimento kraft.

Com base neste aspecto, no presente estudo, reproduziu-se três técnicas de determinação do teor de celulose na madeira. Todos os métodos reproduzidos se baseiam no princípio da solvólise da lignina, utilizando-se um ácido como catalisador. $O$ efeito da catálise ácida sobre a estrutura molecular da lignina e o poder solvolítico de alguns reagentes são fatos que já se encontram devidamente comprovados. 


\section{OBJETIVO}

Este trabalho teve por principal objetivo verificar qual o parâmetro da madeira mais adequado para se selecionar árvores matrizes de Eucalyptus grandis, verificando sua relação com 0 rendimento gravimétrico da deslignificação.

Para se atingir o objetivo principal foram definidos os seguintes objetivos específicos:

- Testar três metodologias não-convencionais de determinação do teor de celulose na madeira denominadas como: método do ácido nítrico, método do ácido peroxiacético e método da celulose Seifert.

- Estudar as relações entre os métodos não-convencionais de determinação do teor de celulose na madeira $e$ os parâmeros da deslignificação, principalmente rendimento bruto gravimétrico e número kappa.

- Investigar as relações entre os métodos tradicionais de determinação da composição química e da densidade básica da madeira e os parâmetros da deslignificação.

- Estudar as relações entre os métodos não-convencionais de determinação do teor de celulose na madeira e as propriedades químicas e densidade básica da madeira. 


\section{REVISÃO DE LITERATURA}

\subsection{Matéria-prima}

Em relação às madeiras de fibra longa, as madeiras de fibra curta apresentam, em geral, uma estrutura física mais complexa. Enquanto as madeiras de fibra longa consistem, essencialmente, de um tipo de fibra, o traqueíde, as madeiras de fibra curta, além de células libriformes normais, contêm uma grande proporção de células de parênquima e uma proporção ainda maior de elementos de vasos curtos porém, com grandes diâmetros (Jackson et al., 1989).

Tomazello Filho (1985) realizou estudo da estrutura anatômica da madeira de oito espécies de Eucalyptus, entre os quais Eucalyptus grandis. Encontrou para esta espécie a seguinte descrição anatômica: vasos pouco numerosos com predominância de pequenos, contorno oval e circular e perfuração única. Raios numerosos com predominância dos unisseriados. Parênquima paratraqueal escasso, vasicêntrico e aliforme. Fibras libriformes predominantemente curtas, estreitas, de espessura de parede média.

O Eucalyptus grandis, já há algumas décadas, tem se destacado como matéria-prima para a produção de celulose.

Kimo (1986) descreve que o Eucalyptus grandis começou a ser amplamente plantado no Brasil na década de 50, quando técnicos da ferrovia Paulista observaram, em alguns locais à margem da ferrovia, que o seu 
crescimento em altura e diâmetro era surpreendente em relação às demais espécies. Especialistas em manejo florestal realizaram então estudos comparativos entre Eucalyptus grandis e outras espécies, nas mesmas condições de clima e solo, e demonstraram sua superioridade silvicultural. Kimo, em seu trabalho, estudou 6 árvores de Eucalyptus grandis, com 9 anos de idade, coletadas na altura do DAP (diâmetro na altura do peito). Segundo o autor, a espécie possui boa potencialidade técnica para fornecer matéria-prima fibrosa para a produção de polpa celulósica.

Clarke et al. (1997), entretanto, estudaram 9 espécies de Eucalyptus e concluíram que, em geral, Eucalyptus grandis tem propriedades inferiores para produção de polpa; apresentou baixo teor de $\alpha$-celulose e altos teores de lignina e extrativos. Mas, segundo Busnardo et al. (1978), a espécie possui características silviculturais favoráveis ao plantio comercial, oferece altos níveis de produtividade em regiões subtropicais, facilita a obtenção de sementes puras e fornece excelentes resultados na deslignificação, branqueamento e fabricação de papel.

A partir da última década uma maior preocupação surgiu no sentido de se planejar adequados investimentos em reflorestamentos, de forma a se obter madeira de Eucalyptus com maior homogeneidade em suas propriedades físicas, químicas e anatômicas, assim como máxima rentabilidade do processo.

Neste aspecto, a necessidade de seleção das árvores matrizes mais adequadas é uma realidade, e o nível de competitividade de cada empresa dependerá, significativamente, dos esforços e recursos despendidos para tal seleção, ou seja, geração de árvores cada vez melhores em termos industriais e ecológicos (Fonseca et al., 1996). 


\subsection{Propriedades físicas, químicas e anatômicas da madeira}

Entre as propriedades da madeira, a densidade básica, propriedade física, é considerada como uma das mais importantes, devido ao fato de se relacionar às demais propriedades da madeira (físicas, químicas e anatômicas) e à qualidade da polpa celulósica produzida. Vários autores, tais como Barrichelo et al., 1993; Foelkel et al., 1974; Shimoyama,1990 e Valente et al., 1992, comentam ser a densidade básica uma propriedade altamente complexa, por ser o resultado da combinação de elementos anatômicos e compostos químicos da madeira.

* Também pode ser observada a ocorrência de interações entre as propriedades químicas e anatômicas, como foi verificado por Demuner et al. (1990) quando analisaram 4 amostras de polpas de Eucalyptus grandis e de Eucalyptus globulus. Concluíram que tais interações influenciaram de forma decisiva as respostas das polpas ao refino.

+ Machado et al. (1988) trabalhando com Eucalyptus grandis e Eucalyptus pilularis, com 7 e 6 anos de idade respectivamente, encontraram que o Eucalyptus pilularis apresentou maior densidade básica do que o Eucalyptus grandis. Como consequência, Eucalyptus pilularis apresentou maior resistência ao rasgo, índice de Runkel, volume específico aparente e opacidade porém, menor coeficiente de flexibilidade, menores resistência à tração, ao estouro e ao alongamento.

As propriedades anatômicas do gênero Eucalyptus se encontram bem estudadas e definidas na literatura, podendo-se encontrar um grande número de trabalhos disponíveis sobre este assunto.

Porém, se por um lado as relações da densidade básica com as propriedades anatômicas e qualidade da polpa se mostram com um certo consenso entre os autores, o mesmo não se pode afirmar em relação às propriedades químicas, além do mais, os trabalhos realizados neste sentido 
são em números reduzidos e utilizam sempre métodos tradicionais de análises químicas.

Shimoyama (1990) destaca que uma vez que a madeira, quimicamente, é formada por compostos de elevados graus de polimerização e massas moleculares, estes devem colaborar para o aumento da densidade básica.

Kellog et al. (1975) citam que a densidade específica dos constituintes químicos da madeira é a seguinte: para a holocelulose $1,521 \mathrm{~g} / \mathrm{cm}^{3}$, lignina $1,366 \mathrm{~g} / \mathrm{cm}^{3}$, hemiceluloses $1,457 \mathrm{~g} / \mathrm{cm}^{3}$ e para a $\alpha$-celulose $1,528 \mathrm{~g} / \mathrm{cm}^{3}$.

A composição química das madeiras de Eucalyptus geralmente tem se mostrado da seguinte forma: 48 a $55 \%$ de celulose, 17 a $22 \%$ de pentosanas, 20 a $24 \%$ de lignina e 5 a $10 \%$ de extrativos (Clarke et al., 1997).

Contudo, o verdadeiro grau de influência de cada um destes elementos sobre a densidade básica ainda merece estudos mais detalhados, devido aos resultados discrepantes encontrados na literatura correlata.

\subsection{Densidade básica, composição química e rendimento em polpa kraft}

\subsubsection{Relação entre densidade básica e composição química da madeira}

O aumento na capacidade produtiva verificado na última década trouxe consigo uma maior preocupação no sentido de se investir em reflorestamentos planejados. Nestas áreas o material reflorestado teria a mesma procedência e estaria sujeito às mesmas condições silviculturais. O maior objetivo desta prática é de se obter matéria-prima mais homogênea quanto à qualidade, visando a necessidade da otimização nos custos e no tempo envolvidos na avaliação e seleção da matéria-prima a ser utilizada.

Como alternativa para uma melhor avaliação e seleção da matériaprima, há algumas décadas, pesquisadores vêm tentando relacionar as 
diversas propriedades da madeira. Como resultado dos estudos realizados já se tem, na literatura, um consenso ao que diz respeito à relação da densidade básica com as propriedades anatômicas da madeira e com a qualidade da polpa. Entretanto, quando a questão se refere às propriedades químicas da madeira, observa-se um número menor de trabalhos disponiveis; isto se deve ao fato de que somente há alguns anos as atenções se tenham voltado mais ao estudo químico da madeira e suas inter-relações.

Segundo Fonseca et al. (1996), nas últimas décadas, os efeitos das propriedades químicas e físicas da madeira no processo de deslignificação e na qualidade da polpa de Eucalyptus obtida pelo processo kraft têm sido observados com mais ênfase.

No entanto, certas correlações encontradas têm sido confirmadas enquanto que outras ainda permanecem sem definição. Vale ressaltar, entretanto, que para o estudo destas correlações tem-se utilizado sempre análises tradicionais, tais como lignina Klason, holocelulose e extrativos totais.

Barrichelo \& Brito (1977), a partir de 10 árvores de Eucalyptus grandis com 6 anos de idade, cujos discos foram retirados na base, meio e topo da altura comercial, estudaram as variações das características da madeira e suas correlações com a produção de polpa. Encontraram que a densidade básica decresceu da base para o topo. A lignina também decresceu da base para o meio, a partir daí permanecendo constante até o topo. O teor de celulose se mostrou maior para as amostras colhidas na região central da árvore. Quanto às correlações, a densidade básica se correlacionou positivamente com diâmetros com e sem casca e negativamente com holocelulose. A lignina também, por sua vez, apresentou correlação negativa com teor de holocelulose. Porém, Vital et al. (1986), estudando clones de Eucalyptus grandis com 30 meses, encontraram que o teor de holocelulose é proporcional à densidade básica. 
Estudos realizados por Vasconcelos Dias \& Cláudio-da-Silva Júnior (1985) utilizando 25 árvores de Eucalyptus grandis de 7 anos de idade e mesma procedência, apontam correlação direta entre teor de lignina e valor de densidade básica da madeira e relação inversa entre densidade básica e hemiceluloses.

Concordando com estes resultados, está Wehr (1991) que estudou 4 lotes de tipos diferentes de madeiras de Eucalyptus grandis provenientes de plantios diferentes, cujas densidades básicas apresentaram amplas variações. Tais variações na densidade básica foram acompanhadas por diferenças na composição química. O autor observou que um aumento na densidade básica provoca aumento no teor de extrativos e lignina e uma diminuição no teor de hemiceluloses.

Resultados diferentes foram encontrados por Fonseca et al. (1996), utilizando 6 clones com idades variando de 1 a 7 anos e plantados em épocas diferentes; encontraram um aumento na densidade básica com a idade e uma diminuição no teor de lignina. Os autores ainda salientam que teores de lignina e extrativos são características químicas fundamentais, pois influenciam diretamente o consumo de álcali, rendimento da deslignificação e o potencial de produção industrial.

Shimoyama (1990), por sua vez, utilizando 30 árvores de Eucalyptus grandis com 7 anos de idade, não encontrou nenhuma correlação entre densidade básica e componentes químicos da madeira.

Machado et al. (1988) compararam a madeira de Eucalyptus pilularis e Eucalyptus grandis, com 6 e 7 anos de idade respectivamente. Ambas as espécies foram seccionadas em 5 toretes de $20 \mathrm{~cm}$ de comprimento localizados na base, $25,50,75$ e $100 \%$ da altura comercial. Os autores relatam que a espécie Eucalyptus pilularis apresentou maior densidade básica, maior solubilidade em água quente, $\mathrm{NaOH} 1 \%$ e álcool/tolueno. Ainda, maior teor de 
holocelulose, pentosanas e cinzas do que o Eucalyptus grandis. O teor de lignina se mostrou semelhante para ambas as espécies.

Foelkel et al. (1992) estudaram várias espécies de Eucalyptus com discos retirados na altura do DAP. Para o Eucalyptus grandis concluíram que um aumento na densidade básica é acompanhado por um decréscimo no teor de extrativos em diclorometano, solubilidade da madeira em $\mathrm{NaOH} 8 \%$ e teor de hemiceluloses.

O conhecimento das relações envolvendo as características da madeira e propriedades das polpas pode representar uma simplificação na avaliação das árvores mais apropriadas para produção de polpa kraft e minimizar o número de ensaios experimentais requeridos para tal. Tem-se buscado, ainda, análises mais rápidas, econômicas e que permitam a avaliação conjunta de várias árvores. Alguns resultados já podem ser encontrados nas literaturas mais recentes, tais como os relatados por Wallis et al. (1996b) e Wright \& Wallis (1998).

As correlações envolvendo densidade básica e composição química da madeira, entretanto, ainda não se encontram definidas. Os resultados verificados por vários autores, como por exemplo Barrichelo et al. (1984) e Shimoyama (1990), para o gênero Eucalyptus são muito discrepantes. É necessário avaliar a eficiência das metodologias tradicionalmente utilizadas, de forma a verificar a possibilidade de desenvolvimento de novas técnicas de avaliação que proporcionem resultados mais reprodutíveis e confiáveis.

\subsubsection{Relação entre densidade básica e rendimento em polpa kraft}

A literatura reforça a importância da densidade básica da madeira como a principal característica que influencia tanto o custo da madeira quanto o rendimento do processo industrial e, sobretudo, na qualidade de polpas e papéis (Foelkel et al., 1992; Shimoyama, 1990; Wehr, 1991). 
Segundo Fonseca et al. (1996), o rendimento da deslignificação e a densidade básica da árvore são características principais quanto à seleção da matéria-prima para produção de polpa kraft, no que diz respeito à capacidade e ao custo de produção de uma planta.

Um estudo realizado por Greaves \& Borralho (1996) aponta o rendimento como o fator de maior efeito sobre o custo total da deslignificação kraft. Segundo os autores, o custo total do processo pode ser descrito como:

$$
\begin{aligned}
& \mathrm{C}_{\text {Total }}=\mathrm{C}_{\text {picagem }}+\mathrm{C}_{\text {digestão }}+\mathrm{C}_{\text {quimicos(năo álcal iefetivo) }}+\mathrm{C}_{\text {evaporaçăo do licor negro }}+\mathrm{C}_{\text {caldeira recuperagăao }}+ \\
& \mathrm{C}_{\text {caustificą̧ăa }}
\end{aligned}
$$

De acordo com os autores, o custo de picagem e dos químicos (exceto álcali efetivo) é inversamente proporcional ao rendimento. O custo do digestor é inversamente proporcional ao produto do rendimento pela densidade básica. O custo dos evaporadores podem ser descritos como:

$$
C_{\text {evap. }}=\left[1 / \mathrm{Db}+\mathrm{k}_{1}{ }^{*}(1-\mathrm{R})-\mathrm{k}_{2}\right] / \mathrm{R}
$$

Onde:

$\mathrm{C}_{\text {evap: }}$ custo dos evaporadores.

Db: densidade básica.

$\mathrm{R}$ : rendimento.

$k_{1} e k_{2}$ são definidos em termos de parâmetros da madeira e industriais, os quais são independentes do rendimento e da densidade básica.

Os custos da caldeira de recuperação e da caustificação são definidos como diretamente proporcionais a um menos rendimento $(1-R)$ e inversamente proporcionais ao rendimento.

$$
\mathrm{C}_{\text {caldeira recuperaçăo }}=\mathrm{C}_{\text {caustificaçăa }}=(1-\mathrm{R}) / \mathrm{R}
$$


Pode-se verificar que o rendimento influencia todos os estágios do processo. Os resultados encontrados pelos autores mostram que, no entanto, o grau de influência do rendimento depende do valor energético produzido pela caldeira; quanto maior este valor menor a influência do rendimento sobre os custos da deslignificação. A densidade básica apresentou maior influência sobre o custo da digestão, mas a importância deste parâmetro consiste também em sua maior variação genética explorável, tornando-se então um importante fator no melhoramento de árvores para polpa kraft.

A densidade básica também influencia diretamente a qualidade da polpa, o que pode ser verificado através das resistências mecânicas, características superficiais e ópticas da mesma.

Uma vez comprovada sua influência sobre a qualidade da polpa, passou-se a verificar se o rendimento da deslignificação, ou seja, de conversão da madeira em polpa, também podia sofrer efeito desta propriedade física da madeira. Neste sentido, vários estudos foram realizados. Existe, na literatura correlata, o consenso de que o rendimento do digestor, volumétrico, está altamente associado à densidade básica. Sua influência no rendimento volumétrico (consumo específico de madeira) e custos dos processos de produção de madeira e polpa é entendida em razão do manuseio de menor volume de toras e cavacos, respectivamente, para uma mesma quantidade de massa (Foelkel et al., 1992; Shimoyama, 1990; Wehr, 1991). Segundo Fonseca et al. (1996), a capacidade do digestor, limitada volumétricamente, é aumentada em massa com a elevação da densidade básica, levando a um aumento no potencial de produção industrial até o limite de saturação da caldeira de recuperação.

Foelkel et al. (1992) relatam que a densidade básica para madeiras de Eucalyptus pode variar de 0,300 a $0,800 \mathrm{~g} / \mathrm{cm}^{3}$, no entanto, para a produção de polpa é recomendado o uso de madeiras cujas densidades básicas estejam entre 0,450 a $0,550 \mathrm{~g} / \mathrm{cm}^{3}$ (Fonseca et al.,1996 e Wehr, 1991). O uso de 
madeiras muito leves levam à redução do rendimento, enquanto que madeiras muito pesadas apresentam dificuldades na picagem e impregnação, consomem quantidades elevadas de reagentes, podem conduzir a baixos rendimentos de processo e elevados teores de rejeitos (Wehr, 1991).

As madeiras densas se caracterizam por possuírem maior espessura de parede e menor lume, ou seja, são madeiras de baixa porosidade. Siau (1971) descreve que a permeabilidade das madeiras de folhosas, em relação aos seus elementos estruturais, ocorre através das células radiais, parênquimas longitudinais, fibras, mas, principalmente, através dos vasos. A condução de líquidos é realizada através de pontuações que ligam os elementos estruturais e das placas de perfuração dos vasos. Ainda segundo o autor, nas folhosas, a porosidade da madeira é um fator de considerável influência no processo de condução de líquidos.

$\mathrm{Na}$ literatura pode-se encontrar estudos relacionando a densidade básica ao rendimento de polpa porém, mais comumente, considera-se rendimento volumétrico (consumo específico de madeira) e não gravimétrico. Zobel et al. (1978) afirmam que rendimento está intimamente relacionado à densidade da madeira e que outros fatores também afetam rendimento e qualidade da polpa.

Foelkel (1974) estudou oito espécies de Eucalyptus com idades próximas a 7 anos. Não encontrou correlação entre rendimento gravimétrico e densidade básica mas, entre esta última e consumo específico de madeira encontrou alta correlação.

Barrichelo \& Brito (1977), em estudo com Eucalyptus grandis de 6 anos de idade, também encontraram correlação negativa entre densidade básica e holocelulose e rendimento gravimétrico da polpação. Os mesmos autores em 1983 encontraram, para a mesma espécie, que a densidade básica não se correlaciona com rendimento gravimétrico de polpa não-branqueada. 
De acordo com o Informações SQCE...(1984), não há correlação entre densidade básica e rendimento gravimétrico da polpação, mas há elevada correlação entre densidade e consumo específico de madeira. Tal conclusão se baseia em um estudo realizado com 15 árvores de Eucalyptus saligna, com 5 anos de idade, das quais foram retiradas baguetas ao nível do DAP.

Vasconcelos Dias \& Cláudio-da-Silva Júnior (1985) utilizaram para o estudo 25 árvores de Eucalyptus grandis de 7 anos e mesma procedência. A densidade básica ao nível do DAP foi considerada como densidade básica da árvore. Concluíram que o rendimento na deslignificação atinge um máximo, em densidade básica próxima à $0,470 \mathrm{~g} / \mathrm{cm}^{3}$, e decresce com um aumento da mesma. Este fato pode ser explicado como uma perda na capacidade de impregnação dos cavacos, pelo licor de polpação, para madeiras mais densas (Wehr, 1991).

+ Collins et al. (1990) em estudo com 8 espécies de folhosas, entre as quais Eucalyptus deglupta e Eucalyptus tereticornis, concluíram que não há uma relação clara entre densidade básica e propriedades da polpa kraft, nem mesmo com a qualidade da polpa resultante.

Wehr (1991) estudando 4 lotes de tipos diferentes de madeiras de Eucalyptus grandis de várias procedências, verificou que a densidade básica associada à espessura dos cavacos influencia consideravelmente tanto o rendimento gravimétrico bruto quanto o depurado.

Foelkel et al. (1992) estudaram discos retirados na altura do DAP de diferentes espécies de Eucalyptus. Encontraram, para o Eucalyptus grandis, uma ligeira tendência de aumento no rendimento acompanhando um aumento na densidade básica. Valente et al. (1992) desenvolveram seus estudos com Eucalyptus globulus. Segundo os autores, parece haver uma relação entre densidade básica e rendimento kraft, mas não confirmada estatisticamente.

Cromer et al. (1998) analisaram 5 tratamentos diferentes de fertilização em plantações de Eucalyptus grandis. Concluíram que um aumento na 
velocidade de crescimento se mostrou associado a um aumento na densidade básica, assim como um aumento no rendimento em polpa kraft.

Embora a densidade básica seja uma propriedade da madeira de considerável importância, uma vez que a maioria dos estudos realizados concordam no sentido de que não há relação entre tal propriedade e rendimento gravimétrico, faz-se necessário encontrar uma característica de similar importância que possa servir como indicador do potencial de polpação de uma árvore. Com este intuito, verificou-se quais os resultados para relação entre composição química da madeira e rendimento.

\subsubsection{Relação entre composição química e rendimento em polpa kraft}

Ao se observar o trabalho de diversos autores torna-se claro que a composição química da madeira despertou o interesse dos mesmos, no sentido de se estudar os eventuais efeitos dos componentes químicos sobre a qualidade das polpas produzidas e, também, sobre o rendimento do processo.

A composição química da madeira assume grande importância frente ao rendimento em polpa kraft. A lignina e os extrativos, por exemplo, influenciam diretamente o consumo de álcali, rendimento da deslignificação e o potencial de produção industrial (Fonseca et al., 1996).

Segundo Collins et al. (1990), a estrutura química dos componentes da madeira pode influenciar incisivamente o comportamento da deslignificação.

Porém, muitas controvérsias são encontradas na literatura no que diz respeito a influência que a composição química exerce sobre o rendimento em polpa kraft.

Barrichelo \& Brito (1977), a partir de árvores de Eucalyptus grandis, encontraram correlação negativa entre teor de lignina e teor de holocelulose e rendimento em polpa. 
Turner et al. (1983) utilizaram em seu estudo 152 árvores de Eucalyptus globulus escolhidas a partir da forma. Os autores afirmam que há alta correlação inversa entre rendimento em polpa e extrativos solúveis em água quente, assim como para carga de álcali.

Utilizando árvores de 5 a 10 anos de Eucalyptus grandis, em um total de 25 árvores para cada idade, com discos retirados no DAP, base, 25, 50, 75 e $100 \%$ da altura comercial, Barrichelo et al. (1983) encontraram que o rendimento em polpa está altamente correlacionado com o teor de hemiceluloses.

A alta correlação entre hemiceluloses e rendimento também foi encontrada por Wehr (1991) em estudo com 4 lotes de tipos diferentes de Eucalyptus grandis. $O$ autor também verificou que madeiras com baixo teor de extrativos e lignina conduzem a um aumento no rendimento.

Amidon (1981) revisando os efeitos das propriedades da madeira e das fibras de folhosas sobre o rendimento da polpa e propriedades do papel, enfatiza que o conceito de flexibilidade das fibras pode ser a "chave" para o conhecimento das propriedades da polpa. A flexibilidade da fibra, segundo o autor, se correlaciona com as propriedades da madeira que podem ser mais facilmente medidas, como o comprimento da fibra e a densidade. $O$ trabalho ainda traz um estudo realizado pela TAPPI Forest Biology Subcommitee $n^{\circ} 2$, que informa que os constituintes da madeira exercem os seguintes efeitos sobre as propriedades da polpa: a lignina se correlaciona negativamente com o rendimento da polpa e resistência da fibra; holocelulose se correlaciona fraca e positivamente com o rendimento da polpa; $\alpha$-celulose se correlaciona positivamente tanto com o rendimento quanto com a resistência da fibra e um aumento nas xilanas pode diminuir ou aumentar o rendimento da polpa, dependendo do constituinte químico pelo qual está sendo substituído. Aumento em quaisquer outras hemiceluloses se correlaciona negativamente com o 
rendimento. Solubilidades em álcool-benzeno e água quente se correlacionam negativamente com rendimento da polpa.

Todos os trabalhos revisados, os que tratam da relação entre componentes químicos e rendimento, acordam com o estudo realizado pela TAPPI Forest Biology Subcommitee $n^{\circ} 2$, no que diz respeito a influência da lignina sobre o rendimento. Quanto maior o teor de lignina, maior a carga de álcali necessária para efetuar a deslignificação. Um aumento na carga de álcali provocaria maior degradação e dissolução dos polissacarídeos da madeira, provocando queda no rendimento.

Este comportamento também foi verificado por Collins et al. (1990) quando estudaram 8 espécies de folhosas incluindo Eucalyptus deglupta e Eucalyptus tereticornis. Enfatizam que nenhum parâmetro baseado no conteúdo de componentes não-polissacarídeos (extrativos e lignina) foi indicador das propriedades da polpa. Entretanto, quando se considerou como base indicativa os polissacarídeos, o rendimento em polpa se mostrou altamente correlacionado a esta base. Também encontraram que o rendimento em polpa decresce com um aumento na carga de álcali necessária para efetuar a deslignificação. Segundo os autores, isto se deve principalmente à degradação e subsequente dissolução que os polissacarídeos sofrem em presença de uma maior concentração de álcali. Desta forma, os verdadeiros indicadores do rendimento são os polissacarídeos.

Raymond et al. (1994), a partir de Eucalyptus regnans, estudaram a existência de correlação entre extrativos solúveis em água quente e rendimento em polpa kraft. A intenção dos autores era desenvolver um método de seleção indireta, onde uma dada característica seria utilizada para aperfeiçoar uma segunda característica correlacionada. Escolheram extrativos solúveis em água quente pela rapidez e facilidade do ensaio, além da economicidade da prática. Entretanto, os resultados não foram satisfatórios. Encontraram que este parâmetro não é um bom preditor de rendimento em polpa, devido à baixa 
correlação existente entre ambos. Este resultado ratifica o relato de Collins et al. (1990).

Wallis et al. (1996b) tentaram correlacionar composição química ao rendimento e composição da polpa kraft de Eucalyptus globulus e Eucalyptus nitens. Encontraram para ambas as espécies forte correlação positiva entre celulose e rendimento em polpa kraft. Com exceção da galactose, todos os outros componentes das hemiceluloses (xilose, arabinose, manose, etc) se correlacionam de forma negativa ao rendimento kraft para as duas espécies. Confirmaram a correlação negativa existente entre rendimento kraft, teor de extrativos totais e lignina Klason. Ainda sob este aspecto, afirmam que a estrutura da lignina tem pouco efeito sobre o rendimento kraft quando comparada à influência exercida pela celulose e outros polissacarídeos. Os autores acreditam que uma análise do teor de celulose na madeira pode indicar um meio rápido e seguro de se avaliar o potencial em polpa kraft de uma floresta de Eucalyptus.

Em um estudo recente, Kibblewhite et al. (1998) estudaram a polpa kraft de 29 árvores de Eucalyptus nitens. Ratificam um aumento no rendimento kraft associado a um decréscimo no teor de lignina e um aumento no teor de polissacarídeos.

Os constantes resultados positivos encontrados para a relação entre rendimento e teor de polissacarídeos na madeira, têm incentivado a idéia de que a "chave" para uma boa seleção de árvores pode estar nesta relação. Com base neste fato, novas técnicas de seleção vêm sendo testadas.

Ona et al. (1995) salientam a importância da seleção de sementes que promovam alta produtividade, mas também a necessidade de se desenvolver um método objetivo para avaliar e selecionar estas sementes. Ainda, segundo os autores, esta nova metodologia deve permitir a avaliação conjunta de múltiplas amostras, relacionando os resultados ao rendimento e qualidade da polpa. 
Wright \& Wallis (1998), baseados em resultados que indicam que 0 teor de celulose se correlaciona direta e positivamente com 0 rendimento gravimétrico em polpa, realizaram estudos envolvendo métodos alternativos de determinação de celulose e chegaram a resultados satisfatórios para o Eucalyptus nitens. Nestes métodos a madeira sofre uma digestão catalisada por ácido, em meio orgânico. As solvólises da lignina e hemiceluloses são catalisadas pelo ácido e estas se tornam solúveis no solvente orgânico. $O$ teor de celulose é então avaliado gravimétricamente.

Estes métodos oferecem rápidos resultados e várias amostras podem ser avaliadas conjuntamente. Se aplicados ao Eucalyptus grandis podem sugerir uma nova alternativa na avaliação e seleção da matéria-prima para uso em produção de polpa kraft.

Tran (1998), a partir dos resultados demonstrados por Wright \& Wallis (1998), resolveu aplicar o método de determinação de celulose Seifert em espécies do gênero Eucalyptus provenientes de várias localizações, tais como Chile, Austrália e África do Sul. Determinou também os teores de lignina residual nos resíduos obtidos. Confrontou os resultados para teores em celulose na madeira com lignina residual e livres de lignina residual, com os teores de $\alpha$-celulose determinados nas madeiras. Concluiu que o teor de celulose Seifert livre de lignina é o que melhor se correlaciona com o teor de $\alpha$ celulose na madeira. Baseado nos resultados observados, o autor concluiu que a denominação mais conveniente para a metodologia seria polpa Seifert, por acreditar que o resíduo obtido se aproxima mais de uma polpa do que de $\alpha$ celulose propriamente dita. 


\subsection{Conceitos químicos dos métodos não-convencionais para determinação de celulose}

O crescente uso de madeira plantada do gênero Eucalyptus pelas indústrias de celulose e papel promoveu uma grande interesse em melhorar as subsequentes plantações através de seleção genética. Um grande desafio, sem dúvida, é de se poder estimar a produtividade em polpa que uma floresta possui. O que se pretende porém, é não somente estimar o rendimento em polpa de uma amostra, mas fazê-lo de uma forma rápida, econômica e, se possivel, através de técnicas de fácil execução.

Partindo-se do fato de que, comprovadamente, a celulose se correlaciona às propriedades da polpa, a intenção é abandonar a técnica normalmente utilizada para obtê-la, técnica esta relativamente trabalhosa, em favor de uma mais simples e direta.

Neste sentido, nos últimos anos, técnicas alternativas para a determinação do teor de celulose na madeira têm sido desenvolvidas, e os resultado são incentivadores.

Wallis et al. (1996a), por exemplo, testaram um método para analisar os polissacarídeos de uma série de Eucalyptus globulus e Eucalyptus nitens. Utilizaram para este fim um cromatógrafo de troca aniônica de alta resolução (HPAEC-PAD - Cromatografia de troca aniônica de alta resolução com detecção amperométrica pulsada), seguindo hidrólise dos extratos com ácido sulfúrico. Confrontaram os resultados àqueles encontrados via técnicas gravimétricas. Concluíram que o HPAEC-PAD consiste em uma técnica rápida, precisa e que exige apenas pequenas quantidades de amostra. Além do mais, tem a vantagem de fornecer informação mais detalhada a respeito dos polissacarídeos da madeira.

Algumas das técnicas estudadas se baseiam no princípio da solvólise (quebra de uma molécula por ação de um solvente específico) catalisada por 
um ácido. As três técnicas estudadas por Wright \& Wallis (1998) e que foram denominadas como método do ácido nítrico, do ácido peroxiacético e da celulose Seifert se enquadram neste princípio.

O efeito da catálise ácida sobre a estrutura molecular da lignina foi amplamente estudado por Sarkanen. Segundo um de seus trabalhos, datado de 1990, a velocidade do processo de catálise parece ser governada pela hidrólise das ligações $\alpha$-éter na molécula de lignina. $O$ autor acredita que outras reações complexas possam ocorrer, tais como condensação, hidrólise parcial das ligações $\beta$-éter, liberação de formaldeído e rearranjos de radicais livres. Segundo ele, é difícil avaliar a extensão de cada uma destas reações, mas pode-se concluir que o efeito catalítico de um ácido depende da concentração de íons hidrogênio que ele fornece ao meio.

A degradação e/ou modificação molecular da lignina também despertou o interesse de outros pesquisadores.

Lundquist (1993), por exemplo, observou que em uma catálise ácida a maior parte das reações iniciais, efetuadas na molécula de lignina, são irreversíveis. Ocorre sempre a retirada de um próton na posição $\beta\left(H_{\beta}\right)$ ou a eliminação de um grupo metil terminal na forma de formaldeído. $O$ autor também confirma a possibilidade de ocorrer degradação da ligação $\beta$-éter-arila.

Além da degradação hidrolítica da lignina alguns solventes possuem a característica de promover degradação oxidativa da mesma. Neste aspecto, Ohi \& Kishino (1997) estudaram o efeito oxidativo do ácido nítrico. Foi observado um rompimento das ligações $C_{\alpha}-C_{\beta}$ em compostos do tipo $\beta-0-4$ não fenólicos. Segundo os autores, as unidades de lignina não fenólicas seriam convertidas, em meio ácido, à estruturas $\alpha-\beta$ insaturadas e, em seguida, ocorreria rompimento oxidativo das ligações $C_{\alpha}-C_{\beta}$.

Outros reagentes solvolíticos, além do ácido nítrico, têm sido estudados. 
Tzanova et al. (1997) comentam que o ácido acético é um bom indutor da hidrólise das hemiceluloses, mas sua capacidade de hidrolisar a celulose é muito pequena. Segundo Sarkanen (1990), tanto o ácido acético como o dioxano são bons solventes para a lignina. Lundquist (1993) cita que, comprovadamente, ácido clorídrico é um eficiente catalisador para hidrólise da lignina.

O que se pôde perceber, através da observação da literatura, é que várias técnicas foram estudadas e desenvolvidas há algum tempo e que, por qualquer motivo, tiveram seus estudos interrompidos; como exemplo podem ser citadas as técnicas do ácido nítrico, do ácido peroxiacético e da celulose Seifert, recentemente avaliadas por Wright \& Wallis (1998).

O conhecimento do esquema reacional de um reagente é de extrema importância, principalmente para o monitoramento de quaisquer modificações ou ajustes necessários para a obtenção de melhores resultados. O esquema de ação tanto do ácido nítrico como do ácido peroxiacético se processa via substituição eletrofílica aromática ou alifática. Este tipo de ataque, atualmente, se relaciona ao processo de branqueamento. O método da celulose Seifert age sob mecanismo de ataque nucleofílico aromático ou alifático, como na deslignificação kraft.

Segundo Sarkanen (1971), no método do ácido nítrico o agente oxidante da lignina é o íon nitrônio $\left(\mathrm{NO}_{2}{ }^{+}\right)$, obtido através da redução do ácido nítrico em meio ácido. Gierer (1990) descreve que o íon nitrônio pode provocar ataque eletrofílico tanto no anel aromático como na cadeia lateral da molécula de lignina. Segundo o autor, o ataque no anel aromático pode ocorrer em 4 diferentes posições, conforme o grupo substituinte, fornecendo diferentes produtos, entre os quais o-quinona.

Fengel (1983) descreve ser o ácido peroxiacético um oxidante específico para a lignina. $\mathrm{O}$ agente oxidante é o ín hidroxônio $\left(\mathrm{OH}^{+}\right)$, que promove ataque eletrofílico via mecanismo de substituição, eliminação ou 
formação de epóxidos. Conforme o autor, seis tipos de ataques são possíveis: adição de grupo hidroxila ao anel, desmetilação oxidativa, abertura oxidativa do anel, ruptura da cadeia lateral, quebra da ligação $\beta$-éter-arila e formação de epóxidos em olefinas.

O agente nucleofílico na preparação da celulose Seifert é a acetilacetona. Ataca a molécula de lignina tanto na cadeia lateral como no anel aromático, promovendo, em ambos os casos, condensação da molécula de lignina (Brauns \& Brauns, 1960). 


\section{MATERIAL E MÉTODOS}

\subsection{Material}

O material consistiu de árvores matrizes de Eucalyptus grandis W. Hill ex-Maiden, de 7 anos de idade, cedidas pela Lwarcel Celulose e Papel Ltda. As árvores eram procedentes de Botucatu, sementes da Duratex, plantio de 01/12/91, com espaçamento 3×2m, plantadas na região de Lençóis Paulista (SP). O relevo da região é suavemente ondulado, a temperatura média anual é de $21^{\circ} \mathrm{C}$ e a precipitação média anual de $1500 \mathrm{~mm}$; o solo é do tipo latossolo vermelho-amarelo (destrófico) com textura franco-arenosa.

\subsection{Métodos}

\subsubsection{Amostragem das árvores}

Dentro do povoamento foram pré-selecionadas 64 árvores considerando uma intensidade de seleção de 1:8000 árvores. As árvores escolhidas apresentavam as seguintes características: diâmetro avantajado $(30 \pm 5 \mathrm{~cm})$, altura total considerável $(35 \pm 5 \mathrm{~m})$, fuste retilíneo, copa uniforme e bem desenvolvida, ótima sanidade e volume superior às demais do talhão. As árvores selecionadas foram abatidas e após a medição das alturas total, 
comercial (diâmetro minimo de $8 \mathrm{~cm}$ com casca) e DAP com casca, retirou-se discos de aproximadamente $3 \mathrm{~cm}$ de espessura na base, $25,50,75$ e 100\% da altura comercial.

\subsubsection{Densidade básica da madeira}

Nos discos coletados foram efetuadas as medições dos diâmetros com e sem casca. Posteriormente, os discos foram divididos em quatro cunhas com ângulos de $90^{\circ}$.

A primeira cunha foi utilizada para a determinação da densidade básica, a segunda para a avaliação da composição química da madeira, a terceira para deslignificação kraft e a quarta cunha guardada como reserva.

A determinação da densidade básica da cunha foi efetuada através do método da balança hidrostática (Norma ABTCP M 14/70). A densidade básica média de cada árvore foi determinada através da densidade básica de cada cunha e o respectivo diâmetro sem casca, através da seguinte expressão:

$$
d b=1 / 2\left\{\left[\left(D^{2}{ }_{B}+D^{2}{ }_{25}\right)\left(d_{B}+d_{25}\right)+\ldots+\left(D^{2}{ }_{75}+D^{2}{ }_{100}\right)\left(d_{75}+d_{100}\right)\right] /\left[D^{2}{ }_{B}+D^{2}{ }_{100}+2\left(D^{2}{ }_{25}+\ldots+D^{2}{ }_{75}\right)\right]\right\}
$$

Onde:

$\mathrm{db}=$ densidade básica média da árvore, $\mathrm{g} / \mathrm{cm}^{3}$.

$\mathrm{D}=$ diâmetro dos discos sem casca a diferentes alturas da árvore, $\mathrm{cm}$.

$\mathrm{d}=$ densidade básica das cunhas a diferentes alturas da árvore, $\mathrm{g} / \mathrm{cm}^{3}$.

$B=$ refere-se ao disco retirado na base da árvore.

\subsubsection{Volume e massa comercial da árvore}

O volume comercial de cada árvore foi determinado pela seguinte expressão: 


$$
\left.V_{c}=\pi / 8 * L *{ }^{*} D^{2}{ }_{B}+D^{2}{ }_{100}+2\left(D^{2}{ }_{25}+\ldots+D^{2}{ }_{75}\right)\right]
$$

Onde:

$V_{c}=$ volume comercial da árvore, $\mathrm{m}^{3}$.

$\mathrm{L}=$ comprimento de cada segmento da árvore, $\mathrm{m}$.

$\mathrm{D}=$ diâmetro dos discos sem casca a diferentes alturas da árvore, $\mathrm{m}$.

$\mathrm{B}=$ refere-se ao disco retirado na base da árvore.

A massa comercial da árvore foi determinada através da seguinte expressão:

$$
m_{c}=\left(d b * v_{c}\right) * 1000
$$

Onde:

$\mathrm{m}_{\mathrm{c}}=$ massa comercial da árvore, $\mathrm{kg}$.

$\mathrm{db}=$ densidade básica média da árvore, $\mathrm{g} / \mathrm{cm}^{3}$.

$v_{c}=$ volume comercial da árvore, $\mathrm{m}^{3}$.

\subsubsection{Percentagem de casca em volume e massa de árvore}

A percentagem de casca em volume foi determinada através da seguinte expressão:

$$
\% C_{v}=\left[\left(V_{c / c}-V_{s / c}\right) / V_{c / c}\right] * 100
$$

Onde:

$\% \mathrm{C}_{\mathrm{v}}=$ percentagem de casca em volume, $\%$.

$\mathrm{V}_{\mathrm{c} / \mathrm{c}}=$ volume da árvore com casca, $\mathrm{m}^{3}$.

$V_{s / c}=$ volume da árvore sem casca, $\mathrm{m}^{3}$.

A percentagem de casca em massa foi determinada pela expressão: 


$$
\% C_{m}=\left[m_{c} /\left(m_{a}+m_{c}\right)\right] * 100
$$

Onde:

$\% \mathrm{C}_{\mathrm{m}}=$ percentagem de casca em massa, $\%$.

$\mathrm{m}_{\mathrm{a}}=$ massa da árvore, $\mathrm{kg}$.

$\mathrm{m}_{\mathrm{c}}=$ massa da casca, $\mathrm{kg}$.

\subsubsection{Composição química da madeira}

A amostra de madeira de cada árvore foi obtida através do agrupamento de palitos obtidos, manualmente, de cunhas retiradas dos discos amostrados nas diferentes alturas comerciais da árvore. Estes palitos foram reduzidos a serragem em macro-moinho Wiley e, posteriormente, a serragem obtida foi classificada para obtenção da fração 40/60 mesh.

Foram efetuadas, para cada árvore, as seguintes análises químicas:

-Preparação da madeira para análises químicas (TAPPI T 264 cm-97)

- Extrativos totais (ABTCP M 3/69)

- Lignina Klason (TAPPI T 222 om - 98)

- Holocelulose: 100 - (\% Extrativos totais + \% Lignina)

\subsubsection{Deslignificação kraft-AQ}

A amostra de madeira de cada árvore foi obtida através do agrupamento de cavacos obtidos, manualmente, de cunhas com ângulos de $90^{\circ}$, retiradas dos discos amostrados nas diferentes alturas comerciais da árvore.

As deslignificações kraft-AQ das árvores foram realizadas em digestor rotativo, com 20 litros de capacidade, utilizando-se cápsulas de tela de aço 
inoxidável com capacidade unitária de $200 \mathrm{~cm}^{3}$, comportando aproximadamente o equivalente a 50 gramas de madeira seca em estufa.

Devido a capacidade limitada do digestor, não houve a possibilidade de se efetuar a deslignificação para as 64 árvores conjuntamente, desta forma as deslignificações foram divididas em duas etapas, cada qual composta por trinta e duas árvores. Para cada etapa de deslignificação foram efetuadas duas repetições.

Para averiguar se o fato de se dividir as deslignificações em duas etapas proporcionaria diferenças nos resultados observados para cada árvore, testou-se, para cada etapa de deslignificação, três árvores. Estas três árvores foram então deslignificadas nas duas etapas $e$, portanto, tiveram quatro repetições cada uma.

As condições adotadas para a deslignificação kraft-AQ foram sugeridas pela indústria Lwarcel Celulose e Papel, sendo as seguintes:

- Álcali efetivo base madeira s.e, $\%=18,5 \mathrm{como} \mathrm{NaOH}$ 14,4 como $\mathrm{Na}_{2} \mathrm{O}$

- Álcali ativo base madeira s.e, $\%=20,0 \mathrm{como} \mathrm{NaOH}$ 15,5 como $\mathrm{Na}_{2} \mathrm{O}$

- Sulfidez do licor, $\%=15,0$

- Antraquinona base madeira s.e, $\%=0,07$

- Temperatura máxima, ${ }^{\circ} \mathrm{C}=174$

- Tempo até temperatura máxima, $\min =80$

- Tempo na temperatura máxima, $\min =30$

Ao final de cada deslignificação, os cavacos foram desfibrados utilizando-se um desintegrador rotativo marca Regmed até se atingir 2000 revoluções. Em seguida, a polpa foi filtrada sobre papel de filtro, lavando-se abundantemente com água para se retirar ao máximo o licor negro. 
A partir da polpa filtrada e lavada foram determinados rendimento bruto da polpação, número kappa da polpa obtida e consumo específico de madeira.

O rendimento bruto foi obtido através da seguinte expressão:

$$
\mathrm{Rb}=(\text { m.s.c. } / \text { m.s.m. }) * 100
$$

Onde:

$\mathrm{Rb}=$ rendimento bruto, $\%$.

m.s.c. $=$ massa de celulose s.e, g.

m.s.m. = massa de madeira s.e, g.

A determinação do número Kappa da polpa foi realizada através da norma TAPPI T $236 \mathrm{~cm}-85$.

O consumo específico de madeira foi determinado através da expressão:

$$
C e=\left[1 /\left(R b * d b_{m}\right)\right] * 100
$$

Onde:

$\mathrm{Ce}=$ consumo específico, $\mathrm{m}^{3}$ de madeira/t de celulose $\mathrm{s} . \mathrm{e}$.

$\mathrm{Rb}=$ rendimento bruto, $\%$.

$\mathrm{db}_{\mathrm{m}}=$ densidade básica média da árvore, $\mathrm{g} / \mathrm{cm}^{3}$.

\subsubsection{Lignina solubilizada na deslignificação kraft-AQ}

A percentagem de lignina solubilizada foi calculada, como base madeira, da seguinte forma:

$\% L S=\left\{\%\right.$ lignina na madeira $-\left[\left(0,147^{*} \mathrm{NK}\right)^{*}(\right.$ rendimento bruto/100) $] / \%$ lignina na madeira $\}^{\star} 100$ 
Onde:

\%LS é a percentagem de lignina solubilizada na deslignificação.

NK é o número kappa.

$\left(0,147^{*} \mathrm{NK}\right)$ é a percentagem de lignina Klason na polpa (TAPPI T $236 \mathrm{~cm}-$ 85)

\subsubsection{Métodos não-convencionais para determinação de celulose}

Os métodos não-convencionais para determinação do teor de celulose na madeira seguiram os métodos descritos por Wright \& Wallis (1998), conforme relacionados abaixo.

\section{Método do ácido peroxiacético}

Dissolver $5,6 \mathrm{~g}$ de perborato de sódio trihidratado em $25,00 \mathrm{~mL}$ de ácido acético glacial e $25,00 \mathrm{~mL}$ de peróxido de hidrogênio $30 \%$.

Remover os extrativos totais de $1,0000 \mathrm{~g}$ de serragem s.e. Transferir quantitativamente para um balão de fundo chato de $250 \mathrm{~mL}$.

Adicionar toda a alíquota da solução preparada e levar a refluxo, em temperatura de $120^{\circ} \mathrm{C}$, por 4 horas.

Esperar esfriar e filtrar, a vácuo, o resíduo de celulose através de cadinho de placa sinterizada $\mathrm{n}^{\circ} 2$ devidamente tarado.

Proceder a lavagem com $500 \mathrm{~mL}$ de água quente e, em seguida, com $25 \mathrm{~mL}$ de etanol.

Levar o residuo à estufa a $100 \pm 5^{\circ} \mathrm{C}$ até peso constante. Esfriar em dessecador e pesar o cadinho.

Calcular o conteúdo em celulose como percentagem a partir do material de partida.

Realizar a análise em duplicata. 


\section{Método do ácido nítrico}

Preparar uma solução contendo $90,00 \mathrm{~mL}$ de ácido nítrico e $732,00 \mathrm{~mL}$ de ácido acético glacial, completando a $1 \mathrm{~L}$ com água.

Remover os extrativos totais de $1,0000 \mathrm{~g}$ de serragem s.e. Transferir quantitativamente para um balão de fundo chato de $50 \mathrm{~mL}$.

Adicionar uma alíquota de $25,00 \mathrm{~mL}$ da solução de ácido nítrico-ácido acético glacial preparada.

Levar a mistura a refluxo por 25 minutos em temperatura de $120^{\circ} \mathrm{C}$.

Esperar esfriar e filtrar, a vácuo, o resíduo de celulose através de cadinho de placa sinterizada $\mathrm{n}^{\circ} 2$ devidamente tarado.

Proceder a lavagem com $500 \mathrm{~mL}$ de água quente e, em seguida, com $25 \mathrm{~mL}$ de etanol.

Levar o residuo à estufa a $100 \pm 5^{\circ} \mathrm{C}$ até peso constante. Esfriar em dessecador e pesar o cadinho.

Calcular o conteúdo em celulose como percentagem a partir do material de partida.

Realizar a análise em duplicata.

\section{Método celulose Seifert}

Remover os extrativos totais de $1,0000 \mathrm{~g}$ de serragem s.e. Transferir quantitativamente para um balão de fundo chato de $50 \mathrm{~mL}$.

Adicionar $6,00 \mathrm{~mL}$ de acetilacetona, 2,00 mL de 1,4-dioxano e 1,50 mL de ácido clorídrico.

Levar a refluxo por 30 minutos em temperatura de $140^{\circ} \mathrm{C}$.

Esperar esfriar e filtrar, a vácuo, o resíduo de celulose através de cadinho de placa sinterizada $n^{\circ} 2$ devidamente tarado. 
Proceder a lavagem sequencial com $100 \mathrm{~mL}$ de metanol, $300 \mathrm{~mL}$ de água quente, $100 \mathrm{~mL}$ de metanol e $100 \mathrm{~mL}$ de acetona.

Levar o residuo à estufa a $100 \pm 5^{\circ} \mathrm{C}$ até peso constante. Esfriar em dessecador e pesar o cadinho.

Calcular o conteúdo em celulose como percentagem a partir do material de partida.

Realizar a análise em duplicata.

\section{Extração alcalina para os métodos do ácido nítrico e ácido peroxiacético}

Este procedimento foi aplicado somente aos resíduos anteriormente obtidos através da metodologia do ácido nítrico e do ácido peroxiacético, para eliminação de possíveis grupos acilas nas cadeias dos polissacarídeos, devido à presença de ácido acético glacial no meio reacional.

Pesar o resíduo absolutamente seco em estufa. Transferir quantitativamente para um béquer.

Adicionar $25,00 \mathrm{~mL}$ de $\mathrm{NaOH} 5,2 \mathrm{~N}$ e levar a banho termostatizado a $25^{\circ} \mathrm{C}$ por exatamente 1 hora. Agitar esporadicamente com um bastão de vidro.

Filtrar, a vácuo, o resíduo através de cadinho de placa sinterizada devidamente tarado.

Proceder a lavagem com $500 \mathrm{~mL}$ de água quente.

Levar o residuo à estufa a $100 \pm 5^{\circ} \mathrm{C}$ até peso constante. Esfriar em dessecador e pesar o cadinho.

Calcular o conteúdo em celulose como percentagem a partir do material de partida. 


\subsubsection{Determinação de $\alpha$-celulose como parâmetro de comparação para} os métodos não-convencionais.

Com o intuito de comparar o percentual de celulose obtido através dos métodos não-convencionais, procedeu-se à determinação deste parâmetro em algumas árvores selecionadas através de sua composição química e desempenho na deslignificação kraft-AQ.

A obtenção da $\alpha$-celulose seguiu a norma ASTM D1103-60. Primeiramente obteve-se holocelulose utilizando-se clorito de sódio. Em seguida, esta foi submetida a uma extração alcalina com $\mathrm{NaOH} 5,2 \mathrm{~N}$ para obtenção da $\alpha$-celulose.

\subsubsection{Análise do custo da deslignificação kraft-AQ para as árvores de Eucalyptus grandis.}

O custo total da deslignificação, por tonelada de polpa não-branqueada, foi calculado em função da densidade básica média da árvore e do rendimento bruto do processo, conforme descrito por Greaves \& Borralho (1996). Segundo os autores, o custo total da deslignificação pode ser descrito como:

$$
\left.\mathrm{C}_{\text {deslignificação }}=200 *\left\{\left(\mathrm{Db}_{\text {base }}\right)^{0,53 *}\left(\mathrm{Rg}_{\text {base }}\right)^{0,70}\right] /\left[(\mathrm{Db})^{0,53 *}(\mathrm{Rg})^{0,70}\right]\right\}
$$

Onde:

Custo médio da deslignificação = \$US 200.00/t não-branqueada s.e.

$\mathrm{Db}_{\text {base }}=$ Densidade básica média para as sessenta e quatro árvores matrizes $\left(0,447 \mathrm{~g} / \mathrm{cm}^{3}\right)$.

$\mathrm{Rg}_{\text {base }}=$ Rendimento gravimétrico médio para as sessenta e quatro árvores matrizes $(53,12 \%)$.

$\mathrm{Db}=$ Densidade básica da árvore matriz analisada.

$\mathrm{Rg}=$ Rendimento gravimétrico da árvore matriz analisada. 


\section{RESULTADOS E DISCUSSÃO}

\subsection{Relações entre propriedades da madeira}

\subsubsection{Resultados dendrométricos}

A tabela 1 mostra as médias dos resultados dendrométricos para as sessenta e quatro árvores estudadas. Os resultados individuais encontram-se no Anexo A.

Tabela 1. Dados dendrométricos médios para sessenta e quatro árvores de Eucalyptus grandis.

\begin{tabular}{c|c|c|c|c|c|c|c}
\hline \multirow{2}{*}{ Parâmetros } & \multirow{2}{*}{$\begin{array}{c}\text { DAP, } \\
\mathrm{cm}\end{array}$} & \multicolumn{2}{|c|}{ Altura, $\mathrm{m}$} & \multicolumn{2}{c|}{ Volume, $\mathrm{m}^{3}$} & \multicolumn{2}{c}{$\%$ em casca } \\
\cline { 5 - 9 } & 29,5 & 34,5 & 28,8 & 1,0178 & 0,8988 & 11,66 & 7,62 \\
\hline Valor Médio & 25,2 & 30,8 & 25,3 & 0,7152 & 0,6109 & 7,41 & 4,52 \\
\hline Valor Mínimo & 33,9 & 38,0 & $32, \overline{9}$ & 1,3902 & 1,2354 & 15,49 & 11,95 \\
\hline Valor Máximo & 2,1 & 1,3 & 1,3 & 0,1696 & 0,1494 & 1,83 & 1,70 \\
\hline Desvio Padrão & 2,1 & 3,7 & 4,5 & 16,67 & 16,62 & 15,72 & 22,28 \\
\hline Coeficiente de Variação, $\%$ & 7,1 & & & & & \multirow{2}{*}{ Volume } & Massa \\
\hline
\end{tabular}

Volume C/C: volume da árvore com casca

Volume S/C: volume da árvore sem casca

Os resultados apresentados na tabela 1 revelam que, apesar da intensidade de seleção aplicada (1:8000) ser bastante expressiva, as árvores apresentaram consideráveis diferenças em seus parâmetros dendrométricos. 
Neste sentido, os resultados confirmam a expressiva diferença existente entre as árvores dentro de um mesmo local.

Embora os parâmetros silviculturais tenham sido o instrumento para a pré-seleção das árvores matrizes, a seleção final das árvores mais adequadas para formação de futuras florestas clonais se baseou, principalmente, nos resultados de densidade básica e composição química da madeira, assim como no comportamento frente ao rendimento da deslignificação kraft, número kappa e consumo especifico de madeira.

\subsubsection{Densidade básica}

Quando se visa a produção de polpa uma série de parâmetros da madeira devem ser analisados cuidadosamente.

A densidade básica, parâmetro físico da madeira, há muito tem se destacado como uma propriedade de expressiva importância quanto à seleção da matéria-prima, uma vez que está diretamente relacionada à qualidade da polpa produzida. Sabe-se, no entanto, que embora seja de fácil avaliação e apresente boa herdabilidade, a densidade básica é uma propriedade altamente complexa, por se tratar de um parâmetro resultante da combinação de elementos anatômicos e compostos químicos da madeira (Barrichelo et al., 1983b; Foelkel et al., 1974; Shimoyama, 1990 e Valente et al., 1992). No entanto, o grau de influência de cada um dos componentes químicos da madeira sobre a densidade básica ainda merece consideráveis estudos, pois os resultados observados nos estudos até então desenvolvidos são bastante discrepantes.

A tabela 2 apresenta os valores médios encontrados para densidade básica para as sessenta e quatro árvores estudadas. Os resultados individuais constam no Anexo B. 
Tabela 2. Densidade básica média para sessenta e quatro árvores de Eucalyptus grandis.

\begin{tabular}{c|c}
\hline Parâmetros & Densidade Básica, $\mathrm{g} / \mathrm{cm}^{3}$ \\
\hline Valor Médio & 0,447 \\
\hline Valor Mínimo & 0,370 \\
\hline Valor Máximo & 0,532 \\
\hline Desvio Padrão & 0,037 \\
\hline Coeficiente de Variação, \% & 8,32 \\
\hline
\end{tabular}

A tabela 2 exemplifica de forma muito clara a ampla faixa de densidade básica encontrada para as árvores matrizes selecionadas para este trabalho.

Segundo Foelkel et al. (1992), a densidade básica para Eucalyptus pode variar de 0,300 a $0,800 \mathrm{~g} / \mathrm{cm}^{3}$, porém para a produção de celulose recomenda-se o uso de densidades entre 0,450 e 0,550 g/ $/ \mathrm{cm}^{3}$ (Fonseca et al., 1996 e Wehr, 1991).

O uso de madeiras muito leves podem reduzir o rendimento do processo, enquanto que o de madeiras muito densas podem dificultar a picagem das toras e a impregnação dos cavacos pelo licor branco, dificultando a deslignificação e aumentando os teores de rejeitos (Wehr, 1991).

Para as árvores utilizadas neste trabalho encontrou-se que a maioria apresenta valor de densidade básica satisfatório para produção de polpa kraft.

\subsubsection{Composição química tradicional da madeira}

Dentro de um processo de seleção, como já afirmado anteriormente, vários aspectos da madeira devem ser considerados. A composição química, celulose, hemiceluloses, lignina e extrativos, desempenha um importante papel econômico em uma planta de produção de polpa. É conhecido, por exemplo, que altos teores de extrativos podem provorar incrustações nos equipamentos 
industriais (pitch), além de causarem problemas de absorção de líquidos e cargas na fabricação do papel. O teor de lignina, por sua vez, é o maior responsável pela carga de álcali necessária para se atingir o grau de deslignificação desejado. Quanto aos polissacarídeos, em trabalhos mais recentes, são considerados como os maiores responsáveis pelo rendimento em polpa. Segundo Wehr (1991), a composição química da madeira também influencia a quantidade de sólidos incorporados ao licor negro. Os sólidos incorporados são compostos orgânicos (provenientes principalmente da degradação da lignina, extrativos e da dissolução de hemiceluloses) e compostos inorgânicos (sulfato e carbonato de sódio). Quanto maior a quantidade de compostos orgânicos incorporados ao licor negro, maior o valor energético produzido pela queima do mesmo.

A tabela 3 mostra a média dos resultados para composição química tradicional das sessenta e quatro árvores analisadas. Os resultados individuais constam no Anexo D.

Tabela 3. Composição química tradicional das árvores analisadas.

\begin{tabular}{c|c|c|c}
\hline Parâmetros & Holocelulose, \% & Lignina, \% & Extrativos Totais, \% \\
\hline Valor Médio & 73,19 & 25,70 & 1,11 \\
\hline Valor Mínimo & 67,79 & 22,96 & 0,08 \\
\hline Valor Máximo & 76,63 & 29,85 & 2,84 \\
\hline Desvio Padrão & 1,76 & 1,55 & 0,73 \\
\hline Coeficiente de Variação, \% & 2,41 & 6,02 & 65,82 \\
\hline
\end{tabular}

Os valores de composição química estão de acordo com aqueles descritos por Clarke et al. (1997), como sendo, para madeiras do gênero Eucalyptus, geralmente de 65 a $77 \%$ de holocelulose, 20 a $24 \%$ de lignina e 5 a $10 \%$ de extrativos. Os baixos valores encontrados para extrativos podem ser explicados pelo fato de se tratarem de árvores jovens, com 7 anos de idade. 
A tabela 4 se refere à matriz de correlação dos componentes químicos da madeira.

Tabela 4. Matriz de correlação dos componentes químicos da madeira de Eucalyptus grandis.

\begin{tabular}{|c|c|c|c|}
\hline Variáveis & Holocelulose & Lignina & Extrativos Totais \\
\hline Holocelulose & 1,00 & $\begin{array}{l}-0,91^{* *} \\
p=0,0\end{array}$ & $\begin{array}{l}-0,48^{* *} \\
p=0,0\end{array}$ \\
\hline Lignina & & 1,00 & $\begin{array}{c}0,08^{\text {n.s. }} \\
p=53,1\end{array}$ \\
\hline Extrativos Totais & & & 1,00 \\
\hline
\end{tabular}

Os resultados apresentados na tabela 4 mostram uma forte correlação negativa entre holocelulose e lignina, o que já havia sido relatado por Barrichelo \& Brito (1977) e Vital et al. (1986).

Fraca, porém significativa, é a correlação entre holocelulose e extrativos que foi encontrada. Vital et al. (1986) descreve não ter encontrado relação entre eles.

Nenhuma relação foi encontrada entre lignina e extrativos totais na madeira.

As figuras 1 e 2 mostram a relação entre lignina versus holocelulose e extrativos totais versus holocelulose, respectivamente. 


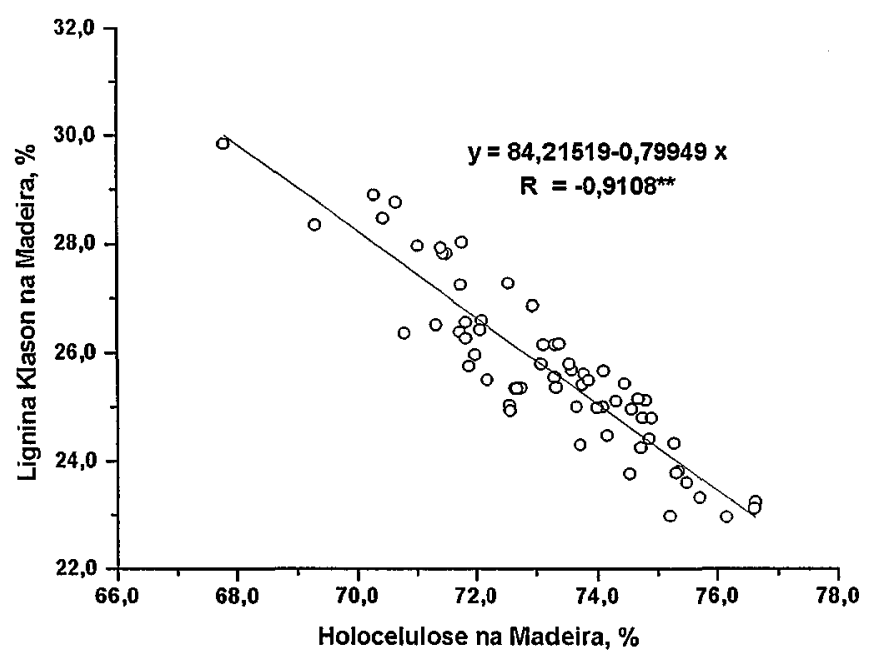

Figura 1 - Relação entre teor de lignina e holocelulose na madeira de Eucalyptus grandis.

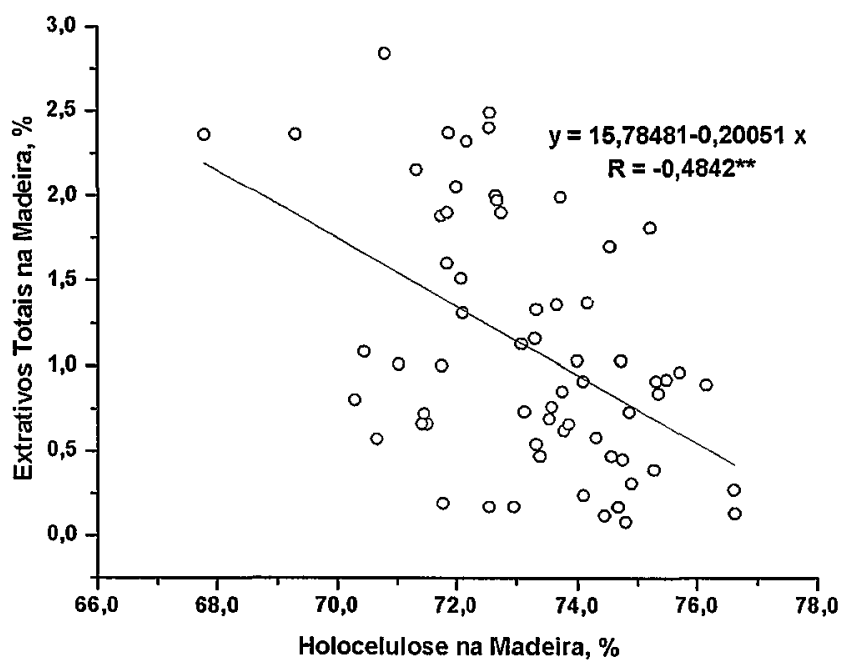

Figura 2 - Relação entre teor de extrativos totais e holocelulose na madeira de Eucalyptus grandis. 
As tabelas 5 e 6 mostram a análise de variância da regressão para lignina versus holocelulose e extrativos totais versus holocelulose.

Tabela 5. Análise de variância da regressão lignina versus holocelulose.

\begin{tabular}{c|c|c|c|c|c}
\hline F.V. & G.L. & S.Q. & Q.M. & F & P \\
\hline Regressão Linear & 1 & 125,32 & 125,32 & $301,78^{\star *}$ & 0,000000 \\
\hline Resíduo & 62 & 25,75 & 0,42 & & \\
\hline Total & 63 & 151,06 & & & \\
\hline ** Equação de regressão significativa a $1 \%$. &
\end{tabular}

Tabela 6. Análise de variância da regressão extrativos totais versus holocelulose.

\begin{tabular}{c|c|c|c|c|c}
\hline F.V. & G.L. & S.Q. & Q.M. & F & P \\
\hline Regressão Linear & 1 & 7,88 & 7,88 & $18,98^{* *}$ & 0,000050 \\
\hline Resíduo & 62 & 25,75 & 0,42 & & \\
\hline Total & 63 & 33,63 & & & \\
\hline ** Equação de regressão significativa a $1 \%$. & \multicolumn{5}{l}{}
\end{tabular}

\subsubsection{Métodos não-convencionais para determinação de celulose}

Em um processo de seleção de matéria-prima existe sempre a preocupação em se poder avaliar um considerável número de árvores no menor tempo possivel.

Aliado a este fator existe o inconveniente de não existir, até o presente momento, um parâmetro que se determinado possa predizer o comportamento da árvore frente ao processo de deslignificação, principalmente no que diz respeito ao rendimento gravimétrico do processo.

Como consequência, nos últimos anos, alguns pesquisadores vêm tentando encontrar uma rota alternativa a fim de otimizar o processo de seleção das melhores árvores para produção de celulose. Inúmeros conceitos têm sido 
utilizados, porém há um certo consenso de que a "chave" encontra-se no teor de polissacarídeos que a madeira da árvore possui, principalmente no teor de celulose da madeira.

A conclusão de que o teor de celulose na madeira possa servir como parâmetro preditor do comportamento da árvore no processo de deslignificação, principalmente quanto ao rendimento gravimétrico, acentuou o interesse em se desenvolver novas técnicas para avaliá-lo. Estas técnicas, neste trabalho denominadas como não-convencionais, deveriam substituir as tradicionalmente utilizadas, as quais se destacam principalmente por seus procedimentos trabalhosos e utilização de cloro ou compostos de cloro, dificultando a viabilidade de realização das análises.

O método de análise do teor de celulose e hemiceluloses na madeira utilizando-se método de hidrólise e passagem por HPAEC-PAD, Cromatografia de Troca Aniônica de Alta Resolução com Deteç̧ão Amperométrica Pulsada, foi estudado por Wallis et al. (1996a). Os autores relatam que os resultados observados foram muito similares àqueles encontrados por determinação gravimétrica, entretanto a análise cromatográfica dos carboidratos permite uma investigação mais eficiente das relações entre composição química da madeira e seu rendimento em polpa, assim como as propriedades do papel. No entanto, a eficiência do método cromatográfico está estritamente vinculada à capacidade de se interpretar corretamente os resultados por ele fornecidos.

Os métodos gravimétricos de determinação de celulose na madeira, entretanto, além de oferecem facilidade de interpretação dos resultados, são, até então, os mais acessíveis e fáceis de executar.

A tabela 7 mostra os valores médios encontrados para teores de celulose na madeira determinados a partir de três técnicas gravimétricas nãoconvencionais. A representação gráfica pode ser observada através da figura 3. Os resultados individuais encontram-se no Anexo $\mathrm{E}$. 
Tabela 7. Determinação de celulose por métodos não-convencionais para sessenta e quatro árvores de Eucalyptus grandis.

\begin{tabular}{c|c|c|c|c|c}
\hline & \multicolumn{5}{|c}{ Métodos de Determinação de Celulose na Madeira, \% } \\
\hline Parâmetros & $\begin{array}{c}\text { Celulose } \\
\text { Seifert }\end{array}$ & $\begin{array}{c}\text { Ácido } \\
\text { Nítrico }\end{array}$ & $\begin{array}{c}\text { Ácido Nitrico } \\
\text { com Extração } \\
\text { Alcalina }\end{array}$ & $\begin{array}{c}\text { Ácido } \\
\text { Peroxiacético }\end{array}$ & $\begin{array}{c}\text { Ácido } \\
\text { Peroxiacético com } \\
\text { Extração Alcalina }\end{array}$ \\
\hline Valor Médio & 44,23 & 52,59 & 42,52 & 55,07 & 45,76 \\
\hline Valor Mínimo & 40,70 & 49,50 & 38,42 & 52,86 & 42,94 \\
\hline Valor Máximo & 47,48 & 57,13 & 46,85 & 58,55 & 49,94 \\
\hline Desvio Padrão & 1,37 & 1,48 & 1,40 & 1,22 & 1,68 \\
\hline Coeficiente de Variação, \% & 3,10 & 2,82 & 3,30 & 2,22 & 3,67 \\
\hline
\end{tabular}

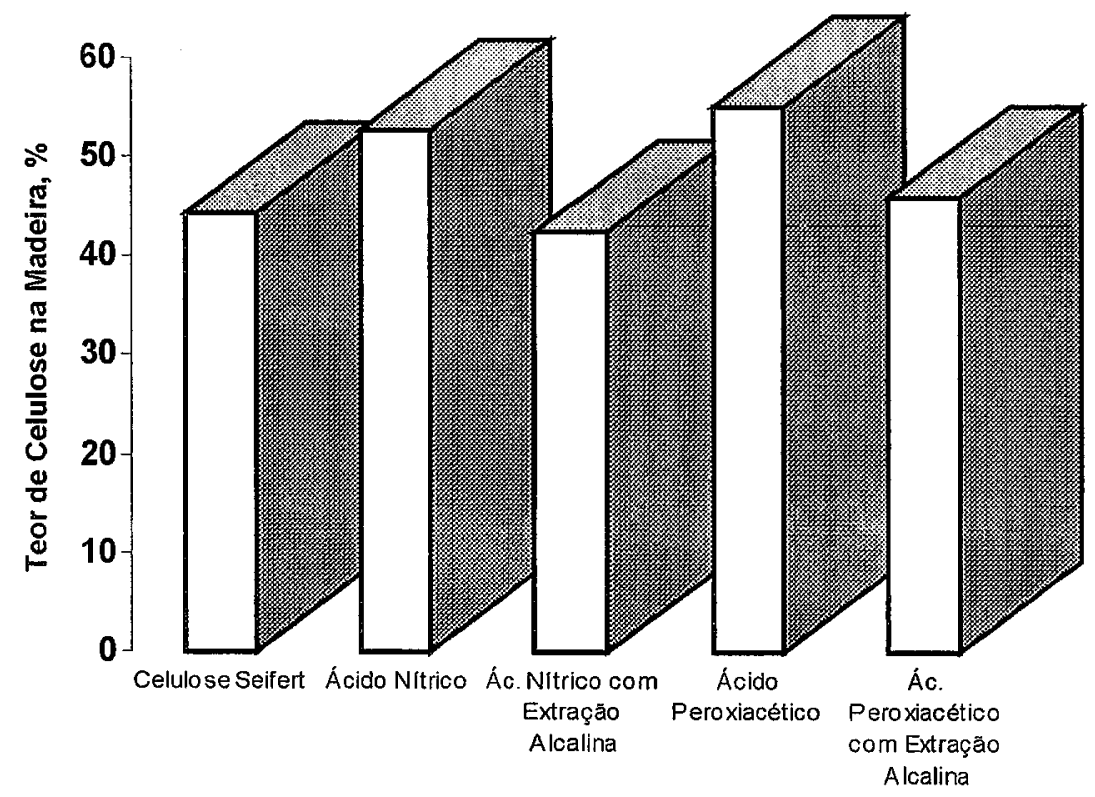

Figura 3 - Determinação de celulose na madeira por métodos nãoconvencionais.

Os métodos não-convencionais testados foram, para efeito de simplificação, denominados como método celulose Seifert, método do ácido nítrico e método do ácido peroxiacético.

Como exposto anteriormente na metodologia, os resíduos obtidos a partir dos métodos do ácido nítrico e do ácido peroxiacético sofreram uma 
extração alcalina para eliminação de possíveis grupos acilas nas cadeias dos polissacarídeos, devido à presença de grande quantidade molar de ácido acético no meio reacional.

Clarke et al. (1997) descrevem que, em geral, a madeira de Eucalyptus apresenta de 48 a $55 \%$ de celulose. Os valores encontrados para celulose, sem submeter os residuos à extração alcalina, variaram de 44 a $55 \%$. Após a extração alcalina este intervalo decresceu para 42 a $45 \%$.

Ainda sem considerar a extração alcalina dos resíduos, coincidentemente, o menor resultado encontrado foi para celulose Seifert, o único método que não empregava ácido acético como solvente. Também, frente aos demais métodos, apresentou o inconveniente de trabalhar com uma alíquota muito pequena de reagente, dificultando a subsequente filtração do resíduo. A alta temperatura exigida, $140^{\circ} \mathrm{C}$, associada ao pequeno volume de reagente utilizado, provocou algumas vezes violenta ebulição, resultando em subida do resíduo pelas paredes do condensador. Entre os três métodos testados foi o que apresentou maior dificuldade em se obter resultados reprodutíveis.

Os métodos do ácido nítrico e do ácido peroxiacético apresentaram após a extração alcalina uma redução de 19 e 17\%, respectivamente, em seus rendimentos. Ambos os métodos se destacaram por sua facilidade de execução e reprodutibilidade nos resultados. $O$ método do ácido peroxiacético apresentou o inconveniente de um representativo tempo de reação. Devido aos bons resultados obtidos para este método, um estudo visando diminuir este tempo pode ser bastante útil.

A tabela 8 se refere à matriz de correlação dos métodos nãoconvencionais para determinação de celulose. 
Tabela 8. Matriz de correlação dos métodos não-convencionais para determinação de celulose.

\begin{tabular}{|c|c|c|c|c|c|}
\hline Variáveis & $\begin{array}{c}\text { Celulose } \\
\text { Seifert }\end{array}$ & $\begin{array}{l}\text { Ácido } \\
\text { Nítrico }\end{array}$ & $\begin{array}{c}\text { Ác. Nítrico } \\
\text { com Extração } \\
\text { Alcalina }\end{array}$ & $\begin{array}{c}\text { Ácido } \\
\text { Peroxiacético }\end{array}$ & $\begin{array}{c}\text { Ác. } \\
\text { Peroxiacético } \\
\text { com Extração } \\
\text { Alcalina }\end{array}$ \\
\hline Celulose Seifert & \multirow[t]{5}{*}{1,00} & $\begin{array}{l}0,35^{* *} \\
p=0,4\end{array}$ & $\begin{array}{c}0,28^{*} \\
p=2,4\end{array}$ & $\begin{array}{l}0,39^{* *} \\
p=0,1\end{array}$ & $\begin{array}{l}0,41^{* *} \\
p=0,1\end{array}$ \\
\hline Ácido Nítrico & & \multirow[t]{4}{*}{1,00} & $\begin{array}{l}0,86^{* *} \\
p=0,0\end{array}$ & $\begin{array}{l}0,52^{* *} \\
p=0,0\end{array}$ & $\begin{array}{l}0,39^{* *} \\
p=0,1\end{array}$ \\
\hline $\begin{array}{l}\text { Ác. Nítrico com } \\
\text { Extração Alcalina }\end{array}$ & & & \multirow[t]{3}{*}{1,00} & $\begin{array}{l}0,24^{\text {n.s. }} \\
p=5,2\end{array}$ & $\begin{array}{c}0,11^{\text {n.s. }} \\
p=37,0\end{array}$ \\
\hline Ácido Peroxiacético & & & & \multirow[t]{2}{*}{1,00} & $\begin{array}{l}0,86^{* *} \\
p=0,0\end{array}$ \\
\hline $\begin{array}{c}\text { Ác. Peroxiacético com } \\
\text { Extração Alcalina }\end{array}$ & & & & & 1,00 \\
\hline
\end{tabular}

A partir da tabela 8 pode-se verificar que, à exceção do método do ácido nítrico com extração alcalina em relação a ambos os métodos do ácido peroxiacético, todos os métodos se correlacionaram significativamente a $5 \%$ de probabilidade, ainda que com baixos coeficientes de correlação. A baixa correlação entre os métodos pode ser atribuída, principalmente, aos níveis de impurezas presentes em cada resíduo. Segundo Wright \& Wallis (1998), os métodos do ácido peroxiacético e do ácido nítrico são os que apresentaram maiores níveis de impurezas, constituídas principalmente por hemiceluloses e ligninas e hemiceluloses oxidadas. É importante considerar que a obtenção de celulose segue, para cada método, uma rota reacional diferente, significando que produtos secundários diferentes serão formados, sendo que alguns podem se solubilizar no meio reacional ou não. Considerando ainda que as madeiras, 
mesmo dentro de uma mesma espécie, podem apresentar diferentes composições químicas, deve-se ponderar sobre a hipótese de que cada metodologia responderá de forma diferenciada quando do tratamento, dependendo de seu grau de seletividade para cada componente químico da madeira assim, uma mesma árvore pode responder de forma diferente a cada um dos tratamentos ao qual é submetida. É importante frisar ainda que os métodos gravimétricos têm por principal objetivo tão somente quantificar a massa de resíduo obtido, ao contrário dos métodos cromatográficos que também avaliam a pureza do mesmo.

4.1.4.1. Determinação de $\alpha$-celulose como parâmetro de comparação para os métodos não-convencionais.

Foram selecionadas, dentre as sessenta e quatro árvores utilizadas neste estudo, as quinze melhores quanto, principalmente, ao rendimento kraft. Para estas árvores foi determinado os teores de $\alpha$-celulose a partir de um método normatizado como descrito no capítulo referente à metodologia.

$\mathrm{Na}$ tabela 9 encontram-se os resultados médios encontrados para as quinze árvores selecionadas Os resultados individuais para as quinze árvores estudadas encontram-se no Anexo F. 
Tabela 9. Determinação de celulose por método normatizado e por métodos não-convencionais para quinze árvores de Eucalyptus grandis.

\begin{tabular}{c|c|c|c|c|c|c}
\hline Parâmetros & $\alpha$-Celulose & $\begin{array}{c}\text { Celulose } \\
\text { Seifert }\end{array}$ & $\begin{array}{c}\text { Ácido } \\
\text { Nitrico }\end{array}$ & $\begin{array}{c}\text { Ácido } \\
\text { Nitrico com } \\
\text { Extração } \\
\text { Alcalina }\end{array}$ & $\begin{array}{c}\text { Ácido } \\
\text { Peroxiacético }\end{array}$ & $\begin{array}{c}\text { Peroxiacético } \\
\text { com } \\
\text { Extração } \\
\text { Alcalina }\end{array}$ \\
\hline Valor Médio & 51,03 & 44,80 & 53,69 & 42,91 & 56,40 & 47,60 \\
\hline Valor Mínimo & 49,23 & 41,44 & 49,81 & 39,78 & 55,23 & 45,44 \\
\hline Valor Máximo & 54,24 & 47,48 & 57,13 & 46,85 & 58,55 & 49,94 \\
\hline Desvio Padrão & 1,14 & 1,54 & 1,67 & 1,85 & 1,00 & 1,31 \\
\hline Coeficiente de Variação, \% & 2,23 & 3,44 & 3,11 & 4,31 & 1,77 & 2,74 \\
\hline
\end{tabular}

A tabela 9 mostra que o valor médio encontrado para $\alpha$-celulose, obtida a partir de um método normatizado, foi de $51,03 \%$ e, portanto, está dentro da faixa percentual encontrada por Clarke et al. (1997), de 48 a 55\%, para madeiras do gênero Eucalyptus.

A tabela 10 refere-se à matriz de correlação dos métodos nãoconvencionais para determinação de celulose e do método normatizado.

Tabela 10. Matriz de correlação dos métodos não-convencionais e do método normatizado para determinação de celulose.

\begin{tabular}{c|c|c|c|c|c}
\hline & $\begin{array}{c}\text { Celulose } \\
\text { Seifert }\end{array}$ & $\begin{array}{c}\text { Ácido } \\
\text { Nítrico }\end{array}$ & $\begin{array}{c}\text { Ácido Nítrico com } \\
\text { Extração Alcalina }\end{array}$ & $\begin{array}{c}\text { Ácido } \\
\text { Peroxiacético }\end{array}$ & $\begin{array}{c}\text { Ácido Peroxiacético } \\
\text { com Extração Alcalina }\end{array}$ \\
\hline \multirow{2}{*}{$\alpha$-Celulose } & $0,47^{\text {n.s. }}$ & $0,58^{*}$ & $0,40^{\text {n.s. }}$ & $0,61^{*}$ & $0,52^{*}$ \\
& $p=7,4$ & $p=2,3$ & $p=14,1$ & $p=1,6$ & $p=4,5$ \\
\hline
\end{tabular}

${ }^{*}$ Coeficiente de correlação significativo a $5 \%$.

$p=$ Nivel de probabilidade, $\%$.

n.s. $=$ Coeficiente de correlação não-significativo.

A tabela 10 revela que as melhores correlações encontradas foram, respectivamente, para o método do ácido peroxiacético, ácido nítrico e ácido peroxiacético com extração alcalina. 
Este resultado sugere que o método do ácido peroxiacético é o mais conveniente para se determinar teor de celulose na madeira, quando comparado aos demais métodos. Se for considerado que a celulose é um bom indicador do rendimento kraft, como afirmado anteriormente, os resultados indicam que este método também pode ser utilizado como um bom indicador do rendimento kraft, auxiliando na seleção das árvores matrizes mais adequadas para a formação de florestas clonais. Outro aspecto interessante do método do ácido peroxiacético é sua extrema facilidade de execução e a possibilidade da avaliação conjunta de inúmeras amostras, tornando a aplicação deste método extremamente viável.

4.1.4.2. Métodos não-convencionais de determinação de celulose e composição química tradicional da madeira.

A tabela 11 mostra os coeficientes de correlação encontrados quando os resultados para os métodos não-convencionais foram confrontados com aqueles obtidos para a composição química da madeira. 
Tabela 11. Matriz de correlação dos métodos não-convencionais e da composição química tradicional da madeira.

\begin{tabular}{l|c|c|c|c|c} 
Variáveis & $\begin{array}{c}\text { Celulose } \\
\text { Seifert }\end{array}$ & $\begin{array}{c}\text { Ácido } \\
\text { Nítrico }\end{array}$ & $\begin{array}{c}\text { Ácido Nítrico } \\
\text { com Extração } \\
\text { Alcalina }\end{array}$ & $\begin{array}{c}\text { Ácido } \\
\text { Peroxiacético }\end{array}$ & $\begin{array}{c}\text { Ácido } \\
\text { Peroxiacético com } \\
\text { Extração Alcalina }\end{array}$ \\
\hline Holocelulose & $0,28^{*}$ & $0,47^{* *}$ & $0,29^{*}$ & $0,48^{* *}$ & $0,47^{* *}$ \\
& $p=2,8$ & $p=0,0$ & $p=2,2$ & $p=0,0$ & $p=0,0$ \\
\hline Lignina & $-0,29^{*}$ & $-0,28^{*}$ & $-0,12^{\text {n.s. }}$ & $-0,46^{* *}$ & $-0,53^{* *}$ \\
& $p=2,2$ & $p=2,5$ & $p=35,1$ & $p=0,0$ & $p=0,0$ \\
\hline \\
Extrativos Totais & $-0,06^{\text {n.s. }}$ & $-0,54^{* *}$ & $-0,44^{* *}$ & $-0,19^{\text {n.s. }}$ & $-0,02^{\text {n.s. }}$ \\
& $p=64,2$ & $p=0,0$ & $p=0,0$ & $p=13,4$ & $p=88,3$ \\
\hline${ }^{*}$ Coeficiente de correlação significativo a $5 \%$. \\
** Coeficiente de correlação significativo a 1\%. \\
p= Nivel de probabilidade, \%. \\
n.s. = Coeficiente de correlação não-significativo.
\end{tabular}

A tabela 11 mostra que para holocelulose foi encontrada significância para todos os métodos, com destaque para os métodos do ácido peroxiacético e ácido nítrico.

Em relação à lignina, exceto para o método do ácido nítrico com extração alcalina, a exemplo do resultado encontrado para holocelulose, encontrou-se resultados significativos e negativos. $O$ melhor resultado encontrado foi para o ácido peroxiacético com extração alcalina.

Considerando-se extrativos totais, significância a $5 \%$ de probabilidade foi obtida somente para ambos os métodos do ácido nítrico, porém com coeficientes bem expressivos.

O trabalho descrito por Wright \& Wallis (1998) e que serviu como referência para o desenvolvimento destes métodos, não abordou a correlação entre os métodos não convencionais e propriedades químicas da madeira. Os resultados obtidos no presente trabalho se mostraram bastante representativos. 
4.1.5. Relação da densidade básica com a composição química tradicional da madeira e com os métodos não-convencionais de determinação de celulose

4.1.5.1. Densidade básica e composição química tradicional da madeira

A tabela 12 mostra os coeficientes de correlação entre densidade básica e composição química tradicional da madeira.

Tabela 12. Matriz de correlação da densidade básica e da composição química tradicional da madeira.

\begin{tabular}{c|c|c|c}
\hline & Holocelulose & Lignina & Extrativos Totais \\
\hline \multirow{2}{*}{ Densidade Básica } & $0,08^{\text {ns. }}$ & $-0,05^{\text {ns. }}$ & $-0,08^{\text {ns. }}$ \\
& $p=55,3$ & $p=71,5$ & $p=51,1$ \\
\hline
\end{tabular}

$p=$ Nivel de probabilidade, $\%$.

n.s. = Coeficiente de correlação não-significativo.

Os resultados obtidos, expostos na tabela 12, concordam com aqueles descritos por Shimoyama (1990), que relata não haver encontrado nenhuma relação entre tais parâmetros para madeira do gênero Eucalyptus.

Porém, Barrichelo \& Brito (1977), também trabalhando com Eucalyptus grandis, encontraram relação negativa entre densidade básica e holocelulose. Discordando destes resultados, Vital et al. (1986) encontraram proporcionalidade direta entre densidade básica e holocelulose.

Vasconcelos Dias \& Cláudio-da-Silva Júnior (1985) e Wehr (1991) concordam que um aumento na densidade básica acarreta um aumento no teor de lignina. Wehr (1991) ainda acrescenta que há um aumento no teor de extrativos na madeira. 
4.1.5.2. Densidade básica e métodos não-convencionais de determinação de celulose na madeira.

A tabela 13 revela os coeficientes de correlação entre densidade básica e os métodos não-convencionais de determinação de celulose.

Tabela 13. Matriz de correlação da densidade básica e dos métodos nãoconvencionais de determinação de celulose na madeira.

\begin{tabular}{c|c|c|c|c|c}
\hline & $\begin{array}{c}\text { Celulose } \\
\text { Seifert }\end{array}$ & $\begin{array}{c}\text { Ácido } \\
\text { Nítrico }\end{array}$ & $\begin{array}{c}\text { Ácido Nítrico } \\
\text { com Extração } \\
\text { Alcalina }\end{array}$ & $\begin{array}{c}\text { Ácido } \\
\text { Peroxiacético }\end{array}$ & $\begin{array}{c}\text { Ácido } \\
\text { Peroxiacético } \\
\text { com Extração } \\
\text { Alcalina }\end{array}$ \\
\hline Densidade Básica & $\begin{array}{c}-0,04^{\text {n.s. }} \\
p=76,3\end{array}$ & $\begin{array}{c}0,26^{*} \\
p=3,7\end{array}$ & $\begin{array}{c}0,26^{*} \\
p=4,2\end{array}$ & $\begin{array}{c}0,18^{\text {n.s. }} \\
p=16,2\end{array}$ & $\begin{array}{c}0,16^{\text {n.s. }} \\
p=20,5\end{array}$ \\
\hline
\end{tabular}

* Coeficiente de correlação significativo a $5 \%$.

$p=$ Nível de probabilidade, $\%$.

n.s. = Coeficiente de correlação não-significativo.

A tabela 13 mostra que os métodos do ácido nítrico foram os únicos que apresentaram resultados significativos frente à densidade básica, mas com um coeficiente de correlação pouco expressivo.

\subsection{Análise da deslignificação kraft-AQ}

Dentro de um processo industrial de polpação química o rendimento é, sem dúvida, uma das variáveis de maior impacto econômico. Estimar o rendimento final de polpa não-branqueada é um importante indicador do ponto de vista econômico ou tecnológico.

Greaves \& Borralho (1996) realizaram um estudo sobre o custo de conversão de madeira verde para polpa kraft não-branqueada, em relação à 
densidade básica e rendimento. Observaram que o rendimento é o fator de maior efeito sobre o custo da deslignificação, porém o grau de influência depende do valor energético produzido pela caldeira de recuperação, alto valor energético reduz a influência do rendimento. Densidade básica apresentou maior influência sobre o custo da digestão, mas a importância da densidade básica consiste também em sua maior variação genética explorável, tornandose então um parâmetro importante no melhoramento de árvores para polpa kraft. A densidade básica também influencia diretamente a qualidade da polpa através das resistências físico-mecânicas, características superficiais e ópticas da mesma.

Porém, outra propriedade da polpa exerce grande impacto sobre a produção industrial, o número kappa. Idealmente o que se almeja é maximizar o rendimento e minimizar o número kappa da polpa.

As condições empregadas na deslignificação kraft-AQ foram cuidadosamente controladas, dentro do limite possível permitido pelo digestor rotativo utilizado, de forma com que os fatores $\mathrm{H}$ tivessem valores os mais próximos possiveis para todas as deslignificações efetuadas.

Para averiguar diferenças na deslignificação foram testadas seis árvores conforme descrito no ítem $3.2 .6 \mathrm{da}$ metodologia. Os resultados encontrados são apresentados na tabela 14. 
Tabela 14. Valores de número kappa para as seis árvores testadas na deslignificação kraft-AQ.

\begin{tabular}{c|c|c}
\hline Árvore Testada & $\begin{array}{c}\text { Número Kappa Médio do } \\
\text { Teste Efetuado }\end{array}$ & $\begin{array}{c}\text { Número Kappa Médio da } \\
\text { Deslignificação }\end{array}$ \\
\hline 09 & 17,6 & 18,3 \\
\hline 12 & 16,6 & 17,3 \\
\hline 26 & 19,2 & 19,8 \\
\hline 37 & 18,3 & 16,9 \\
\hline 42 & 15,5 & 14,3 \\
\hline 52 & 20,9 & 18,7 \\
\hline
\end{tabular}

Conforme pode ser observado pela tabela 14 , os valores médios encontrados para número kappa de cada árvore estão bem próximos, significando que ao se deslignificar conjuntamente várias árvores, o resultado individual de cada uma é pouco afetado.

Os valores da deslignificação kraft-AQ das árvores individuais constam no Anexo $G$ e os valores médios para as sessenta e quatro árvores analisadas na tabela 15. Os valores individuais de consumo específico para cada árvore analisada estão descritos no Anexo $\mathrm{H}$.

Tabela 15. Valores médios da deslignificação kraft-AQ das sessenta e quatro árvores analisadas.

\begin{tabular}{c|c|c|c}
\hline Parâmetros & $\begin{array}{c}\text { Rendimento Bruto da } \\
\text { Deslignificação, } \%\end{array}$ & $\begin{array}{c}\text { Número Kappa } \\
\text { da Polpa }\end{array}$ & $\begin{array}{c}\text { Consumo Específico de } \\
\text { Madeira, }{ }^{3} / t \text { de polpa s.e }\end{array}$ \\
\hline Valor Médio & 53,12 & 18,22 & 4,24 \\
\hline Valor mínimo & 50,12 & 14,34 & 3,33 \\
\hline Valor máximo & 57,03 & 24,40 & 5,19 \\
\hline Desvio padrão & 1,35 & 2,10 & 0,39 \\
\hline Coeficiente de variação, \% & 2,55 & 11,80 & 9,22 \\
\hline
\end{tabular}


A tabela 16 mostra o grau de correlação observado entre os parâmetros estudados na deslignificação kraft-AQ.

Tabela 16. Matriz de correlação dos parâmetros da deslignificação kraft-AQ.

\begin{tabular}{|c|c|c|c|}
\hline Variáveis & $\begin{array}{l}\text { Rendimento da } \\
\text { Deslignificação }\end{array}$ & $\begin{array}{c}\text { Número Kappa } \\
\text { da Polpa }\end{array}$ & $\begin{array}{c}\text { Consumo Específico } \\
\text { de Madeira }\end{array}$ \\
\hline Rendimento & 1,00 & $\begin{array}{l}-0,20^{\text {n.s. }} \\
p=11,8\end{array}$ & $\begin{array}{l}-0,44^{\star \star} \\
p=0,0\end{array}$ \\
\hline Número Kappa & & 1,00 & $\begin{array}{l}-0,38^{\star \star} \\
p=0,2\end{array}$ \\
\hline Consumo Específico de Madeira & & & 1,00 \\
\hline
\end{tabular}

A análise da tabela 15 e dos Anexos $\mathrm{G}$ e $\mathrm{H}$ permitem observar a variação nos resultados, possibilitando a escolha das árvores com maior potencial para deslignificação kraft-AQ. Vários autores, como Masura (1996) e Marcoccia et al. (1998), relataram a dificuldade em se estimar o rendimento industrial de polpa kraft, principalmente pelo fato da madeira se tratar de um material heterogêneo e a deslignificação ser fortemente influenciada pelas condições químicas reacionais. A heterogeneidade da matéria-prima, em relação à sua qualidade, pode ser facilmente observada nos resultados apresentados na tabela 15. Apesar de serem árvores selecionadas, é evidente - comportamento diferenciado das árvores frente às mesmas condições aplicadas no processo de deslignificação.

O estabelecimento da relação rendimento versus número kappa nos resultados da deslignificação foi uma investigação efetuada para facilitar a escolha das melhores árvores. Conforme pode ser observado na figura 4, o gráfico de rendimento versus número kappa mostra pares de valores significativamente espalhados. 


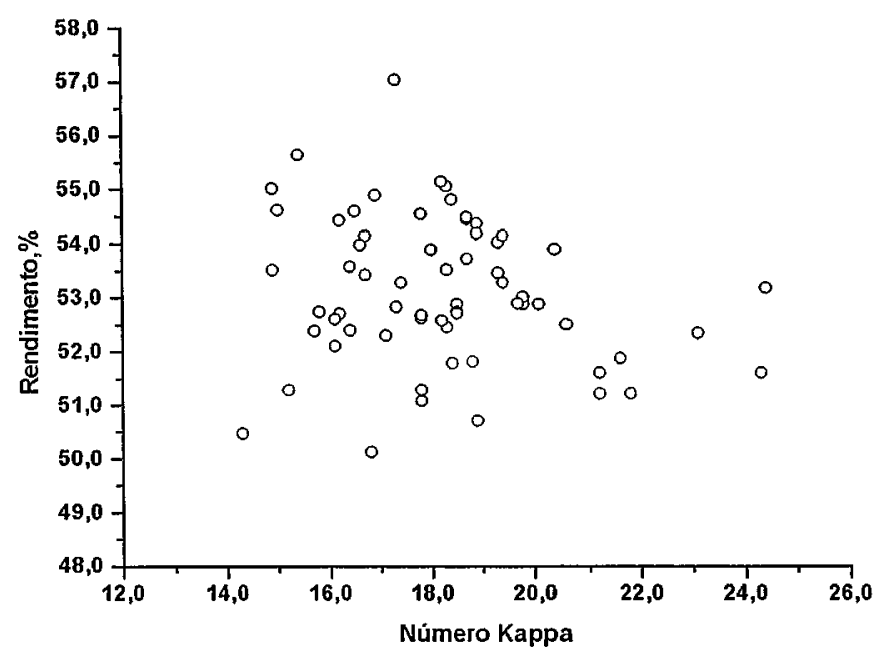

Figura 4 - Relação entre rendimento da deslignificação versus número kappa da polpa.

Masura (1996) relata em seu trabalho ter encontrado uma forte dependência entre rendimento e número kappa e/ou percentagem em lignina. Esta dependência, segundo o autor, foi obtida através de uma modificação matemática, adotando como variável dependente a relação rendimento/número kappa e como variável independente o número kappa, conforme mostrado na figura 5 . 


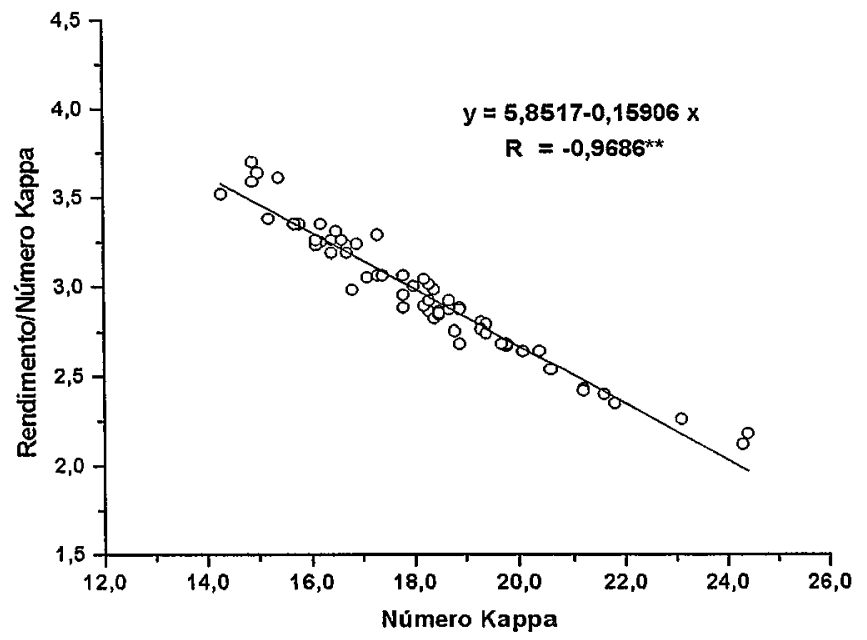

Figura 5 - Relação entre rendimento/número kappa versus número kappa da polpa.

Conforme pode ser observado na figura 5, a relação de dependência de ligação entre as variáveis diminui consideravelmente o espalhamento de pares de valores. Uma melhor linearização da figura 5 pode ser obtida através da adoção de In(rendimento/número kappa) como variável dependente e In(número kappa) como variável independente, como mostra a figura 6. 


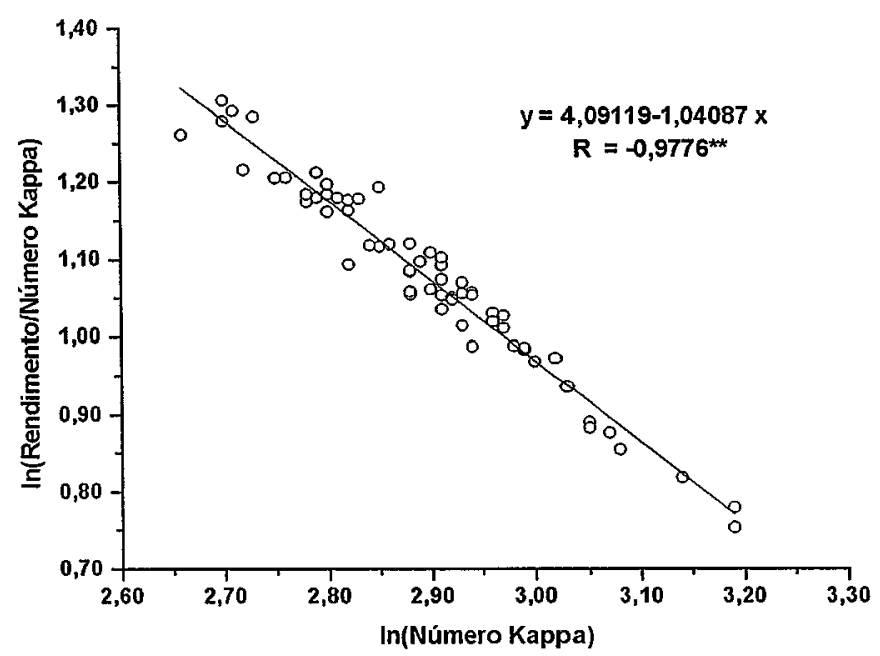

Figura 6 - Relação logarítmica do rendimento/número kappa versus número kappa da polpa.

De acordo com a figura 6 , a relação logarítmica linear do quociente rendimento/número kappa versus número kappa pode ser expressa matematicamente pela equação logarítmica da linha reta:

$$
\ln y=k^{*} \ln x+\ln b
$$

Onde:

$y=$ Relação Rendimento/Número Kappa

$\mathrm{x}=$ Número Kappa

$k=$ Coeficiente angular da reta

Inb = Intercepção da reta

Outro parâmetro estudado na deslignificação kraft-AQ foi o consumo específico de madeira, isto é, quantos metros cúbicos de madeira são necessários para se produzir uma tonelada de polpa seca em estufa. O consumo específico de madeira, na verdade, é um parâmetro calculado a partir do rendimento da deslignificação e da densidade básica média da madeira. Os 
resultados encontrados permitiram observar comportamento diferenciado das árvores em relação a este parâmetro.

\subsection{Principais relações entre densidade básica e deslignificação kraft-AQ}

A tabela 17 mostra o grau de correlação observado entre densidade básica e os parâmetros estudados na deslignificação kraft-AQ.

Tabela 17. Matriz de correlação da densidade básica e da deslignificação Kraft$A Q$.

\begin{tabular}{l|c|c|c}
\hline & $\begin{array}{c}\text { Rendimento da } \\
\text { Deslignificação }\end{array}$ & $\begin{array}{c}\text { Número Kappa da } \\
\text { Polpa }\end{array}$ & $\begin{array}{c}\text { Consumo Específico de } \\
\text { Madeira }\end{array}$ \\
\hline \multirow{2}{*}{ Densidade Básica } & $0,20^{\text {n.s. }}$ & $0,45^{\star *}$ & $-0,95^{\star *}$ \\
& $p=10,7$ & $p=0,0$ & $p=0,0$ \\
\hline
\end{tabular}

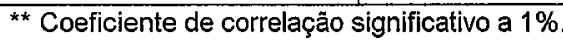

$p=$ Nivel de probabilidade, $\%$.

n.s. = Coeficiente de correlação não-significativo.

\subsubsection{Densidade básica e rendimento gravimétrico}

Há muito que a densidade básica é considerada como um forte indicador da qualidade da madeira. O rendimento da deslignificação e a densidade básica são características principais quanto à seleção da matériaprima para produção de celulose, no que diz respeito à capacidade e ao custo de produção de uma planta (Fonseca et al., 1996).

A importância da densidade básica como parâmetro de qualidade da madeira motivou a execução de inúmeros trabalhos visando a observação da influência desta característica frente à qualidade da celulose. 
Atualmente é bastante conhecido que a densidade básica exerce influência direta na qualidade da celulose, o que é refletida em sua resistência mecânica e em suas características superficiais e ópticas. Segundo Barrichelo et al. (1983b), de uma maneira geral, quanto maior a densidade maior resistência ao rasgo e menor colapso, o que ocasiona menor lisura, menor resistência à tração e ao arrebentamento e maior opacidade.

Frente à influência exercida pela densidade básica junto à qualidade da polpa, houve também a preocupação em se verificar tal efeito sobre o rendimento gravimétrico em polpa.

Os resultados obtidos neste trabalho levaram a concluir que não há correlação significativa entre densidade básica e rendimento bruto gravimétrico, isto quer dizer que árvores mais densas não produzem, necessariamente, maior quantidade de polpa. Resultados similares foram obtidos por Barrichelo et al. (1983a), Foelkel (1974), Goyal et al. (1999), Turner et al. (1983), Valente et al. (1992) e Vasconcelos Dias \& Cláudio-da-Silva Júnior (1985). Exceção foi encontrada por Barrichelo \& Brito (1977) que encontraram correlação negativa e significativa entre densidade básica e rendimento.

Assim, sendo rendimento uma característica de relativa importância no critério de seleção de árvores, faz-se necessário encontrar, através de estudos mais detalhados, uma característica da madeira que possa servir como indicador do potencial de deslignificação da árvore.

\subsubsection{Densidade básica e número kappa}

A quantidade de lignina residual na polpa é expressa através da determinação do número kappa. Atualmente, com a crescente exigência quanto à alvura da polpa, também em relação ao controle das implicações ambientais que o processo de branqueamento pode acarretar, torna-se cada vez mais 
necessário obter polpa com menor número kappa. Porém, é conhecido que um aumento na carga de álcali provoca a degradação de parte dos polissacarídeos, comprometendo a quantidade e a qualidade da polpa produzida. Um raciocínio lógico é de que quanto menor o teor de lignina na madeira mais fácil é a deslignificação. Entretanto, outros fatores também influenciam o processo, sendo que um fenômeno físico que exerce considerável influência neste aspecto é a permeabilidade da madeira. Wehr (1991) relatou que a impregnação dos cavacos pelo licor de deslignificação é prejudicada quando estes são obtidos a partir de madeiras densas. As madeiras densas se caracterizam por possuírem maior espessura de parede $e$ menor lume (Barrichelo et al., 1984). Portanto, a porosidade destas madeiras é menor do que madeiras leves. Bamber (1985) relata que a produção de polpa de alta qualidade está diretamente associada à total impregnação da madeira pelo licor de deslignificação. Segundo o autor, a permeabilidade da madeira depende da presença de canais ao longo dos quais os materiais possam se mover livremente. Assim sendo, um aumento na densidade básica significa uma diminuição na porosidade da madeira $e$, consequentemente, verifica-se uma maior dificuldade do licor de deslignificação impregnar os cavacos, porque a permeabilidade da madeira é menor, levando a uma queda na eficiência da deslignificação e produzindo polpas com maior número kappa. É evidente que um resultado de número kappa é função também de outras variáveis como teor de lignina na madeira e, segundo Goyal (1999), da própria estrutura molecular da lignina.

A figura 7 mostra a relação entre número kappa e densidade básica da madeira. 


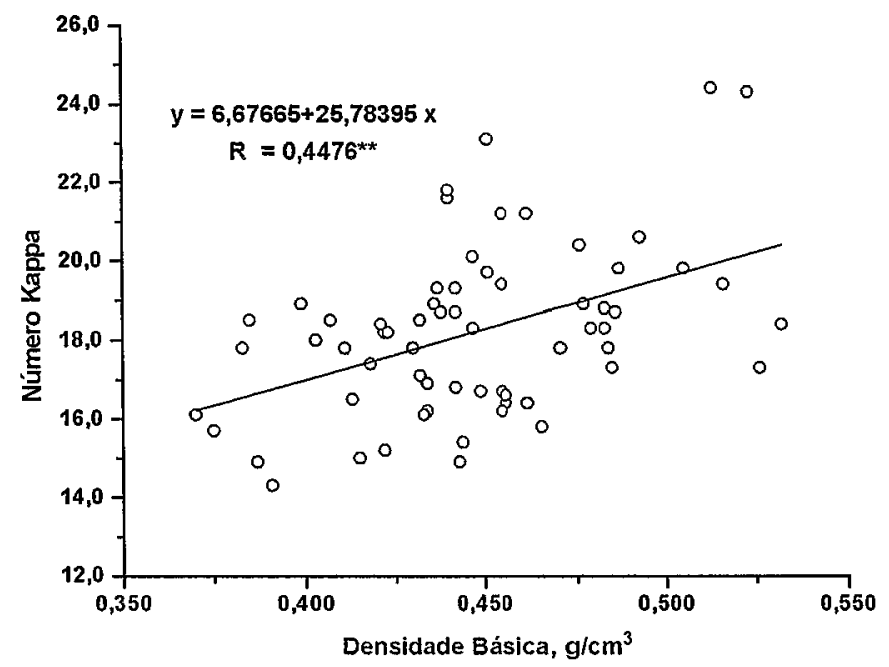

Figura 7 - Relação entre número kappa da polpa e densidade básica da madeira.

Conforme pode ser observado, houve uma tendência das árvores com densidades mais baixas produzirem polpas com menores números kappa. Mortha (1992), trabalhando com híbridos poplar, relata que uma menor densidade básica diminui as limitações de difusão da lignina para fora dos cavacos, resultando em maior velocidade de deslignificação. Outra explicação pode ser a estrutura diferente da lignina nas árvores. A relação siringila/guaiacila na lignina tem relação linear e positiva com a velocidade de deslignificação (Chang \& Sarkanen, 1973). Portanto, árvores com mesma densidade básica podem apresentar velocidades de deslignificação diferentes devido à estrutura da lignina. 
A figura 8 mostra a relação entre lignina solubilizada na deslignificação e densidade básica da madeira. Pode ser notado que nas árvores com menores densidades básicas ocorreram maiores remoções de lignina. Os valores de lignina solubilizada na deslignificação para as sessenta e quatro árvores encontram-se no Anexo G.

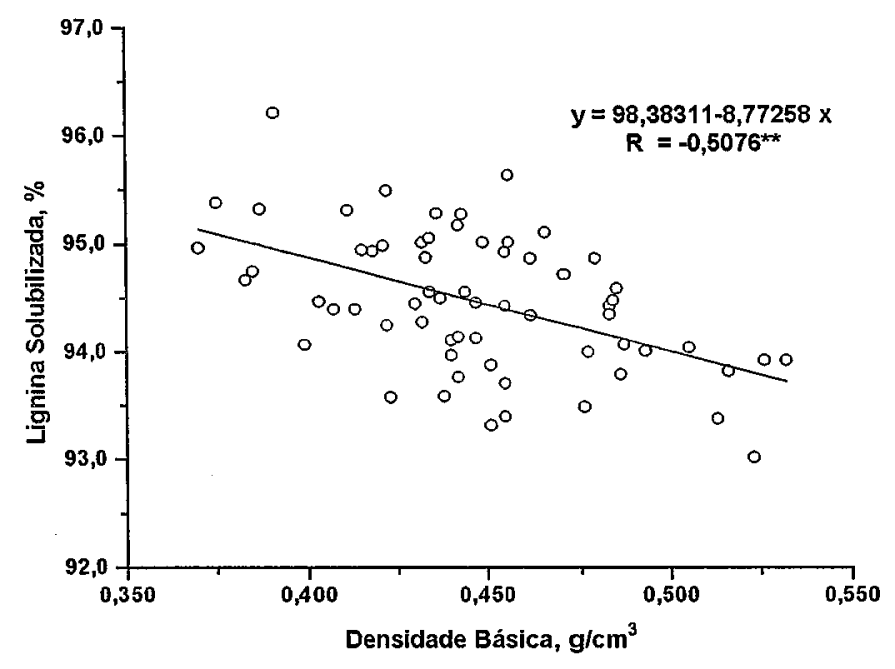

Figura 8 - Relação entre lignina solubilizada na deslignificação e densidade básica da madeira.

As tabelas 18 e 19 mostram a análise de variância da regressão para número kappa e lignina solubilizada em relação à densidade básica.

Tabela 18. Análise de variância da regressão número kappa versus densidade básica.

\begin{tabular}{c|c|c|c|c|c}
\hline F.V. & G.L. & S.Q. & Q.M. & F & P \\
\hline Regressão Linear & 1 & 57,96 & 57,96 & $15,53^{* \star}$ & 0,000209 \\
\hline Resíduo & 62 & 231,34 & 3,73 & & \\
\hline \multicolumn{2}{|c|}{ Total } & 63 & 289,30 & & \\
\hline
\end{tabular}


Tabela 19. Análise de variância da regressão lignina solubilizada versus densidade básica.

\begin{tabular}{c|c|c|c|c|c}
\hline F.V. & G.L. & S.Q. & Q.M. & F & P \\
\hline Regressão Linear & 1 & 6,68 & 6,68 & $21,47^{* *}$ & 0,000019 \\
Resíduo & 62 & 19,30 & 0,3113 & & \\
\hline Total & 63 & 25,98 & \multicolumn{3}{|l}{} \\
\hline
\end{tabular}

** Equação de regressão significativa a $1 \%$.

\subsubsection{Densidade básica e consumo específico de madeira}

O consumo específico de madeira é função do rendimento da deslignificação e da densidade básica da madeira. A figura 9 mostra a relação entre consumo específico de madeira/tonelada de polpa e densidade básica.

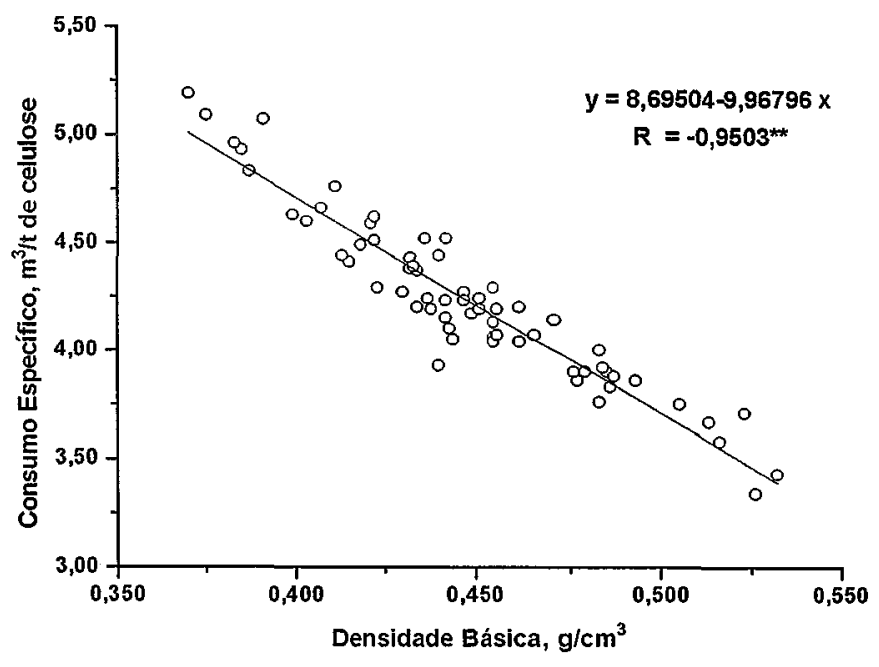

Figura 9 - Relação entre consumo específico de madeira/tonelada de polpa e densidade básica da madeira.

Este resultado é confirmado por um número expressivo de trabalhos publicados. Foi discutido anteriormente que a densidade básica não é um bom 
preditor para rendimentos gravimétricos mas sim para rendimentos volumétricos, devido a capacidade volumétrica limitada do digestor (Foelkel, 1974; Fonseca et al., 1996; Goyal et al., 1999 e Valente et al., 1992;). Esta expressiva relação entre consumo específico de madeira e densidade básica pode ser entendida da seguinte forma: quanto mais densa for a madeira, menor será o volume necessário deste material para se produzir uma tonelada de polpa porque a massa de madeira contida no digestor é maior. Torna-se evidente então que a demanda volumétrica de madeira para se produzir uma tonelada de polpa é menor para madeiras mais densas, ou seja, quanto maior for a densidade básica da madeira, menor será seu consumo específico.

A tabela 20 mostra a análise de variância da regressão para consumo específico e densidade básica.

Tabela 20. Análise de variância da regressão consumo específico versus densidade básica.

\begin{tabular}{c|c|c|c|c|c}
\hline F.V. & G.L. & S.Q. & Q.M. & F & P \\
\hline Regressão Linear & 1 & 8,68 & 8,68 & $576,20^{* *}$ & 0,000000 \\
Resíduo & 62 & 0,9335 & 0,0151 & & \\
\hline Total & 63 & 9,61 & & \\
\hline ** Equação de regressão significativa a 1\%.
\end{tabular}

\subsection{Principais relações entre componentes químicos da madeira e a deslignificação kraft-AQ}

O conhecimento da composição química da madeira em seus componentes principais (celulose, hemiceluloses, lignina e extrativos) é importante para interpretar o comportamento da madeira no processo de deslignificação, assim como para determinar a qualidade da polpa. Ao se 
consultar a literatura fica evidenciado que a composição química despertou o interesse dos centros de pesquisa, no sentido de se poder verificar as influências desta característica sobre a qualidade das polpas produzidas. Além do mais, acredita-se que através do conhecimento da composição química da madeira seja possivel estimar o rendimento da deslignificação. Para Raymond et al. (1994), o método de seleção indireta é uma opção eficiente quando se pretende melhorar uma dada característica através de uma outra característica. É necessário, no entanto, que a característica que está sendo usada para seleção de genótipos seja mais variável e mais hereditária do que aquela a qual se pretende melhorar. Imprescindivel também é haver alta correlação entre ambas características. A linha de raciocínio seguida por Raymond, na verdade, traduz a intenção de diversos autores $e$, inclusive, a deste trabalho, ou seja, a de encontrar uma característica da madeira que, se determinada, possa ajudar a selecionar as melhores árvores quanto principalmente ao rendimento, através de metodologias eficientes, rápidas e fáceis de executar.

A tabela 21 se refere aos graus de correlação encontrados para os componentes químicos da madeira em relação aos parâmetros analisados na deslignificação kraft-AQ. 
Tabela 21. Matriz de correlação dos componentes químicos tradicionais da madeira e da deslignificação kraft-AQ.

\begin{tabular}{c|c|c|c}
\hline Variáveis & $\begin{array}{c}\text { Rendimento da } \\
\text { Deslignificação }\end{array}$ & $\begin{array}{c}\text { Número Kappa da } \\
\text { Polpa }\end{array}$ & $\begin{array}{c}\text { Consumo } \\
\text { Específico de } \\
\text { Madeira }\end{array}$ \\
\hline Holocelulose & $0,56^{* *}$ & $-0,32^{* *}$ & $-0,21^{\text {n.s. }}$ \\
& $p=0,0$ & $p=0,8$ & $p=8,9$ \\
\hline Lignina & $-0,53^{* *}$ & $0,30^{*}$ & $0,17^{\text {n.s. }}$ \\
\hline Extrativos Totais & $p=0,0$ & $p=1,5$ & $p=17,6$ \\
\hline
\end{tabular}

* Coeficiente de correlaçăo significativo a $5 \%$.

** Coeficiente de correlação significativo a $1 \%$.

$p=$ Nivel de probabilidade, $\%$.

n.s. = Coeficiente de correlação não-significativo.

Conforme pode ser observado pela tabela 21, nenhum dos parâmetros da deslignificação se correlacionou significativamente aos extrativos totais.

Os resultados obtidos indicam que, praticamente, holocelulose e lignina exerceram o mesmo grau de influência sobre o número kappa, porém em sentidos contrários. As figuras 10 e 11 mostram a relação entre número kappa e holocelulose e lignina Klason, respectivamente. 


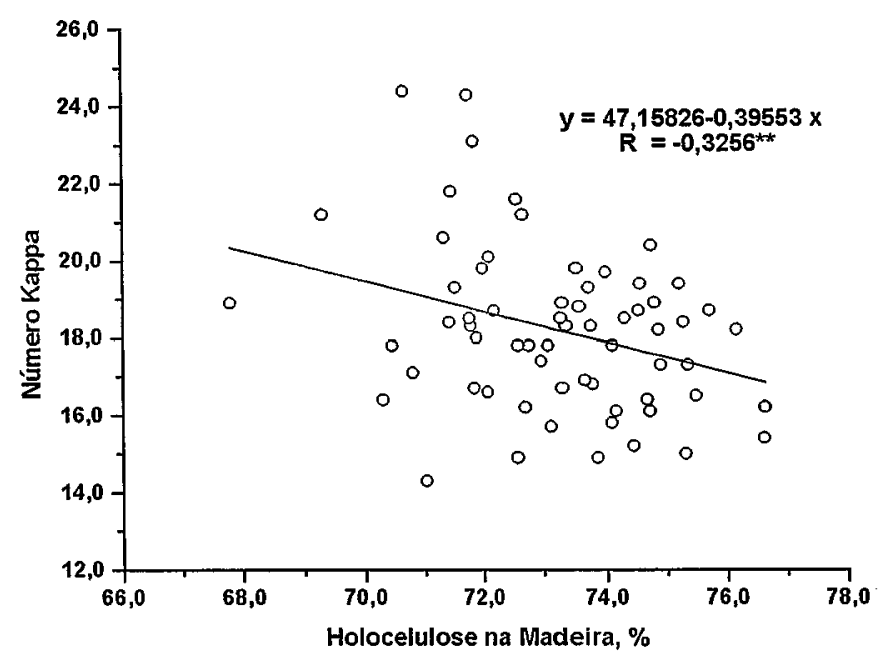

Figura 10 - Relação entre número kappa na polpa e teor de holocelulose na madeira.

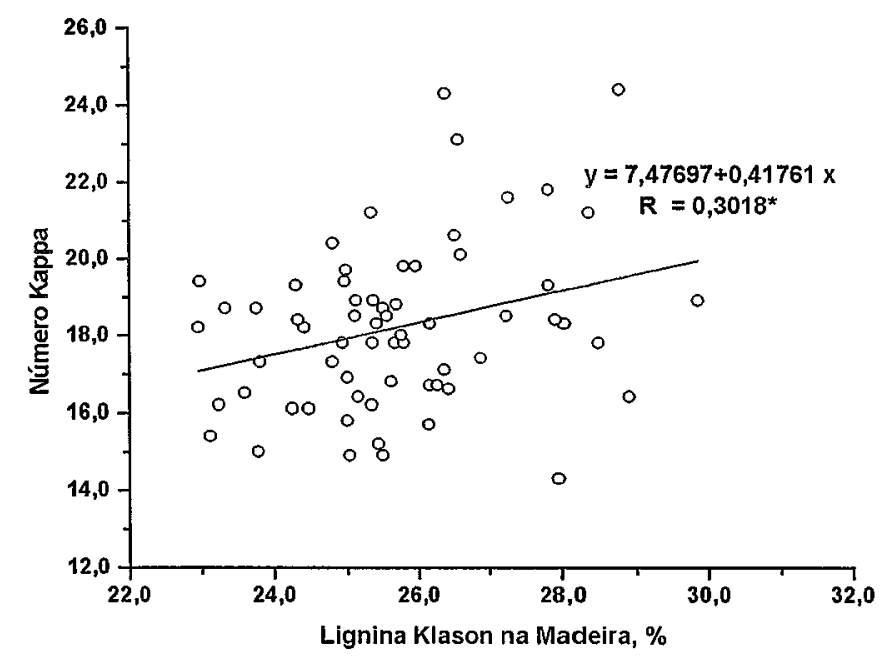

Figura 11 - Relação entre número kappa na polpa e teor de lignina Klason na madeira. 
As tabelas 22 e 23 mostram a análise de variância da regressão para número kappa versus holocelulose e número kappa versus lignina Klason, respectivamente.

Tabela 22. Análise de variância da regressão número kappa versus holocelulose na madeira.

\begin{tabular}{c|c|c|c|c|c}
\hline F.V. & G.L. & S.Q. & Q.M. & F & P \\
\hline Regressão Linear & 1 & 30,67 & 30,67 & $7,35^{\star *}$ & 0,008653 \\
Resíduo & 62 & 258,63 & 4,17 & & \\
\hline Total & 63 & 289,30 & & \\
\hline
\end{tabular}

** Equação de regressão significativa a $1 \%$.

Tabela 23. Análise de variância da regressão número kappa versus lignina Klason na madeira.

\begin{tabular}{c|c|c|c|c|c}
\hline F.V. & G.L. & S.Q. & Q.M. & F & P \\
\hline Regressão Linear & 1 & 26,35 & 26,35 & $6,21^{* \star}$ & 0,015378 \\
Resíduo & 62 & 262,96 & 4,24 & & \\
\hline Total & 63 & 289,31 & & & \\
\hline ** Equação de regressão significativa a 1\%.
\end{tabular}

A dependência negativa entre número kappa e holocelulose poderia ser entendida como resultado direto da correlação negativa entre holocelulose e lignina Klason, pelo fato desta se aproximar de uma unidade. Desta forma, quanto maior o teor de holocelulose, menor o teor de lignina na madeira $e$, consequentemente, menor quantidade de lignina existe para ser removida no processo de deslignificação, o que pode favorecer a obtenção de um menor teor de lignina residual na polpa, isto é, menor número kappa. Porém, Goyal et al. (1999), através de estudos com híbridos poplar, afirma que a velocidade de deslignificação parece ser independente do teor de lignina Klason na madeira. 
O autor acredita que uma explicação viável possa estar relacionada à diferença na estrutura molecular da lignina entre os híbridos.

Segundo Chang \& Sarkanen (1973), as espécies que contêm mais lignina do tipo siringila possuem maior velocidade de deslignificação kraft, uma vez que muito provavelmente devem apresentar menor número de ligações carbono-carbono, que não são hidrolisáveis, e são menos suscetiveis às reações de condensação. Em seus estudos os autores encontraram que nas folhosas a estrutura e a composição química da lignina podem variar amplamente. A percentagem de unidades de siringilpropano, por exemplo, apresentou variação de 26 a $62 \%$.

Portanto, o real efeito da lignina da madeira sobre o número kappa da polpa parece ser algo de considerável complexidade, exigindo estudos mais específicos a respeito da molécula de lignina.

A figura 12 mostra a relação entre rendimento da deslignificação kraft$A Q$ e teor de lignina Klason na madeira, podendo observar uma correlação negativa entre as variáveis, concordando com Amidon (1981). A análise de variância da regressão para esta relação pode ser observada na tabela 24. 


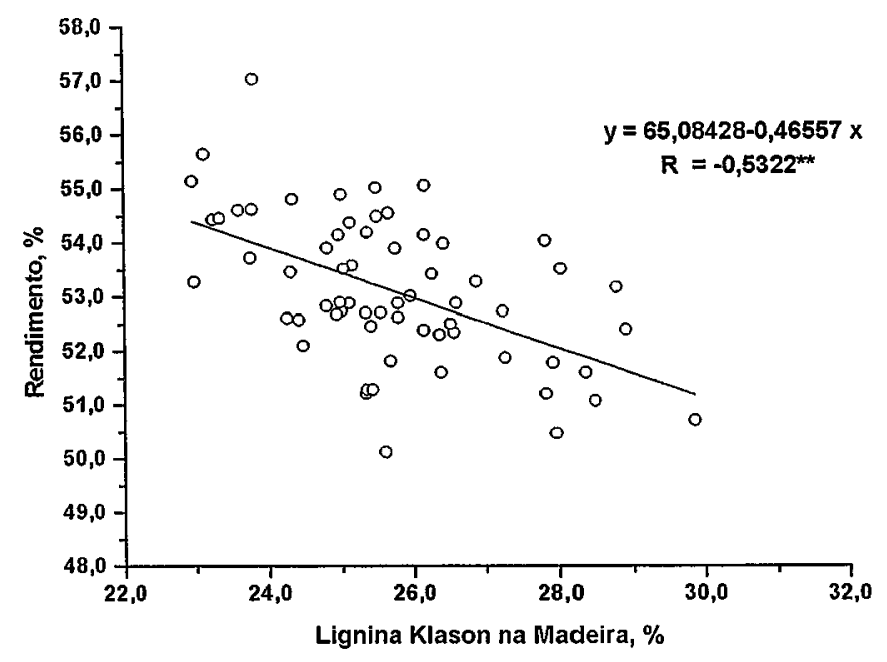

Figura 12 - Relação entre rendimento da deslignificação e teor de lignina Klason na madeira.

Tabela 24. Análise de variância da regressão rendimento da deslignificação versus teor de lignina Klason na madeira.

\begin{tabular}{c|c|c|c|c|c}
\hline F.V. & G.L. & S.Q. & Q.M. & F & P \\
\hline Regressão Linear & 1 & 32,74 & 32,74 & $24,50^{* *}$ & 0,000006 \\
Resíduo & 62 & 82,87 & 1,34 & & \\
\hline Total & 63 & 115,62 & & & \\
\hline
\end{tabular}

** Equação de regressão significativa a $1 \%$.

A figura 13 mostra a relação entre rendimento da deslignificação kraft$\mathrm{AQ}$ e teor de holocelulose na madeira, obtendo uma correlação positiva entre as variáveis. Vários trabalhos mostram que o rendimento da deslignificação kraft de folhosas é positivamente correlacionado com o teor de celulose na madeira e mais fracamente correlacionado com 0 teor de hemiceluloses (Amidon, 1981). Em madeiras de do gênero Eucalyptus, o rendimento da deslignificação kraft correlaciona forte e positivamente com o teor de celulose e fraca e negativamente com o teor de hemiceluloses (Wallis et al., 1996b). 
Portanto, o rendimento da deslignificação kraft pode correlacionar fraca e positivamente com o teor de holocelulose na madeira. Não foi encontrado correlação significativa entre rendimento e extrativos totais, confirmando os resultados observados por Raymond et al. (1994). No entanto, Turner et al. (1983) encontraram alta dependência entre rendimento e solúveis em água quente da madeira.

Os resultados observados para rendimento, holocelulose e lignina são amplamente confirmados na literatura em trabalhos realizados por Amidon (1981), Barrichelo \& Brito (1977), Barrichelo et al. (1983a), Collins et al. (1990), Kibblewhite et al. (1998) e Wallis et al. (1996b).

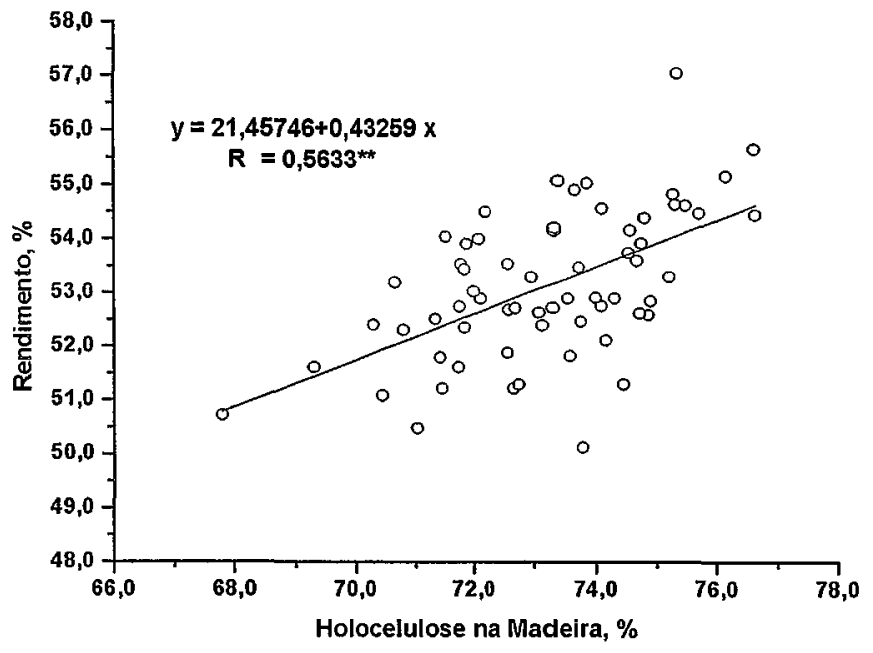

Figura 13. Relação entre rendimento da deslignificação e teor de holocelulose na madeira.

A tabela 25 mostra a análise de variância da regressão para rendimento da deslignificação e teor de holocelulose na madeira. 
Tabela 25. Análise de variância da regressão rendimento da deslignificação versus teor de holocelulose na madeira.

\begin{tabular}{c|c|c|c|c|c}
\hline F.V. & G.L. & S.Q. & Q.M. & F & P \\
\hline Regressão Linear & 1 & 36,69 & 36,69 & $28,82^{* *}$ & 0.000001 \\
Resíduo & 62 & 78,93 & 1,27 & & \\
\hline \multicolumn{2}{c|}{ Total } & 63 & 115,62 & & \\
** Equação de regressão significativa a 1\%.
\end{tabular}

Wallis et al. (1996b) observaram que o efeito exercido pela estrutura da lignina sobre o rendimento é muito inferior àquele exercido pela celulose e outros polissacarídeos. Collins et al. (1990) constataram em seu estudo que os verdadeiros indicadores do rendimento são os polissacarídeos. Segundo os autores, o decréscimo no rendimento observado com o aumento no teor de lignina na madeira é consequência direta da degradação e dissolução dos polissacarídeos, visto a maior carga de álcali necessária para se efetuar a deslignificação. Os constantes resultados positivos encontrados para a dependência entre rendimento e polissacarídeos, têm motivado os pesquisadores a considerarem que a "chave" para uma boa seleção de árvores pode encontrar-se nesta dependência, proporcionando o desenvolvimento de novas técnicas de avaliação de polissacarídeos na madeira.

Como já relatado anteriormente, a conclusão de que os polissacarídeos da madeira, principalmente a celulose, conseguem explicar o comportamento do rendimento em polpa, levou muitos pesquisadores a um interesse em se desenvolver metodologias mais eficientes para determiná-los. Alguns estudos para se desenvolver uma metodologia para determinação de celulose datam de algumas décadas atrás, porém, ao que parece, nenhuma delas foi desenvolvida no intuito de se verificar a dependência entre os resultados obtidos para a celulose e o rendimento da deslignificação kraft. Visto os resultados obtidos mais recentemente, alguns autores têm retomado o desenvolvimento destas metodologias. Wright \& Wallis (1998) publicaram um 
trabalho cujos resultados foram muito satisfatórios, o que incentivou a reprodução das técnicas utilizadas pelo autor para as sessenta e quatro árvores do estudo em questão. Seguindo o intuito do estudo, para os resultados observados, foi avaliado o grau de correlação entre estes e os resultados obtidos na deslignificação kraft-AQ efetuada, como pode ser observado na tabela 26.

Tabela 26. Matriz de correlação dos métodos não-convencionais para determinação de celulose na madeira e da deslignificação kraft$A Q$.

\begin{tabular}{c|c|c|c}
\hline Variáveis & $\begin{array}{c}\text { Rendimento da } \\
\text { Deslignificação }\end{array}$ & $\begin{array}{c}\text { Número Kappa } \\
\text { da Polpa }\end{array}$ & $\begin{array}{c}\text { Consumo Específico de } \\
\text { Madeira }\end{array}$ \\
\hline Celulose Seifert & $0,39^{* *}$ & $-0,32^{* *}$ & $-0,02^{\text {n.s. }}$ \\
& $p=0,2$ & $p=1,0$ & $p=86,4$ \\
\hline Ácido Nítrico & $0,40^{\star *}$ & $-0,13^{\text {n.s. }}$ & $-0,33^{* *}$ \\
& $p=0,1$ & $p=31,3$ & $p=0,8$ \\
\hline Ác. Nítrico com Extração & $0,13^{\text {n.s. }}$ & $0,01^{\text {n.s. }}$ & $-0,24^{\text {n.s. }}$ \\
Alcalina & $p=29,0$ & $p=92,9$ & $p=5,3$ \\
\hline Ácido Peroxiacético & $0,67^{* *}$ & $-0,37^{* *}$ & $-0,35^{* *}$ \\
\hline Ác. Peroxiacético com & $p=0,0$ & $p=0,3$ & $p=0,4$ \\
Extração Alcalina & $0,67^{* *}$ & $-0,35^{\star *}$ & $-0,32^{* *}$ \\
\hline
\end{tabular}

${ }^{\text {* }}$ Coeficiente de correlação significativo a $5 \%$.

** Coeficiente de correlação significativo a $1 \%$.

$p=$ Nivel de probabilidade, $\%$.

n.s. = Coeficiente de correlação não-significativo.

Considerando o rendimento da deslignificação, o método de melhor resultado, como pode ser observado na tabela 26 , foi obtido para o ácido peroxiacético, sem e com extração alcalina, seguido pelo método do ácido nítrico e celulose Seifert, respectivamente. 
A figura 14 mostra a relação entre rendimento da deslignificação kraft$\mathrm{AQ}$ e o teor de celulose na madeira pelo método do ácido peroxiacético.

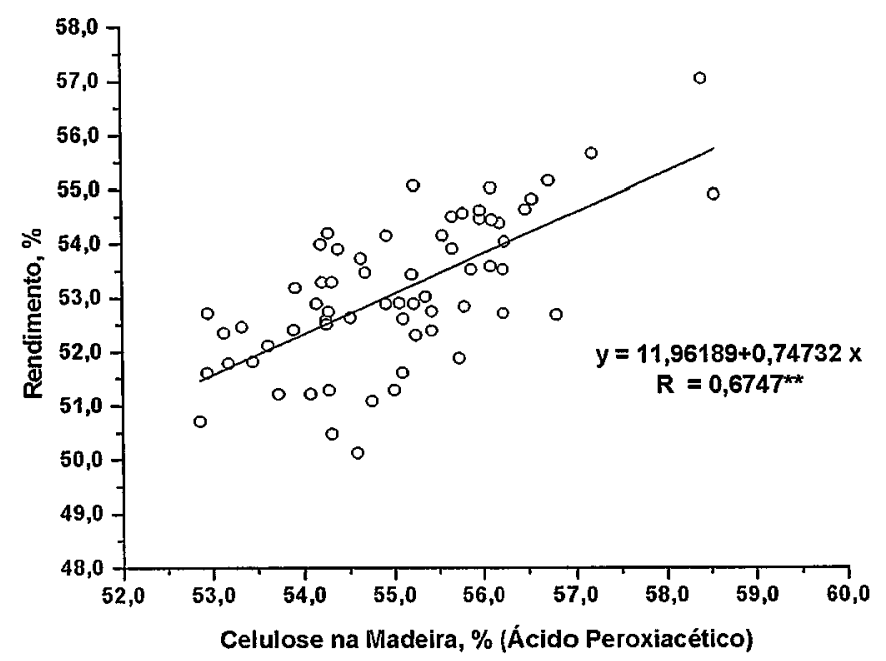

Figura 14 - Relação entre rendimento da deslignificação e teor de celulose na madeira pelo método do ácido peroxiacético.

A tabela 27 mostra a análise de variância da regressão para rendimento da deslignificação e teor de celulose na madeira pelo método do ácido peroxiacético.

Tabela 27. Análise de variância da regressão rendimento da deslignificação versus celulose na madeira pelo método do ácido peroxiacético.

\begin{tabular}{c|c|c|c|c|c}
\hline F.V. & G.L. & S.Q. & Q.M. & F & P \\
\hline Regressão Linear & 1 & 52,64 & 52,64 & $51,82^{* *}$ & 0,000000 \\
Resíduo & 62 & 62,98 & 1.02 & & \\
\hline Total & 63 & 115,62 & & & \\
\hline
\end{tabular}

** Equação de regressão significativa a $1 \%$.

Wright \& Wallis (1998) encontraram, para Eucalyptus nitens, que o método de melhor correlação com rendimento em polpa Kraft foi o da celulose 
Seifert, seguido pelo método do ácido nítrico e, por fim, do ácido peroxiacético. Os autores ainda determinaram o teor de celulose na madeira utilizando método cromatográfico. Encontraram que o teor correspondente para celulose Seifert foi o que mais se aproximou do teor observado por técnica cromatográfica. Os autores afirmam que os resíduos do método do ácido nítrico e ácido peroxiacético apresentaram significativos niveis de impureza presentes como hemiceluloses e outros materiais, elevando a massa do residuo obtido. Esta possibilidade foi considerada neste trabalho, o que ratifica a submissão dos resíduos a uma extração alcalina. Através deste procedimento pretendeuse eliminar as hemiceluloses remanescentes e os grupos acilas provenientes da utilização do ácido acético.

O resumo dos resultados obtidos por Wright \& Wallis (1998) encontrase na tabela 28.

Tabela 28. Resultados médios encontrados por Wright \& Wallis (1998) para os métodos não-convencionais de determinação de celulose.

\begin{tabular}{c|c|c|c}
\hline & Celulose, $\%$ & $\alpha$-Celulose, $\%$ & Impurezas, \% \\
\hline Celulose Seifert & 39,3 & 34,6 a 38,5 & 2,0 a 4,0 \\
\hline Ácido Nítrico & 46,7 & 35,3 a 42,1 & 5,0 a 10,0 \\
\hline Ácido Peroxiacético & 49,3 & 35,9 a 41,9 & 7,0 a 14,0 \\
\hline
\end{tabular}

Estes resultados foram obtidos através da análise dos carboidratos por cromatografia. Os resultados médios obtidos no presente estudo foram, respectivamente para ácido peroxiacético, nítrico e celulose Seifert de 55,1\%; $52,6 \%$ e $44,2 \%$. Após a extração alcalina de $45,8 \% ; 42,6 \%$ e $44,2 \%$. Assim, após a extração alcalina dos resíduos dos métodos do ácido peroxiacético e nítrico, os valores se aproximaram àqueles que, segundo Wright \& Wallis (1998), seriam os reais teores de celulose nos resíduos obtidos por eles em seus estudos. No entanto, o rendimento kraft encontrado pelos autores variou 
de 46 a $54 \%$, inferior ao observado neste trabalho de 50 a $57 \%$. Além do mais, o teor de celulose Seifert encontrado foi cerca de $12 \%$ maior do que o encontrado pelos autores. De qualquer forma, considerando ou não a extração alcalina dos resíduos, os melhores resultados de correlação encontrados neste trabalho foram apresentados pelo método do ácido peroxiacético. Este método pode realmente significar um caminho para se conseguir estimar o rendimento da deslignificação de uma árvore através de um método simples de determinação de celulose na madeira.

Os resultados verificados para os graus de correlação entre os métodos não-convencionais e número kappa, também indicam como melhor resultado aquele obtido para o método do ácido peroxiacético, embora nenhum dos métodos deva ser considerado como um bom preditor de número kappa.

A figura 15 exemplifica a correlação entre número kappa e celulose na madeira a partir do método do ácido peroxiacético.

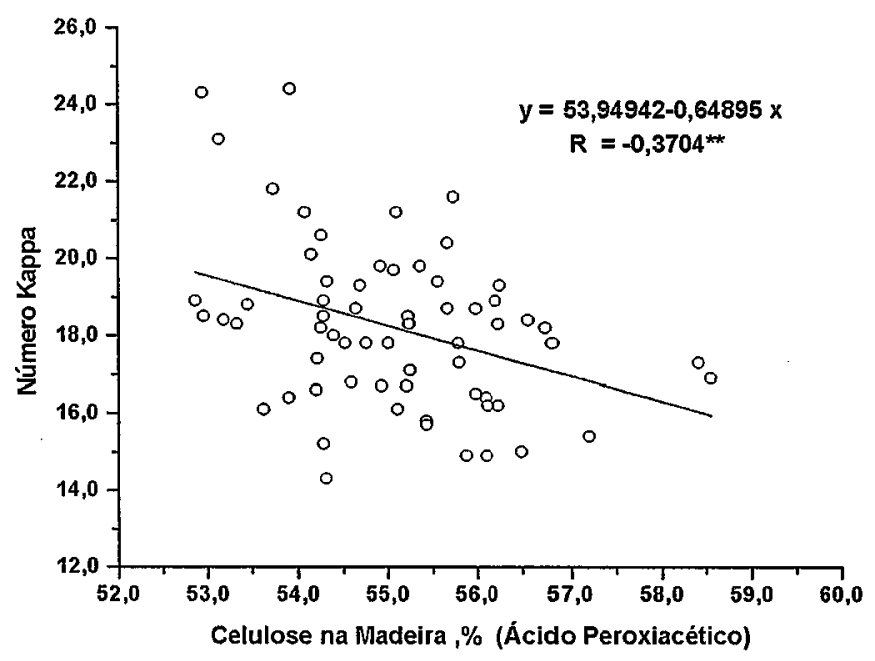

Figura 15 - Relação entre número kappa e celulose na madeira pelo método do ácido peroxiacético. 
A tabela 29 mostra a análise de variância da regressão para número kappa versus celulose na madeira pelo método do ácido peroxiacético.

Tabela 29. Análise de variância da regressão número kappa versus celulose na madeira pelo método do ácido peroxiacético.

\begin{tabular}{c|c|c|c|c|c}
\hline F.V. & G.L. & S.Q. & Q.M. & F & P \\
\hline Regressão Linear & 1 & 39,69 & 39,69 & $9,86^{* *}$ & 0,002589 \\
\hline Resíduo & 62 & 249,61 & 4,03 & & \\
\hline Total & 63 & 289,30 & & & \\
\hline ** Equação de regressão significativa a $1 \%$. & \multicolumn{4}{l}{}
\end{tabular}

\subsection{Seleção tecnológica das árvores matrizes para produção de polpa kraft}

A identificação das árvores que apresentaram melhor comportamento na deslignificação kraft-AQ foi estabelecida através da adoção de critérios para rendimento da deslignificação e do número kappa da polpa produzida. Os critérios adotados basearam-se nas médias obtidas para as sessenta e quatro árvores estudadas. Para rendimento estabeleceu-se como critério árvores cujos rendimentos na deslignificação fossem superiores ou iguais ao valor médio $(53,12 \%)$ e para número kappa árvores com valores inferiores ou iguais ao valor médio $(18,2)$.

A partir do estabelecimento dos critérios acima especificados, utilizouse o programa Microsoft Acess para a identificação das árvores que correspondessem aos critérios adotados.

O resultado da pesquisa realizada, a partir do banco de dados com sessenta e quatro árvores, consta na tabela 30. 
Tabela 30. Árvores selecionadas através dos critérios adotados nos resultados de rendimento e número kappa da deslignificação.

\begin{tabular}{c|c|c}
\hline Árvore Selecionada & $\begin{array}{c}\text { Rendimento na } \\
\text { Deslignificação, } \%\end{array}$ & Número Kappa da Polpa \\
\hline 5 & 54,55 & 17,8 \\
\hline 6 & 57,03 & 17,3 \\
\hline 7 & 53,58 & 16,4 \\
\hline 29 & 54,14 & 16,7 \\
\hline 33 & 54,43 & 16,2 \\
\hline 34 & 53,28 & 17,4 \\
\hline 37 & 54,89 & 16,9 \\
\hline 40 & 54,62 & 15,0 \\
\hline 41 & 55,02 & 14,9 \\
\hline 43 & 53,98 & 16,6 \\
\hline 45 & 55,64 & 15,4 \\
\hline 48 & 53,89 & 18,0 \\
\hline 49 & 53,52 & 14,9 \\
\hline 55 & 53,42 & 16,7 \\
\hline 59 & 55,14 & 18,2 \\
\hline 61 & 54,60 & 16,5 \\
\hline Valor Médio & $\mathbf{5 4 , 4 8 \pm 0 , 6 8}$ & $\mathbf{1 6 , 6 \pm 0 , 8}$ \\
\hline
\end{tabular}

A tabela 30 mostra que dezesseis árvores foram selecionadas por corresponderem aos critérios estabelecidos. O conhecimento dos parâmetros da madeira, densidade básica, composição química tradicional e teor de celulose na madeira determinado através do método do ácido peroxiacético, para as árvores selecionadas, pode indicar a possibilidade de se proceder a seleção através destes parâmetros. Na tabela 31 estão relacionados os valores de densidade básica, composição química tradicional e determinação de celulose pelo método do ácido peroxiacético para as dezesseis árvores selecionadas. 
Tabela 31. Densidade básica, composição química tradicional e determinação de celulose pelo método do ácido peroxiacético para as dezesseis árvores selecionadas quanto aos critérios da deslignificação.

\begin{tabular}{c|c|c|c|c|c}
\hline $\begin{array}{c}\text { Árvore } \\
\text { Selecionada }\end{array}$ & $\begin{array}{c}\text { Densidade } \\
\text { Básica, } \\
\mathrm{g} / \mathrm{cm}^{3}\end{array}$ & $\begin{array}{c}\text { Holocelulose, } \\
\%\end{array}$ & Lignina, \% & $\begin{array}{c}\text { Extrativos } \\
\text { Totais, \% }\end{array}$ & $\begin{array}{c}\text { Celulose pelo } \\
\text { Método do Ác. } \\
\text { Peroxiacético, \% }\end{array}$ \\
\hline 5 & 0,430 & 74,10 & 25,66 & 0,24 & 55,79 \\
\hline 6 & 0,526 & 75,35 & 23,81 & 0,84 & 58,41 \\
\hline 7 & 0,462 & 74,68 & 25,15 & 0,17 & 56,09 \\
\hline 29 & 0,455 & 73,31 & 26,15 & 0,54 & 54,93 \\
\hline 33 & 0,455 & 76,63 & 23,34 & 0,13 & 56,11 \\
\hline 34 & 0,418 & 72,96 & 26,87 & 0,17 & 54,21 \\
\hline 37 & 0,434 & 73,64 & 25,00 & 1,36 & 58,55 \\
\hline 40 & 0,415 & 75,31 & 23,78 & 0,91 & 56,49 \\
\hline 41 & 0,443 & 73,85 & 25,49 & 0,66 & 56,10 \\
\hline 43 & 0,456 & 72,07 & 26,42 & 1,51 & 54,20 \\
\hline 45 & 0,444 & 76,61 & 23,12 & 0,27 & 57,20 \\
\hline 48 & 0,403 & 71,88 & 25,75 & 2,37 & 54,39 \\
\hline 49 & 0,387 & 72,57 & 25,03 & 2,40 & 55,88 \\
\hline 55 & 0,449 & 71,84 & 26,26 & 1,90 & 55,21 \\
\hline 59 & 0,423 & 76,15 & 22,96 & 0,89 & 56,74 \\
\hline 61 & 0,413 & 75,48 & 23,60 & 0,92 & 55,98 \\
\hline Valor Médio & $0,438 \pm 0,022$ & $74,15 \pm 1,17$ & $24,90 \pm 0,91$ & $0,96 \pm 0,54$ & $56,02 \pm 0,92$ \\
\hline & & & & & \\
\hline
\end{tabular}

Os valores médios para as sessenta e quatro árvores em relação aos parâmetros mostrados na tabela 31 são: $0,447 \mathrm{~g} / \mathrm{cm}^{3}$ para densidade básica, $73,19 \%$ para holocelulose, $25,70 \%$ para lignina, $1,11 \%$ para extrativos totais e $55,07 \%$ para determinação de celulose através do método do ácido peroxiacético.

A partir da tabela 31 pode-se observar que algumas árvores selecionadas não apresentaram os melhores resultados no que diz respeito aos parâmetros da madeira em questão, ou seja, pode-se encontrar valores de 
densidade básica e holocelulose abaixo dos valores médios para estes parâmetros, por outro lado, teores de lignina e extrativos totais superiores ao valor médio para as sessenta e quatro árvores $e$, ainda, percentagem de celulose determinado pelo método do ácido peroxiacético inferior ao valor médio encontrado.

Atendendo a um dos objetivos deste trabalho, verificou-se a possibilidade de se poder selecionar estas dezesseis árvores a partir das análises efetuadas na madeira, assim como através das inter-relações entre as propriedades da mesma.

As regressões lineares efetuadas, entre densidade básica e os parâmetros da deslignificação, mostram coeficientes de correlação bastante significativos com consumo específico de madeira $\left(r=-0,95^{* *}\right)$ e com número kappa $\left(r=0,45^{* *}\right)$. Considerando a importância da densidade básica no processo de seleção das árvores, selecionou-se, através do Microsoft Acess, as vinte árvores com melhores resultados para densidade básica, isto é, as com maiores densidades. Uma vez determinadas as árvores, verificou-se quais delas haviam sido também selecionadas quanto aos critérios do rendimento e número kappa da polpa. Entre as vinte árvores selecionadas somente duas coincidem com aquelas que foram selecionadas pelos critérios da deslignificação. Portanto, a densidade básica não se mostrou ser um bom parâmetro de seleção de árvores quando utilizada inicialmente e de forma isolada.

Para holocelulose e lignina na madeira foi desenvolvido o mesmo procedimento efetuado para densidade básica. Identificou-se as vinte árvores com melhores teores em holocelulose e as vinte com os menores teores em lignina. Uma vez que estes dois parâmetros se correlacionam com um coeficiente bastante significativo $\left(r=-0,91^{* \star}\right)$, esperava-se encontrar resultados muito semelhantes para os dois parâmetros, como realmente foi constatado. Entre as vinte árvores selecionadas tanto para holocelulose como para lignina, 
somente sete coincidem com aquelas selecionadas pelos parâmetros da deslignificação. Assim, como para densidade básica, os resultados mostram que não é conveniente considerar holocelulose ou lignina como únicos parâmetros de seleção de árvores.

De todos os métodos não-convencionais testados neste trabalho, o método do ácido peroxiacético foi o que apresentou os melhores resultados, principalmente com os parâmetros da deslignificação. Apresentou correlação significativa a $1 \%$ com rendimento $\left(r=0,67^{* *}\right)$, número kappa $\left(r=-0,37^{* *}\right)$ e com consumo específico de madeira $\left(r=-0,35^{* *}\right)$. Identificou-se, dentre as sessenta e quatro árvores estudadas, as vinte com os melhores resultados, ou seja, as com maiores teores de celulose. Os resultados se mostraram superiores aos encontrados para densidade básica, holocelulose e lignina. A tabela 32 mostra as vinte árvores selecionadas quanto ao teor de celulose na madeira pelo método do ácido peroxiacético, assim como quais as árvores que coincidem com as selecionadas pelos critérios de rendimento e número kappa. 
Tabela 32. Árvores selecionadas quanto aos critérios de teor de celulose na madeira pelo método do ácido peroxiacético.

\begin{tabular}{|c|c|c|}
\hline \multicolumn{2}{|c|}{$\begin{array}{l}\text { Árvores Selecionadas pelo Critério do Método do Äcido } \\
\text { Peroxiacético }\end{array}$} & $\begin{array}{l}\text { Ärvores Selecionadas pelos Critérios nos } \\
\text { Resultados de Rendimento e Número Kappa }\end{array}$ \\
\hline Árvore Selecionada & Teor de Celulose na Madeira, $\%$ & Árvores Selecionadas e Coincidentes \\
\hline 2 & 56,20 & - \\
\hline$\overline{3}$ & 55,74 & - \\
\hline 5 & 55,79 & 5 \\
\hline 6 & 58,41 & 6 \\
\hline 7 & 56,09 & 7 \\
\hline 12 & 55,80 & - \\
\hline 15 & 56,25 & - \\
\hline 23 & 56,23 & - \\
\hline 25 & 56,56 & - \\
\hline 33 & 56,11 & 33 \\
\hline 37 & 58,55 & 37 \\
\hline 40 & 56,49 & 40 \\
\hline 41 & 56,10 & 41 \\
\hline 45 & 57,20 & 45 \\
\hline 49 & 55,88 & 49 \\
\hline 51 & 56,81 & - \\
\hline 52 & 55,98 & - \\
\hline 53 & 56,23 & - \\
\hline 59 & 56,74 & 59 \\
\hline 61 & 55,98 & 61 \\
\hline
\end{tabular}

A tabela 32 mostra que dentre as vinte árvores selecionadas, onze coincidem com as dezesseis que foram selecionadas pelos critérios da deslignificação. Este resultado significa que $69 \%$ das árvores com melhores comportamentos na deslignificação (rendimento e número kappa) estão incluídas entre as vinte de maiores teores de celulose na madeira pelo método do ácido peroxiacético. Desta forma, pode-se considerar o método do ácido peroxiacético como um bom parâmetro de seleção de árvores e, ainda, como 
um parâmetro melhor do que os tradicionalmente utilizados como densidade básica e composição química tradicional.

Portanto, a determinação do teor de celulose na madeira pelo método do ácido peroxiacético deve ser a primeira variável a ser considerada na seleção das árvores matrizes, tendo em vista a obtenção de polpas com elevados rendimentos gravimétricos e simultaneamente baixos números kappa.

No entanto, quando se considera todo o processo de deslignificação, um outro fator possui relativo impacto na produção industrial, o rendimento volumétrico. O rendimento volumétrico é avaliado através do consumo específico de madeira. Anteriormente foi visto que de todas as propriedades da madeira, a densidade básica é a que melhor se correlaciona com o consumo específico de madeira em um processo de deslignificação $\left(r=-0,95^{* *}\right)$. Este resultado mostra claramente que árvores com baixas densidades básicas conduzirão a elevados consumos específicos, isto é, baixos rendimentos volumétricos. Ao se considerar consumo específico de madeira como um parâmetro de seleção de árvores, naturalmente se exclui as árvores de baixas densidades. As árvores selecionadas quanto aos três parâmetros da deslignificação, rendimento, número kappa da polpa e consumo específico de madeira, encontram-se na tabela 33. 
Tabela 33. Árvores selecionadas através dos critérios adotados nos resultados de rendimento, número kappa e consumo específico de madeira da deslignificação.

\begin{tabular}{c|c|c|c}
\hline Árvore Selecionada & $\begin{array}{c}\text { Rendimento na } \\
\text { Deslignificação, } \%\end{array}$ & $\begin{array}{c}\text { Número Kappa da } \\
\text { Polpa }\end{array}$ & $\begin{array}{c}\text { Consumo Específico de } \\
\text { Madeira, m/t celulose seca }\end{array}$ \\
\hline 6 & 57,03 & 17,3 & 3,33 \\
\hline 7 & 53,58 & 16,4 & 4,04 \\
\hline 29 & 54,14 & 16,7 & 4,06 \\
\hline 33 & 54,43 & 16,2 & 4,04 \\
\hline 37 & 54,89 & 16,9 & 4,20 \\
\hline 41 & 55,02 & 14,9 & 4,10 \\
\hline 43 & 53,98 & 16,6 & 4,07 \\
\hline 45 & 55,64 & 15,4 & 4,05 \\
\hline 55 & 53,42 & 16,7 & 4,17 \\
\hline Valor Médio & $\mathbf{5 4 , 6 8 \pm 0 , 8 0}$ & $\mathbf{1 6 , 3 4 \pm 0 , 5 3}$ & $\mathbf{4 , 0 1 \pm 0 , 1 8}$ \\
\hline
\end{tabular}

A tabela 33 mostra nove árvores selecionadas. São árvores que correspondem aos três critérios estabelecidos para os resultados da deslignificação. Estas árvores possuem um comportamento diferenciado, pois apresentam rendimento superior ao valor médio, número kappa e consumo específico de madeira inferiores ao valor médio encontrado para cada um destes parâmetros.

A partir da identificação destas árvores, procurou-se, novamente, verificar a possibilidade de selecionar estas nove árvores através das propriedades da madeira.

Os resultados revelaram, como constatado anteriormente, que densidade básica, holocelulose e lignina não são bons parâmetros de seleção de árvores, se utilizados inicialmente e de forma isolada. Entre as vinte árvores selecionadas quanto ao critério estabelecido para densidade básica, somente duas encontram-se entre as que foram selecionadas pelos resultados da deslignificação. Considerando as vinte árvores com teores mais elevados de 
holocelulose ou aquelas com menores teores de lignina, o número de árvores coincidentes foi quatro. Investigando os resultados para o método do ácido peroxiacético novamente se chega ao método que melhor resultado apresenta. Considerando a importância da densidade básica em relação ao rendimento volumétrico, conclui-se que as árvores de altos teores de celulose pelo método do ácido peroxiacético, mas com baixas densidades básicas, não corresponderão às árvores selecionadas pelo critério de rendimento volumétrico. A correlação existente entre o método do ácido peroxiacético e a densidade básica não é significativa, portanto, o teor de celulose observado a partir do método do ácido peroxiacético não tem nenhuma dependência com o valor de densidade básica da árvore analisada. A tabela 34 exemplifica claramente esta independência entre os dois parâmetros. 
Tabela 34. Árvores selecionadas quanto ao critério adotado para determinação de celulose pelo método do ácido peroxiacético e suas respectivas densidades básicas.

\begin{tabular}{|c|c|c|}
\hline Árvores Selecionada & Teor de Celulose na Madeira, \% & Densidade Básica, $\mathrm{g} / \mathrm{cm}^{3}$ \\
\hline 2 & 56,20 & 0,477 \\
\hline 3 & 55,74 & 0,440 \\
\hline 5 & 55,79 & 0,430 \\
\hline 6 & 58,41 & 0,526 \\
\hline 7 & 56,09 & 0,462 \\
\hline 12 & 55,80 & 0,485 \\
\hline 15 & 56,25 & 0,437 \\
\hline 23 & 56,23 & 0,479 \\
\hline 25 & 56,56 & 0,532 \\
\hline 33 & 56,11 & 0,455 \\
\hline 37 & 58,55 & 0,434 \\
\hline 40 & 56,49 & 0,415 \\
\hline 41 & 56,10 & 0,443 \\
\hline 45 & 57,20 & 0,444 \\
\hline 49 & 55,88 & 0,387 \\
\hline 51 & 56,81 & 0,484 \\
\hline 52 & 55,98 & 0,438 \\
\hline 53 & 56,23 & 0,434 \\
\hline 59 & 56,74 & 0,423 \\
\hline 61 & 55,98 & 0,413 \\
\hline
\end{tabular}

A tabela 34 mostra a ampla faixa de densidade básica observada para as árvores selecionadas quanto ao critério estabelecido para o método do ácido peroxiacético. A partir da tabela 34 também pode-se observar que árvores com baixas densidades básicas não conduzem necessariamente a baixos teores de celulose pelo método do ácido peroxiacético, o que confirma a ausência de correlação significativa entre os dois parâmetros. Dada a expressiva correlação significativa observada entre densidade básica e rendimento volumétrico $\left(r=-0,95^{* *}\right)$, torna-se necessário excluir, dentre as vinte árvores selecionadas, aquelas com densidades básicas consideravelmente 
baixas. Através da tabela 34 pode-se observar que estas árvores correspondem às de número $5,40,49,59$ e 61. Portanto, quinze são as árvores selecionadas pelo método do ácido peroxiacético e que apresentam densidades básicas mais apropriadas para polpação.

$\mathrm{Na}$ tabela 35 encontram-se as árvores selecionadas pelo método do ácido peroxiacético, com densidades básicas mais apropriadas para polpação, $e$ as coincidentes com as selecionadas pelos três parâmetros da deslignificação.

Tabela 35. Árvores selecionadas quanto ao critério adotado para determinação de celulose pelo método do ácido peroxiacético.

\begin{tabular}{|c|c|c|c|}
\hline \multicolumn{3}{|c|}{$\begin{array}{l}\text { Árvores Selecionadas pelo Critério do Método do Ácido } \\
\qquad \text { Peroxiacético }\end{array}$} & \multirow{2}{*}{\begin{tabular}{|c|}
$\begin{array}{c}\text { Arvores Selecionadas pelos Critérios nos } \\
\text { Resultados de Rendimento, Número Kappa } \\
\text { e Consumo Específico de Madeira }\end{array}$ \\
Árvores Selecionadas e Coincidentes
\end{tabular}} \\
\hline $\begin{array}{c}\text { Árvore } \\
\text { Selecionada }\end{array}$ & $\begin{array}{l}\text { Teor de Celulose } \\
\text { na Madeira, \% }\end{array}$ & $\begin{array}{c}\text { Densidade Básica, } \\
\mathrm{g} / \mathrm{cm}^{3}\end{array}$ & \\
\hline 2 & 56,20 & 0,477 & - \\
\hline 3 & 55,74 & 0,440 & - \\
\hline 6 & 58,41 & 0,526 & 6 \\
\hline 7 & 56,09 & 0,462 & 7 \\
\hline 12 & 55,80 & 0,485 & - \\
\hline 15 & 56,25 & 0,437 & - \\
\hline 23 & 56,23 & 0,479 & - \\
\hline 25 & 56,56 & 0,532 & - \\
\hline 33 & 56,11 & 0,455 & 33 \\
\hline 37 & 58,55 & 0,434 & 37 \\
\hline 41 & 56,10 & 0,443 & 41 \\
\hline 45 & 57,20 & 0,444 & 45 \\
\hline 51 & 56,81 & 0,484 & - \\
\hline 52 & 55,98 & 0,438 & - \\
\hline 53 & 56,23 & 0,434 & - \\
\hline
\end{tabular}

A tabela 35 mostra que entre as quinze árvores selecionadas, seis coincidem com as nove selecionadas pelos critérios da deslignificação. Este 
resultado representa que $67 \%$ das árvores com melhores resultados na deslignificação, considerando rendimento, número Kappa e consumo específico de madeira, encontram-se entre as quinze que apresentaram maiores teores de celulose na madeira pelo método do ácido peroxiacético e densidades básicas mais apropriadas para polpação.

A análise destes resultados permite propor uma metodologia de seleção de árvores matrizes a partir das propriedades da madeira que conduza a otimização do rendimento gravimétrico, número kappa e consumo específico de madeira. Dentre um "pool" de árvores matrizes, selecionou-se, em uma primeira etapa, aquelas com maiores teores de celulose na madeira pelo método do ácido peroxiacético. Este procedimento conduziu a obtenção de polpas com rendimentos gravimétricos mais elevados e baixos números kappa. Em uma segunda etapa de seleção, excluiu-se as árvores com menores densidades básicas, visando a otimização do consumo especifico de madeira. Esta proposta pode ser considerada como nova e viável para seleção das melhores árvores matrizes para produção de celulose kraft.

\subsubsection{Análise do custo da deslignificação kraft-AQ para as árvores de Eucalyptus grandis.}

Com base nos estudos realizados por Greaves \& Borralho (1996) a respeito da influência da densidade básica e do rendimento gravimétrico sobre - custo total da deslignificação kraft da madeira de Eucalyptus, estimou-se o custo da deslignificação para as sessenta e quatro árvores de Eucalyptus grandis utilizadas no presente estudo. A estimativa do custo total da deslignificação teve como principal finalidade ratificar o considerável impacto da densidade básica e do rendimento gravimétrico sobre o custo do processo de deslignificação kraft. Os resultados individuais para as sessenta e quatro árvores constam no Anexo l. 
A tabela 36 mostra o comportamento das nove árvores selecionadas pelos três critérios da deslignificação em relação ao custo total da deslignificação.

Tabela 36. Análise do custo total da deslignificação para as nove árvores de Eucalyptus grandis selecionadas tecnologicamente.

\begin{tabular}{c|c}
\hline Árvore Selecionada Tecnologicamente & $\begin{array}{c}\text { Custo Total da Deslignificação, \$US/t } \\
\text { Celulose Não-Branqueada Seca }\end{array}$ \\
\hline 6 & 174.59 \\
\hline 45 & 194.23 \\
\hline 33 & 194.86 \\
\hline 7 & 195.45 \\
\hline 29 & 195.63 \\
\hline 43 & 195.74 \\
\hline 41 & 195.95 \\
\hline 37 & 198.56 \\
\hline 55 & 198.66 \\
\hline Custo Médio & 193.74 \\
\hline
\end{tabular}

A partir da tabela 36 pode-se verificar que o custo médio da deslignificação para as nove árvores selecionadas é de \$US 193.74. Este valor significa uma redução no custo total da deslignificação de aproximadamente \$US 6.26 por tonelada de celulose não-branqueada seca produzida, quando comparado com custo médio de \$US 200.00 citado por Greaves \& Borralho (1996). Considerando que estas árvores também apresentam valores de número kappa expressivamente baixos (valor médio de 16,3), acredita-se que o custo de branqueamento destas polpas também seja inferior ao das demais árvores não selecionadas. Considerando ainda os custos de exploração, corte e transporte da madeira, para um mesmo volume de madeira, quanto maior for a densidade básica da árvore, maior a massa de madeira e menor a 
quantidade de água que ela contêm. Desta forma, ao se transportar esta madeira, na realidade, maior massa de madeira estará sendo transportada, diminuindo os custos referentes a este procedimento.

Ao se observar o Anexo I pode-se notar que algumas árvores não selecionadas possuem custo de deslignificação menor do que as selecionadas. É importante notar que são árvores com valores de número kappa consideravelmente superiores aos das árvores selecionadas, portanto, o custo no branqueamento também será maior $e$, ainda, as condições mais drásticas no branqueamento poderá acarretar perda na qualidade da polpa. A análise do Anexo I também permite verificar que as árvores de menores densidades básicas foram as que tiveram maiores valores de custo da deslignificação, salvo as árvores que, embora com baixas densidades básicas, tenham apresentado rendimentos mais elevados.

A análise do custo total da deslignificação para a madeira de Eucalyptus grandis permite concluir que vários fatores devem ser considerados quando se pretende diminuir o custo total do processo. As melhores árvores devem apresentar valores de densidade básica e rendimento gravimétrico relativamente altos, porém baixos valores de número kappa. A observação destes parâmetros conduzirá a menor custo de exploração, de deslignificação $e$ de branqueamento, reduzindo o custo total do processo. 


\section{CONCLUSÕES}

Os resultados observados no presente trabaiho permitem extrair as seguintes conclusões:

A) Os polissacarídeos da madeira, principalmente a celulose, são, de fato, os melhores indicadores para rendimento gravimétrico da polpação, confirmando a importância do desenvolvimento e aplicação de novas metodologias para seleção tecnológica de árvores matrizes para produção de polpa kraft.

B) O teor de celulose na madeira pelo método do ácido peroxiacético foi, entre os não-convencionais testados, o que melhor correlação linear apresentou com os resultados da deslignificação.

C) O método do ácido peroxiacético foi o melhor parâmetro de seleção de árvores matrizes quando considerado rendimento gravimétrico e número kappa da polpa como critérios de seleção.

D) Os métodos tradicionalmente utilizados na seleção de árvores matrizes, densidade básica e composição química tradicional, não se mostraram bons parâmetros de seleção quando utilizados inicialmente e de forma isolada.

E) As árvores com melhores comportamentos na deslignificação, em relação ao rendimento, número kappa da polpa e consumo específico de madeira, podem ser selecionadas considerando, em uma primeira etapa, o teor de 
celulose na madeira pelo método do ácido peroxiacético e, posteriormente, a densidade básica da madeira.

F) As extrações alcalinas realizadas nos resíduos do método do ácido nítrico e do ácido peroxiacético não proporcionaram melhorias significativas nos resultados de correlação. 


\section{SUGESTÕES DE PROSSEGUIMENTO DA PESQUISA}

Tendo em vista os resultados satisfatórios encontrados para determinação de celulose na madeira pelo método do ácido peroxiacético, sugere-se as seguintes continuidades da pesquisa:

A) Avaliar novamente a validade do método do ácido peroxiacético através da investigação de outras árvores matrizes.

B) Verificar a possibilidade de redução do tempo reacional exigido na metodologia do ácido peroxiacético (4horas).

C) Realizar uma análise cromatográfica do resíduo obtido de forma a se quantificar e especificar as impurezas presentes, verificando a possibilidade de eliminação destas impurezas através de tratamentos químicos. 


\section{REFERÊNCIAS BIBLIOGRÁFICAS}

AMIDON, T.E. Effect of the wood properties of hardwoods on kraft paper properties. Tappi, v.64, n.3, p.123-126, Mar. 1981.

ASSOCIAÇÃO BRASILEIRA TÉCNICA DE CELULOSE E PAPEL. Métodos de Ensaio. São Paulo: 1974.

BAMBER, K. The wood anatomy of eucalypts and papermaking. Appita, v.38, n.03, p.210-216, May 1985.

BARRICHELO, L.E.G.; BRITO, J.O. Variações das características da madeira de Eucalyptus grandis e suas correlações com a produção de celulose. In: CONGRESSO ANUAL DA ABTCP - Semana do Papel, 10, São Paulo, 1977. Anais. São Paulo: s. ed., 1977. p.41-46.

BARRICHELO, L.E.G.; BRITO, J.O.; COUTO, H.T.Z. \& CAMPINHOS JUNIOR, E. Densidade básica, teor de holocelulose e rendimento em celulose de madeiras de Eucalyptus grandis. Silvicultura, v.8, n.32, p.802-808, set. 1983.

BARRICHELO, L.E.G.; BRITO, J.O.; BAZANELLI, A.V. Densidade básica e características das fibras de madeira de Eucalyptus grandis. In: CONGRESSO LATINO-AMERICANO DE CELULOSE E PAPEL, 3, São Paulo, 1983. Anais. São Paulo: s. ed., 1983. p.113-125.

BARRICHELO, L.E.G.; NARIYOSHI, A.H.; BEIG, O.; DINIZ, A.S. Variações das características da madeira de eucalipto para diferentes espécies, idades e locais. In: CONGRESSO ANUAL DA ABTCP - Semana do Papel, 17, São Paulo, 1984. Anais. São Paulo: s. ed., 1984. p.385-399. 
BRAUNS, F.E.; BRAUNS, D.A. The Chemistry of Lignin. New York: Academic Press, 1960. p.90-95: The isolation of lignin.

BUSNARDO, C.A.; FOELKEL, C.E.B.; SVINAKEVICIUS, C.; KAJIVA, S.; ALVES, E.E. Estudo comparativo da qualidade da madeira de algumas espécies de eucaliptos tropicais. In: CONGRESSO ANUAL DA ABTCP, 11, São Paulo, 1978. Anais. São Paulo: s. ed., 1978. p.191-197.

CHANG, H.; SARKANEN, K. V. Species variation in lignin. Effect of species on the rate of Kraft delignification. Tappi, v.56, n.3, p.132-134, Mar.1973.

CLARKE, C.R.E.; GARBUTT, D.C.F.; PEARCE, J. Growth and wood properties of provenances and trees of nine Eucalypt species. Appita Journal, v.50, n.2, p.121-130, Mar. 1997.

COLLINS, D.J.; PILOTTI, C.A.; WALLIS, A.F.A. Correlation of chemical composition and kraft pulping properties of some Papua New Guinea reforestation woods. Appita, v.43, n.3, p.193-198, May 1990.

CROMER, R.N.; BALODIS, V.; CAMERON, D.; GARLAND, C.P.; RANCE, S.; RYAN, P. Eucalyptus grandis fertilizer trials: growth, wood properties and kraft pulp yield. Appita Journal, v.51, n.1, p.45-49, Jan. 1998.

DEMUNER, B.J.; MANFREDI, V.; SILVA JUNIOR, C.E. Refino da celulose de eucalipto - uma análise fundamental. O Papel, v.51, n.8, p.44-54, ago. 1990.

FENGEL, D.; WEGENER, G. Wood. Chemistry, Ultrastructure, Reactions. Berlim: Copyright, 1983. Cap. 10, p.268-292: Reactions in acidic medium.

FOELKEL, C.E.B. Rendimentos em celulose sulfato de Eucalyptus spp em função do grau de deslignificação e da densidade da madeira. IPEF, v.9, p. 61-77, dez. 1974.

FOELKEL, C.; MORA, E.; MENOCHELLI, S. Densidade básica: sua verdadeira utilidade como índice de qualidade da madeira de eucalipto para produção de celulose. O Papel, v.53, n.5, p.35-40, maio 1992. 
FONSECA, S.M.; OLIVEIRA, R.C. \& SILVEIRA, P.N. Seleção da árvore industrial. Revista Árvore, v.20, n.1, p.69-85, jan. 1996.

GIERER, J. Basic principles of bleaching. Part 1: Cationic and radical processes. Holzforschung, v.44, n.5, p.387-394, 1990.

GOYAL, G.C.; FISHER, J.J.; KROHN, M.J.; PACKOOD, R.E.; OLSON, J.R. Variability in pulping and fiber characteristics of hybrid poplar trees due to their genetic makeup, environmental factors, and tree age. Tappi Journal, v.82, n.5, p.141-147, May 1999.

GREAVES, B.L.; BORRALHO, N.M.G. The influence of basic density and pulp yield on the cost of eucalypt Kraft pulping: a theoretical model for tree breeding. Appita, v.49, n.02, p.90-95, Mar 1996.

INFORMAÇÕES SQCE. Piracicaba: ESALQ-USP, n.6, p.1-5, fev. 1984.

JACKSON, M.; FALK, B.; MOLDENIUS, S.; EDSTRON, A. A fabricação e o potencial da utilização de polpa de alto rendimento de eucalipto. O Papel, v.50, n.9, p.49-56, set. 1989.

KELLOGG, R.M. Relations between cell-wall composition and cell-wall density. Wood and Fiber, v.7, p.170-177, 1975.

KIBBLEWHITE, R.P.; RIDDELL, M.J.C.; SHELBOURNE, C.J.A. Kraft fibre and pulp qualities of 29 trees of New Zealand grown Eucalyptus nitens. Appita Journal, v.51, n.2, p.114-121, Apr. 1998.

KIMO, J.W. Aspectos químicos da madeira de Eucalyptus grandis, W. Hill exMaiden, visando à produção de polpa celulósica. Viçosa, $1986.45 p$. Dissertação (Mestrado) - Universidade Federal de Viçosa.

LUNDQUIST, K. Lignin reactions in acid and neutral media. In: BRAZILIAN SYMPOSIUM ON CHEMISTRY OF LIGNINS AND OTHER WOOD COMPONENTS, 3, Belo Horizonte, 1993. Proceedings. Belo Horizonte: Universidade Federal de Uberlândia, 1993. p.51-59. 
MACHADO, F.J.J.; GOMIDE, J.L.; CAMPOS, W.O.: CAPITANI, L.R. Caracterização da madeira de Eucalyptus pilularis e estudos para produção de celulose kraft. Revista Árvore, v.12, n.2, p.111-122, 1988.

MARCOCCIA, B.; STROMBERG, B.; PROUGH, J.R. A novel method for realtime measurement of alkaline pulping yield. (compact disc). In: TAPPI PULPING CONFERENCE, Montreal, 1998. Proceedings. Montreal: Copyright by Tappi Press, 1998.

MASURA, V. A linear logarithmic relationship of yield vs. Kappa number and yield vs. lignin content for sulphite, Kraft and Soda pulps. Cellulose Chemistry and Technology, v.30, p.81-94, 1996.

MORTHA, G.; SARKANEN, K.; GUSTAFSON, R. Alkaline pulping kinetics of short-rotation, intensively cultured hybrid poplar. Tappi Journal, p.99-104, nov.1992.

$\mathrm{OHI}, \mathrm{H}$; $\mathrm{KISHINO}$, M. Cleavage of $\mathrm{C} \alpha-\mathrm{C} \beta$ bonds of lignin model compounds by nitrite and nitric acid. Holzforschung, v.51, n.4, p.343-348, 1997.

ONA, T.; SONODA, T.; SHIBATA, M.; FUKAZAWA, K. Small-scale method to determine the content of wood components from multiple eucalypt samples. Tappi Journal, v.78, n.3, p.121-126, Mar. 1995.

RAYMOND, C.A.; BALODIS, V.; DEAN, G.H. Hot water extract and pulp yield in provenances of Eucalyptus regnans. Appita, v.47, n.2, p.159-162, Mar. 1994.

SARKANEN, K.V. Chemistry of solvent pulping. Tappi Journal, p.215-219, Oct. 1990.

SARKANEN, K.V.; LUDWIG, C.H. Lignin: Ocurrence, Formation, Struture and Reactions. New York: Wiley Interscience, 1971. p.419-423: Halogenation and nitration.

SHIMOYAMA, V.R.S. Variações da densidade básica e características anatômicas e químicas da madeira de Eucalyptus ssp. Piracicaba, 1990. 
101p. Dissertação (Mestrado) - Escola Superior de Agricultura "Luiz de Queiroz", Universidade de São Paulo.

SIAU, J.F. Flow in wood. New York: Syracuse University, 1971. 131p.

SOUZA, C.; MOREIRA, E.J.; SANTOS, G.G.; SILVA JUNIOR., C.E.; DIAS, R.L.V. Uma análise do comportamento dos extrativos de madeira no cozimento kraft. In: CONGRESSO LATINO-AMERICANO DE CELULOSE E PAPEL, 3, São Paulo, 1983. Anais. São Paulo: s. ed., 1983. p.347-357.

TECHNICAL ASSOCIATION OF THE PULP AND PAPER INDUSTRY - CDROM. 1998-1999 TAPPI Test Methods (compact disc). Atlanta: TAPPI 1999.

TOMAZELLO FILHO, M. Estrutura da madeira de oito espécies de eucalipto cultivadas no Brasil. IPEF, v.29, p.25-35, abr. 1985.

TRAN, A. V. Cellulose procedures - The mail box. Tappi Journal, v.18, n.9, p.12-13, Sep. 1998.

TURNER, C.H.; BALODIS, V.; DEAN, G.H. Variability in pulping quality of Eucalyptus globulus from Tasmanian provenances. Appita, v.36, n.5, p.371-376, Nov. 1983.

TZANOVA, S.; SAVOV, K.; DRAGANOVA, R. Behaviour of the carbohydrate component of the plant complex during interaction with the "acetic acid catalyst" reaction system. Cellulose Chemistry and Technology, v.31, p.415-424, 1997.

VALENTE, C.A.; SOUSA, A.P.M.; FURTADO, F.P.; CARVALHO, A.P. Improvement program for Eucalyptus globulus at Portucel: Technological component. Appita, v.45, n.6, p.403-407, Nov. 1992.

VASCONCELOS DIAS, R.L. \& SILVA JUNIOR, C.E. A influência da densidade básica da madeira de híbridos de Eucalyptus grandis em suas características químicas e propriedades de polpação e do papel. In: CONGRESSO ANUAL DA ABTCP - Semana do Papel, 18, São Paulo, 1985. Anais. São Paulo: s. ed., 1985. p.31-55. 
VITAL, R.B.R.; JESUS, R.M.; VALENTE, O.F. Efeito da constituição química e da densidade da madeira de clones de Eucalyptus grandis na produção de carvão vegetal. Revista Árvore, V.10, n.2, p.151-160, 1986.

WALLIS, A.F.A.; WEARNE, R.H.; WRIGHT, P.J. Chemical analysis of polysaccharides in plantation eucalypt woods and pulps. Appita, v.49, n.4, p.258-262, Jul. 1996.

WALLIS, A.F.A.; WEARNE, R.H.; WRIGHT, P.J. Analytical characteristics of plantation eucalypt woods relating to kraft pulp yields. Appita Journal, v.49, n.6, p.427-432, Nov. 1996.

WEHR, T.R. Variações nas características da madeira de Eucalyptus grandis W. Hill ex- Maiden e suas influências na qualidade de cavacos em cozimentos kraft. Piracicaba, 1991. 84p. Dissertação (Mestrado) - Escola Superior de Agricultura "Luiz de Queiroz", Universidade de São Paulo.

WRIGHT, P.J. \& WALLIS, A.F.A. Rapid determination of cellulose in plantation eucalypt woods to predict kraft pulps yields. Tappi Journal, v.81, n.2, p.126-130, Feb. 1998.

ZOBEL, B.; JETT, J.B.; HUTTO, R. Improving wood density to short-rotation southern pine. Tappi, v.61, n.3, p.41-44, Mar. 1978. 


\section{BIBLIOGRAFIA RECOMENDADA}

BARRICHELO, L.E.G.; FOELKEL, C.E.B.; TAMEZAWA, J.; BRITO, J. O. Variação da densidade básica e composição química de madeira de Pinus elliottii e Pinus taeda em função da idade. O Papel, v.36, n.11, p.110-112, nov. 1975.

BARRICHELO, L.E.G.; KAGEYAMA, P.Y.; SPELTZ, R.M.; BONISH, H.J.; BRITO, J.O.; FERREIRA, M. Estudos de procedências de Pinus taeda visando seu aproveitamento industrial. IPEF, v.6, n.18, p.1-14, jul. 1978.

BARRICHELO, L.E.G. Estudo das características físicas, anatômicas e químicas da madeira de Pinus caribaea var. hondurensis Barr. e Golf para a produção de celulose kraft. Piracicaba, 1979. 167p. Tese (Livre Docência)

- Escola Superior de Agricultura "Luiz de Queiroz", Universidade de São Paulo.

BARROTTI, S.L.B.; BUGAJER, S.; CAHEN, R.; KUAN, G. S. S.; LIMA, A. F.; SILVA, O.F. Influência da densidade básica nas características de polpação de Pinus elliottii e Pinus taeda. O Papel, v.40, n.5, p.39-45, maio 1979.

BROWNING, B.L. Cellulose Isolation and Determination. In: Browning, B.L. Methods of Wood Chemistry. New York: Interscience Publishers, 1967. cap.19, p.388-389: Cellulose isolation and determination.

COLE, D.E.; ZOBEL, B.J.; ROBERDS, J.H. Slash, loblolly and longleaf pine in a mixed natural stand; a comparison of their wood properties, pulp yield, and paper properties. Tappi, v. 49, n.4, p.161-166, Apr. 1966. 
FOELKEL, C.E.B.; DINIZ, A.S.; GARCIA, W.; FERREIRA, M. Estudo da Influência da densidade da madeira nas propriedades das celuloses kraft de Pinus elliottii obtidas a uma mesma condição de cozimento. O Papel, v.36, n. 10, p.65-69, out. 1975.

GONZAGA, J.V. Qualidade da madeira e da celulose kraft de 13 espécies de Eucalyptus. Viçosa, 1983. 119p. Dissertação (Mestrado) - Universidade Federal de Viçosa.

LIMA, A.F.; GERYTCH, J.C.; JORDÃO, M.C.S.; ALMEIDA, M.L.O.; CORAIOLA, R. Efeito da estocagem de cavacos de Pinus elliottii sobre a polpação kraft e aproveitamento de subprodutos. In: CONGRESSO ANUAL DA ABTCP, 13, São Paulo, 1980. Anais. São Paulo: s. ed.; 1980. p.249-256.

REDKO, B.V.P.; NARIYOSHI, A.H.; ARAGÃO, J.B. Características da madeira e da celulose sulfato branqueada de Pinus caribaea var. hondurensis. 0 Papel, v.54, n.11, p.20-26, nov. 1993.

TEIXEIRA, M. L.; MENDES, L.M. Correlação entre densidade básica e componentes químicos da madeira de Pinus oocarpa. O Papel, v.56, n.11, p.37-40, nov. 1995 . 
ANEXO: Tabelas 
Anexo A. Resultados dendrométricos para sessenta e quatro árvores de Eucalyptus grandis.

\begin{tabular}{|c|c|c|c|c|c|c|c|}
\hline \multirow{2}{*}{ Árvore } & \multirow{2}{*}{$\begin{array}{c}\text { DAP, } \\
\mathrm{cm}\end{array}$} & \multicolumn{2}{|c|}{ Altura, $\mathrm{m}$} & \multicolumn{2}{|c|}{ Volume, $\mathrm{m}^{3}$} & \multicolumn{2}{|c|}{$\%$ de casca } \\
\hline & & Total & Comercial & $\mathrm{C} / \mathrm{C}$ & $\mathrm{S} / \mathrm{C}$ & Volume & Massa \\
\hline 1 & 30,9 & 34,6 & 28,9 & 1,0688 & 0,9381 & 12,23 & 7,70 \\
\hline 2 & 33,2 & 35,5 & 29,9 & 1,3005 & 1,1820 & 9,11 & 6,17 \\
\hline 3 & 30,6 & 35,7 & 30,3 & 1,2248 & 1,0700 & 12,63 & 8,04 \\
\hline 4 & 30,3 & 34,8 & 28,2 & 1,0739 & 0,9456 & 11,95 & 7,87 \\
\hline 5 & 30,9 & 33,9 & 28,9 & 0,9998 & 0,8923 & 10,75 & 6,79 \\
\hline 6 & 31,2 & 37,1 & 31,7 & 1,2063 & 1,0629 & 11,89 & 6,00 \\
\hline 7 & 32,8 & 36,0 & 29,8 & 1,2165 & 1,0758 & 11,57 & 5,89 \\
\hline 8 & 32,4 & 34,9 & 29,5 & 1,2780 & 1,1594 & 9,28 & 5,10 \\
\hline 9 & 31,8 & 35,5 & 29,8 & 1,2770 & 1,1267 & 11,77 & 7,36 \\
\hline 10 & 31,1 & 34,7 & 30,0 & 1,2014 & 1,0471 & 12,84 & 8,47 \\
\hline 11 & 29,9 & 33,3 & 27,1 & 0,9903 & 0,8636 & 12,79 & 8,63 \\
\hline 12 & 32,8 & 35,8 & 30,1 & 1,3854 & 1,2023 & 13,22 & 8,84 \\
\hline 13 & 30,7 & 34,8 & 28,2 & 1,0864 & 0,9571 & 11,90 & 8,03 \\
\hline 14 & 29,7 & 34,6 & 28,4 & 1,0058 & 0,9020 & 10,32 & 6,97 \\
\hline 15 & 29,9 & 34,1 & 28,1 & 1,0209 & 0,9168 & 10,19 & 5,78 \\
\hline 16 & 29,5 & 34,4 & 29,2 & 1,0557 & 0,9152 & 13,31 & 9,01 \\
\hline 17 & 32,2 & 34,1 & 29,2 & 1,2915 & 1,0990 & 14,90 & 9,75 \\
\hline 18 & 31,7 & 35,4 & 30,0 & 1,1722 & 1,0317 & 11,99 & 8,73 \\
\hline 19 & 31,4 & 35,3 & 29,5 & 1,0983 & 0,9531 & 13,21 & 8,93 \\
\hline 20 & 33,9 & 34,6 & 30,3 & 1,3902 & 1,2354 & 11,14 & 6,94 \\
\hline 21 & 32,2 & 34,1 & 28,9 & 1,1826 & 1,0618 & 10,22 & 6,03 \\
\hline 22 & 32,0 & 33,3 & 28,7 & 1,0908 & 0,9609 & 11,92 & 6,66 \\
\hline 23 & 31,2 & 35,0 & 29,6 & 1,0818 & 0,9451 & 12,63 & 8,50 \\
\hline 24 & 31,2 & 34,4 & 28,3 & 1,1330 & 1,0132 & 10,58 & 5,20 \\
\hline 25 & 30,3 & 35,1 & 29,7 & 1,1657 & 1,0047 & 13,81 & 7,41 \\
\hline 26 & 31,4 & 38,0 & 32,9 & 1,2374 & 1,0995 & 11,15 & 6,49 \\
\hline 27 & 27,2 & 35,9 & 30,0 & 0,9210 & 0,8043 & 12,67 & 7,78 \\
\hline 28 & 30,7 & 35,2 & 29,1 & 1,1615 & 1,0182 & 12,33 & 7,67 \\
\hline 29 & 27,0 & 32,3 & 27,3 & 0,8713 & 0,7566 & 13,16 & 10,42 \\
\hline 30 & 29,5 & 34,8 & 29,2 & 1,0207 & 0,9451 & 7,41 & 4,52 \\
\hline 31 & 27,8 & 34,6 & 29,4 & 0,9180 & 0,8116 & 11,59 & 7,36 \\
\hline 32 & 27,4 & 35,6 & 29,9 & 0,9345 & 0,8332 & 10,84 & 5,33 \\
\hline 33 & 27,6 & 37,0 & 29,5 & 1,0031 & 0,8979 & 10,48 & 5,64 \\
\hline 34 & 32,1 & 36,9 & 30,3 & 1,1407 & 1,0190 & 10,67 & 6,19 \\
\hline 35 & 28,6 & 33,9 & 27,0 & 0,9287 & 0,8306 & 10,57 & 7,08 \\
\hline 36 & 29,8 & 35,9 & 28,8 & 1,0487 & 0,9157 & 12,69 & 7,99 \\
\hline 37 & 30,4 & 33,3 & 28,3 & 1,0148 & 0,9070 & 10,62 & 5,73 \\
\hline
\end{tabular}


Anexo A. Resultados dendrométricos para sessenta e quatro árvores de Eucalyptus grandis.

\begin{tabular}{c|c|c|c|c|c|c|c}
38 & 26,7 & 32,4 & 26,7 & 0,7520 & 0,6666 & 11,35 & 5,64 \\
\hline 39 & 26,9 & 34,4 & 26,9 & 0,7872 & 0,7164 & 8,99 & 6,43 \\
\hline 40 & 26,4 & 33,8 & 26,9 & 0,7965 & 0,6909 & 13,26 & 8,13 \\
\hline 41 & 26,8 & 31,1 & 26,1 & 0,7800 & 0,6602 & 15,36 & 8,29 \\
\hline 42 & 29,5 & 33,8 & 28,4 & 0,9667 & 0,8599 & 11,04 & 6,56 \\
\hline 43 & 30,2 & 35,5 & 29,4 & 1,1119 & 0,9543 & 14,18 & 9,09 \\
\hline 44 & 26,7 & 34,3 & 29,1 & 0,8660 & 0,7771 & 10,26 & 6,61 \\
\hline 45 & 27,3 & 32,2 & 27,6 & 0,8616 & 0,7552 & 12,35 & 7,07 \\
\hline 46 & 25,2 & 33,5 & 28,0 & 0,7266 & 0,6540 & 9,99 & 6,73 \\
\hline 47 & 26,5 & 34,1 & 28,4 & 0,8196 & 0,7185 & 12,34 & 9,43 \\
\hline 48 & 30,9 & 35,2 & 29,7 & 1,0860 & 0,9618 & 11,44 & 7,39 \\
\hline 49 & 26,4 & 34,0 & 26,2 & 0,7832 & 0,6862 & 12,39 & 9,58 \\
\hline 50 & 27,4 & 34,0 & 28,1 & 0,8703 & 0,7820 & 10,16 & 7,05 \\
\hline 51 & 27,5 & 34,1 & 28,0 & 0,8426 & 0,7503 & 10,96 & 7,80 \\
\hline 52 & 28,3 & 35,4 & 30,0 & 0,9243 & 0,7905 & 14,48 & 9,84 \\
\hline 53 & 28,8 & 34,1 & 29,0 & 0,8849 & 0,7921 & 10,49 & 7,42 \\
\hline 54 & 28,5 & 35,4 & 29,8 & 1,0507 & 0,8879 & 15,49 & 10,14 \\
\hline 55 & 30,1 & 34,9 & 29,0 & 0,9847 & 0,9111 & 7,48 & 5,35 \\
\hline 56 & 26,5 & 34,0 & 28,4 & 0,7598 & 0,6981 & 8,12 & 5,96 \\
\hline 57 & 26,6 & 34,4 & 27,9 & 0,7914 & 0,7239 & 8,53 & 7,94 \\
\hline 58 & 28,4 & 33,2 & 27,8 & 0,8685 & 0,7606 & 12,43 & 9,82 \\
\hline 59 & 29,5 & 33,8 & 28,0 & 0,9801 & 0,8355 & 14,75 & 11,44 \\
\hline 60 & 27,0 & 33,9 & 27,9 & 0,7732 & 0,6934 & 10,32 & 8,43 \\
\hline 61 & 26,7 & 30,8 & 25,3 & 0,7152 & 0,6109 & 14,58 & 11,85 \\
\hline 62 & 29,0 & 34,2 & 27,2 & 0,9131 & 0,8316 & 8,92 & 5,38 \\
\hline 63 & 27,9 & 35,2 & 30,0 & 0,8885 & 0,7902 & 11,07 & 8,47 \\
\hline 64 & 29,0 & 33,5 & 28,2 & 0,9045 & 0,7757 & 14,23 & 11,95 \\
\hline Média & $\mathbf{2 9 , 5}$ & $\mathbf{3 4 , 5}$ & $\mathbf{2 8 , 8}$ & $\mathbf{1 , 0 1 7 8}$ & $\mathbf{0 , 8 9 8 8}$ & $\mathbf{1 1 , 6 6}$ & $\mathbf{7 , 6 2}$ \\
\hline Mínimo & $\mathbf{2 5 , 2}$ & $\mathbf{3 0 , 8}$ & $\mathbf{2 5 , 3}$ & $\mathbf{0 , 7 1 5 2}$ & $\mathbf{0 , 6 1 0 9}$ & $\mathbf{7 , 4 1}$ & $\mathbf{4 , 5 2}$ \\
\hline Máximo & 33,9 & $\mathbf{3 8 , 0}$ & $\mathbf{3 2 , 9}$ & $\mathbf{1 , 3 9 0 2}$ & $\mathbf{1 , 2 3 5 4}$ & $\mathbf{1 5 , 4 9}$ & $\mathbf{1 1 , 9 5}$ \\
\hline DesvPad & $\mathbf{2 , 1 2}$ & $\mathbf{1 , 2 8}$ & $\mathbf{1 , 3 2}$ & $\mathbf{0 , 1 6 9 6}$ & $\mathbf{0 , 1 4 9 4}$ & $\mathbf{1 , 8 3}$ & 1,70 \\
\hline C.V.,\% & $\mathbf{7 , 2 1}$ & $\mathbf{3 , 7 0}$ & $\mathbf{4 , 5 8}$ & $\mathbf{1 6 , 6 7}$ & $\mathbf{1 6 , 6 2}$ & $\mathbf{1 5 , 7 2}$ & $\mathbf{2 2 , 2 8}$ \\
\hline DAP. & & & & &
\end{tabular}

DAP: Diâmetro da árvore à altura do peito

Volume c/c: Volume comercial da árvore com casca

Volume s/c: Volume comercial da árvore sem casca

DesvPad: Desvio padrão

C.V: Coeficiente de variação 
Anexo B. Densidade básica dos discos em diferentes posições em relação à altura comercial e densidade básica média para Eucalyptus grandis.

\begin{tabular}{|c|c|c|c|c|c|c|}
\hline \multirow[b]{2}{*}{ Árvore } & \multicolumn{5}{|c|}{ Densidade Básica dos Discos, $\mathrm{g} / \mathrm{cm}^{3}$} & \multirow{2}{*}{$\begin{array}{c}\text { Densidade Básica } \\
\text { Média da Árvore, } \\
\mathrm{g} / \mathrm{cm}^{3}\end{array}$} \\
\hline & $\begin{array}{c}0 \% \text { da altura } \\
\text { comercial }\end{array}$ & $\begin{array}{c}25 \% \text { da altura } \\
\text { comercial }\end{array}$ & $\begin{array}{l}50 \% \text { da altura } \\
\text { comercial }\end{array}$ & $\begin{array}{c}75 \% \text { da altura } \\
\text { comercial }\end{array}$ & $\begin{array}{c}100 \% \text { da altura } \\
\text { comercial }\end{array}$ & \\
\hline 1 & 0,470 & 0,411 & 0,518 & 0,519 & 0,475 & 0,466 \\
\hline 2 & 0,510 & 0,422 & 0,518 & 0,500 & 0,500 & 0,477 \\
\hline 3 & 0,467 & 0,422 & 0,428 & 0,455 & 0,480 & 0,440 \\
\hline 4 & 0,419 & 0,373 & 0,439 & 0,444 & 0,480 & 0,411 \\
\hline 5 & 0,436 & 0,389 & 0,464 & 0,470 & 0,458 & 0,430 \\
\hline 6 & 0,540 & 0,515 & 0,524 & 0,533 & 0,536 & 0,526 \\
\hline 7 & 0,493 & 0,427 & 0,441 & 0,517 & 0,536 & 0,462 \\
\hline 8 & 0,462 & 0,408 & 0,439 & 0,500 & 0,488 & 0,442 \\
\hline 9 & 0,469 & 0,423 & 0,442 & 0,472 & 0,500 & 0,447 \\
\hline 10 & 0,529 & 0,437 & 0,466 & 0,506 & 0,500 & 0,476 \\
\hline 11 & 0,502 & 0,464 & 0,474 & 0,500 & 0,548 & 0,483 \\
\hline 12 & 0,500 & 0,444 & 0,519 & 0,517 & 0,500 & 0,485 \\
\hline 13 & 0,495 & 0,391 & 0,412 & 0,458 & 0,466 & 0,432 \\
\hline 14 & 0,488 & 0,424 & 0,437 & 0,510 & 0,529 & 0,456 \\
\hline 15 & 0,453 & 0,432 & 0,417 & 0,449 & 0,462 & 0,437 \\
\hline 16 & 0,431 & 0,400 & 0,481 & 0,466 & 0,480 & 0,436 \\
\hline 17 & 0,520 & 0,436 & 0,456 & 0,447 & 0,444 & 0,462 \\
\hline 18 & 0,432 & 0,399 & 0,419 & 0,453 & 0,500 & 0,422 \\
\hline 19 & 0,481 & 0,415 & 0,478 & 0,473 & 0,500 & 0,455 \\
\hline 20 & 0,502 & 0,403 & 0,465 & 0,451 & 0,433 & 0,447 \\
\hline 21 & 0,535 & 0,544 & 0,505 & 0,486 & 0,467 & 0,523 \\
\hline 22 & 0,441 & 0,424 & 0,432 & 0,473 & 0,526 & 0,440 \\
\hline 23 & 0,508 & 0,447 & 0,478 & 0,523 & 0,488 & 0,479 \\
\hline 24 & 0,521 & 0,486 & 0,520 & 0,545 & 0,545 & 0,513 \\
\hline 25 & 0,565 & 0,534 & 0,523 & 0,500 & 0,467 & 0,532 \\
\hline 26 & 0,518 & 0,475 & 0,510 & 0,560 & 0,533 & 0,505 \\
\hline 27 & 0,511 & 0,478 & 0,552 & 0,569 & 0,538 & 0,516 \\
\hline 28 & 0,532 & 0,411 & 0,446 & 0,420 & 0,474 & 0,451 \\
\hline 29 & 0,457 & 0,470 & 0,438 & 0,431 & 0,470 & 0,455 \\
\hline 30 & 0,453 & 0,373 & 0,401 & 0,516 & 0,500 & 0,421 \\
\hline 31 & 0,457 & 0,358 & 0,387 & 0,430 & 0,429 & 0,399 \\
\hline 32 & 0,522 & 0,459 & 0,439 & 0,480 & 0,458 & 0,471 \\
\hline 33 & 0,481 & 0,422 & 0,458 & 0,474 & 0,517 & 0,455 \\
\hline 34 & 0,437 & 0,413 & 0,393 & 0,430 & 0,478 & 0,418 \\
\hline 35 & 0,376 & 0,345 & 0,443 & 0,396 & 0,447 & 0,385 \\
\hline
\end{tabular}


Anexo B. Densidade básica dos discos em diferentes posições em relação à altura comercial e densidade básica média para Eucalyptus grandis.

\begin{tabular}{c|c|c|c|c|c|c}
36 & 0,381 & 0,353 & 0,397 & 0,424 & 0,486 & 0,383 \\
\hline 37 & 0,448 & 0,429 & 0,419 & 0,436 & 0,481 & 0,434 \\
\hline 38 & 0,493 & 0,476 & 0,514 & 0,500 & 0,517 & 0,493 \\
\hline 39 & 0,437 & 0,399 & 0,423 & 0,456 & 0,440 & 0,422 \\
\hline 40 & 0,456 & 0,397 & 0,423 & 0,353 & 0,478 & 0,415 \\
\hline 41 & 0,421 & 0,430 & 0,440 & 0,511 & 0,500 & 0,443 \\
\hline 42 & 0,404 & 0,363 & 0,397 & 0,414 & 0,470 & 0,391 \\
\hline 43 & 0,485 & 0,422 & 0,448 & 0,500 & 0,500 & 0,456 \\
\hline 44 & 0,378 & 0,360 & 0,372 & 0,400 & 0,429 & 0,375 \\
\hline 45 & 0,434 & 0,438 & 0,446 & 0,465 & 0,480 & 0,444 \\
\hline 46 & 0,520 & 0,462 & 0,458 & 0,515 & 0,500 & 0,483 \\
\hline 47 & 0,518 & 0,447 & 0,500 & 0,512 & 0,529 & 0,487 \\
\hline 48 & 0,394 & 0,396 & 0,406 & 0,438 & 0,400 & 0,403 \\
\hline 49 & 0,373 & 0,354 & 0,397 & 0,460 & 0,455 & 0,387 \\
\hline 50 & 0,432 & 0,407 & 0,436 & 0,489 & 0,474 & 0,432 \\
\hline 51 & 0,514 & 0,450 & 0,500 & 0,500 & 0,500 & 0,484 \\
\hline 52 & 0,482 & 0,391 & 0,447 & 0,447 & 0,526 & 0,438 \\
\hline 53 & 0,445 & 0,412 & 0,435 & 0,461 & 0,500 & 0,434 \\
\hline 54 & 0,502 & 0,480 & 0,468 & 0,496 & 0,516 & 0,486 \\
\hline 55 & 0,463 & 0,416 & 0,466 & 0,478 & 0,500 & 0,449 \\
\hline 56 & 0,499 & 0,408 & 0,425 & 0,466 & 0,452 & 0,442 \\
\hline 57 & 0,456 & 0,410 & 0,469 & 0,448 & 0,483 & 0,442 \\
\hline 58 & 0,402 & 0,396 & 0,407 & 0,437 & 0,435 & 0,407 \\
\hline 59 & 0,497 & 0,388 & 0,400 & 0,430 & 0,450 & 0,423 \\
\hline 60 & 0,403 & 0,342 & 0,349 & 0,397 & 0,474 & 0,370 \\
\hline 61 & 0,417 & 0,390 & 0,418 & 0,437 & 0,500 & 0,413 \\
\hline 62 & 0,451 & 0,446 & 0,449 & 0,484 & 0,500 & 0,455 \\
\hline 63 & 0,422 & 0,394 & 0,488 & 0,456 & 0,500 & 0,433 \\
\hline 64 & 0,449 & 0,422 & 0,466 & 0,492 & 0,545 & 0,451 \\
\hline Média & 0,467 & $\mathbf{0 , 4 2 1}$ & $\mathbf{0 , 4 5 0}$ & $\mathbf{0 , 4 7 1}$ & $\mathbf{0 , 4 8 7}$ & $\mathbf{0 , 4 4 7}$ \\
\hline Mínimo & $\mathbf{0 , 3 7 3}$ & $\mathbf{0 , 3 4 2}$ & $\mathbf{0 , 3 4 9}$ & $\mathbf{0 , 3 5 3}$ & $\mathbf{0 , 4 0 0}$ & $\mathbf{0 , 3 7 0}$ \\
\hline Máximo & $\mathbf{0 , 5 6 5}$ & $\mathbf{0 , 5 4 4}$ & $\mathbf{0 , 5 5 2}$ & $\mathbf{0 , 5 6 9}$ & $\mathbf{0 , 5 4 8}$ & $\mathbf{0 , 5 3 2}$ \\
\hline DesvPad & $\mathbf{0 , 0 4 6}$ & $\mathbf{0 , 0 4 2}$ & $\mathbf{0 , 0 4 2}$ & $\mathbf{0 , 0 4 1}$ & $\mathbf{0 , 0 3 2}$ & $\mathbf{0 , 0 3 7}$ \\
\hline C.V.,\% & $\mathbf{9 , 8 0}$ & $\mathbf{1 0 , 0 3}$ & $\mathbf{9 , 4 0}$ & $\mathbf{8 , 7 8}$ & $\mathbf{6 , 6 6}$ & $\mathbf{8 , 3 2}$ \\
\hline D. & & & & &
\end{tabular}

DesvPad: Desvio padrão

C.V.: Coeficiente de variação 
Anexo C. Massa comercial de sessenta e quatro árvores de Eucalyptus grandis.

\begin{tabular}{|c|c|c|c|}
\hline Árvore & $\begin{array}{c}\text { Volume } \\
\text { Sem } \\
\text { Casca, } \\
\mathrm{m}^{3}\end{array}$ & $\begin{array}{c}\text { Densidade } \\
\text { Básica } \\
\text { Média, } \\
\mathrm{g} / \mathrm{cm}^{3} \\
\end{array}$ & $\begin{array}{c}\text { Massa } \\
\text { Comercial } \\
\text {, kg seco }\end{array}$ \\
\hline 1 & 0,9381 & 0,466 & 437,17 \\
\hline 2 & 1,1820 & 0,477 & 563,73 \\
\hline 3 & 1,0700 & 0,440 & 470,89 \\
\hline 4 & 0,9456 & 0,411 & 389,10 \\
\hline 5 & 0,8923 & 0,430 & 383,64 \\
\hline 6 & 1,0629 & 0,526 & 559,01 \\
\hline 7 & 1,0758 & 0,462 & 496,50 \\
\hline 8 & 1,1594 & 0,442 & 512,28 \\
\hline 9 & 1,1267 & 0,447 & 503,69 \\
\hline 10 & 1,0471 & 0,476 & 498,33 \\
\hline 11 & 0,8636 & 0,483 & 416,95 \\
\hline 12 & 1,2023 & 0,485 & 583,48 \\
\hline 13 & 0,9571 & 0,432 & 413,16 \\
\hline 14 & 0,9020 & 0,456 & 411,62 \\
\hline 15 & 0,9168 & 0,437 & 400,45 \\
\hline 16 & 0,9152 & 0,436 & 398,77 \\
\hline 17 & 1,0990 & 0,462 & 507,57 \\
\hline 18 & 1,0317 & 0,422 & 434,89 \\
\hline 19 & 0,9531 & 0,455 & 433,45 \\
\hline 20 & 1,2354 & 0,447 & 552,62 \\
\hline 21 & 1,0618 & 0,523 & 555,69 \\
\hline 22 & 0,9609 & 0,440 & 422,90 \\
\hline 23 & 0,9451 & 0,479 & 453,03 \\
\hline 24 & 1,0132 & 0,513 & 519,65 \\
\hline 25 & 1,0047 & 0,532 & 534,82 \\
\hline 26 & 1,0995 & 0,505 & 554,94 \\
\hline 27 & 0,8043 & 0,516 & 415,33 \\
\hline 28 & 1,0182 & 0,451 & 459,03 \\
\hline 29 & 0,7566 & 0,455 & 343,92 \\
\hline 30 & 0,9451 & 0,421 & 397,86 \\
\hline 31 & 0,8116 & 0,399 & 324,05 \\
\hline 32 & 0,8332 & 0,471 & 392,38 \\
\hline 33 & 0,8979 & 0,455 & 408,24 \\
\hline 34 & 1,0190 & 0,418 & 426,38 \\
\hline 35 & 0,8306 & 0,385 & 319,58 \\
\hline 36 & 0,9157 & 0,383 & 351,04 \\
\hline
\end{tabular}

\begin{tabular}{|c|c|c|c|}
\hline Árvore & $\begin{array}{c}\text { Volume } \\
\text { Sem } \\
\text { Casca, } \\
\mathrm{m}^{3}\end{array}$ & $\begin{array}{c}\text { Densidade } \\
\text { Básica } \\
\text { Média, } \\
\mathrm{g} / \mathrm{cm}^{3} \\
\end{array}$ & $\begin{array}{c}\text { Massa } \\
\text { Comercial } \\
, \mathrm{kg} \mathrm{seco}\end{array}$ \\
\hline 37 & 0,9070 & 0,434 & 393,56 \\
\hline 38 & 0,6666 & 0,493 & 328,79 \\
\hline 39 & 0,7164 & 0,422 & 302,66 \\
\hline 40 & 0,6909 & 0,415 & 286,39 \\
\hline 41 & 0,6602 & 0,443 & 292,81 \\
\hline 42 & 0,8599 & 0,391 & 336,32 \\
\hline 43 & 0,9543 & 0,456 & 434,95 \\
\hline 44 & 0,7771 & 0,375 & 291,11 \\
\hline 45 & 0,7552 & 0,444 & 335,52 \\
\hline 46 & 0,6540 & 0,483 & 315,75 \\
\hline 47 & 0,7185 & 0,487 & 349,86 \\
\hline 48 & 0,9618 & 0,403 & 387,31 \\
\hline 49 & 0,6862 & 0,387 & 265,38 \\
\hline 50 & 0,7820 & 0,432 & 338,09 \\
\hline 51 & 0,7503 & 0,484 & 363,30 \\
\hline 52 & 0,7905 & 0,438 & 345,85 \\
\hline 53 & 0,7921 & 0,434 & 344,05 \\
\hline 54 & 0,8879 & 0,486 & 431,21 \\
\hline 55 & 0,9111 & 0,449 & 409,40 \\
\hline 56 & 0,6981 & 0,442 & 308,32 \\
\hline 57 & 0,7239 & 0,442 & 320,12 \\
\hline 58 & 0,7606 & 0,407 & 309,32 \\
\hline 59 & 0,8355 & 0,423 & 353,57 \\
\hline 60 & 0,6934 & 0,370 & 256,44 \\
\hline 61 & 0,6109 & 0,413 & 252,02 \\
\hline 62 & 0,8316 & 0,455 & 378,37 \\
\hline 63 & 0,7902 & 0,433 & 342,24 \\
\hline 64 & 0,7757 & 0,451 & 349,93 \\
\hline Média & 0,8927 & 0,447 & 401,08 \\
\hline Mínimo & 0,6109 & 0,370 & 252,02 \\
\hline Máximo & 1,2354 & 0,532 & 583,48 \\
\hline DesvPad & 0,1509 & 0,037 & 84,84 \\
\hline C.V.,\% & 16,91 & 8,32 & 21,15 \\
\hline
\end{tabular}


Anexo D. Composição química da madeira de sessenta e quatro árvores de Eucalyptus grandis.

\begin{tabular}{|c|c|c|c|}
\hline Árvore & Holocelulose, \% & Lignina, \% & Extrativos Totais, \% \\
\hline 1 & 74,1 & 25,0 & 0,91 \\
\hline 2 & 74,8 & 25,1 & 0,08 \\
\hline 3 & 72,6 & 27,3 & 0,17 \\
\hline 4 & 70,4 & 28,5 & 1,08 \\
\hline 5 & 74,1 & 25,7 & 0,24 \\
\hline 6 & 75,4 & 23,8 & 0,84 \\
\hline 7 & 74,7 & 25,2 & 0,17 \\
\hline 8 & 73,8 & 25,6 & 0,62 \\
\hline 9 & 73,7 & 25,4 & 0,85 \\
\hline 10 & 74,8 & 24,8 & 0,45 \\
\hline 11 & 73,6 & 25,7 & 0,76 \\
\hline 12 & 74,9 & 24,8 & 0,31 \\
\hline 13 & 74,3 & 25,1 & 0,58 \\
\hline 14 & 70,3 & 28,9 & 0,80 \\
\hline 15 & 71,5 & 27,8 & 0,66 \\
\hline 16 & 67,8 & 29,8 & 2,36 \\
\hline 17 & 69,3 & 28,3 & 2,36 \\
\hline 18 & 74,9 & 24,4 & 0,73 \\
\hline 19 & 72,7 & 25,3 & 2,00 \\
\hline 20 & 72,1 & 26,6 & 1,31 \\
\hline 21 & 71,7 & 26,4 & 1,88 \\
\hline 22 & 71,5 & 27,8 & 0,72 \\
\hline 23 & 71,9 & 28,0 & 0,19 \\
\hline 24 & 70,7 & 28,8 & 0,57 \\
\hline 25 & 75,3 & 24,3 & 0,39 \\
\hline 26 & 73,5 & 25,8 & 0,69 \\
\hline 27 & 74,6 & 25,0 & 0,47 \\
\hline 28 & 71,8 & 26,6 & 1,60 \\
\hline 29 & 73,3 & 26,2 & 0,54 \\
\hline 30 & 71,4 & 27,9 & 0,66 \\
\hline 31 & 73,3 & 25,4 & 1,33 \\
\hline 32 & 72,8 & 25,4 & 1,90 \\
\hline 33 & 76,6 & 23,2 & 0,13 \\
\hline 34 & 73,0 & 26,9 & 0,17 \\
\hline 35 & 71,8 & 27,2 & 1,00 \\
\hline 36 & 73,1 & 25,8 & 1,13 \\
\hline 37 & 73,6 & 25,0 & 1,36 \\
\hline 38 & 71,3 & 26,5 & 2,15 \\
\hline
\end{tabular}


Anexo D. Composição química da madeira de sessenta e quatro árvores de Eucalyptus grandis.

\begin{tabular}{|c|c|c|c|}
\hline 39 & 74,4 & 25,4 & 0,12 \\
\hline 40 & 75,3 & 23,8 & 0,91 \\
\hline 41 & 73,8 & 25,5 & 0,66 \\
\hline 42 & 71,0 & 28,0 & 1,01 \\
\hline 43 & 72,1 & 26,4 & 1,51 \\
\hline 44 & 73,1 & 26,1 & 0,73 \\
\hline 45 & 76,6 & 23,1 & 0,27 \\
\hline 46 & 73,4 & 26,2 & 0,47 \\
\hline 47 & 72,0 & 26,0 & 2,05 \\
\hline 48 & 71,9 & 25,8 & 2,37 \\
\hline 49 & 72,6 & 25,0 & 2,40 \\
\hline 50 & 70,8 & 26,4 & 2,84 \\
\hline 51 & 72,6 & 24,9 & 2,49 \\
\hline 52 & 75,7 & 23,3 & 0,96 \\
\hline 53 & 72,7 & 25,3 & 1,97 \\
\hline 54 & 74,5 & 23,8 & 1,70 \\
\hline 55 & 71,8 & 26,3 & 1,90 \\
\hline 56 & 72,2 & 25,5 & 2,32 \\
\hline 57 & 73,7 & 24,3 & 1,99 \\
\hline 58 & 73,3 & 25,6 & 1,16 \\
\hline 59 & 76,2 & 23,0 & 0,89 \\
\hline 60 & 74,2 & 24,5 & 1,37 \\
\hline 61 & 75,5 & 23,6 & 0,92 \\
\hline 62 & 75,2 & 23,0 & 1,81 \\
\hline 63 & 74,7 & 24,2 & 1,03 \\
\hline 64 & 74,0 & 25,0 & 1,03 \\
\hline Média & 73,2 & 25,7 & 1,11 \\
\hline Mínimo & 67,8 & 23,0 & 0,08 \\
\hline Máximo & 76,6 & 29,8 & 2,84 \\
\hline DesvPad & 1,8 & 1,6 & 0,73 \\
\hline C.V.,\% & 2,4 & 6,0 & 65,82 \\
\hline
\end{tabular}


Anexo E. Determinação de celulose na madeira de sessenta e quatro árvores de Eucalyptus grandis pelos métodos não-convencionais.

\begin{tabular}{|c|c|c|c|c|c|}
\hline \multirow[b]{2}{*}{ Árvore } & \multicolumn{5}{|c|}{ Métodos de Determinação de Celulose na Madeira } \\
\hline & $\begin{array}{l}\text { Celulose } \\
\text { Seifert, \% }\end{array}$ & $\begin{array}{c}\text { Ácido } \\
\text { Nítrico, \% }\end{array}$ & $\begin{array}{l}\text { Ác. Nítrico com } \\
\text { Extração } \\
\text { Alcalina, \% }\end{array}$ & $\begin{array}{c}\text { Ácido } \\
\text { Peroxiacético, } \\
\%\end{array}$ & $\begin{array}{c}\text { Ác. Peroxiacético } \\
\text { com Extração } \\
\text { Alcalina, \% }\end{array}$ \\
\hline 1 & $44,30 \pm 0,26$ & $52,87 \pm 0,49$ & $42,96 \pm 0,94$ & $55,43 \pm 0,16$ & $45,18 \pm 1,21$ \\
\hline 2 & $43,58 \pm 0,90$ & $53,52 \pm 0,48$ & $41,81 \pm 0,09$ & $56,20 \pm 0,41$ & $47,18 \pm 0,80$ \\
\hline 3 & $42,15 \pm 0,69$ & $52,25 \pm 0,09$ & $42,62 \pm 0,24$ & $55,74 \pm 0,12$ & $45,10 \pm 0,65$ \\
\hline 4 & $42,14 \pm 1,42$ & $51,77 \pm 0,52$ & $41,86 \pm 0,11$ & $54,76 \pm 0,26$ & $44,02 \pm 0,52$ \\
\hline 5 & $43,58 \pm 0,49$ & $53,41 \pm 0,84$ & $43,35 \pm 0,67$ & $55,79 \pm 0,13$ & $46,37 \pm 0,42$ \\
\hline 6 & $47,48 \pm 0,42$ & $57,13 \pm 0,03$ & $46,85 \pm 0,55$ & $58,41 \pm 0,21$ & $49,94 \pm 0,37$ \\
\hline 7 & $45,53 \pm 0,48$ & $54,63 \pm 0,29$ & $43,87 \pm 0,39$ & $56,09 \pm 0,24$ & $46,25 \pm 0,27$ \\
\hline 8 & $43,28 \pm 0,97$ & $52,84 \pm 0,51$ & $43,68 \pm 0,76$ & $54,59 \pm 0,31$ & $45,10 \pm 0,47$ \\
\hline 9 & $41,59 \pm 0,98$ & $51,86 \pm 0,27$ & $41,91 \pm 0,74$ & $53,33 \pm 0,20$ & $43,90 \pm 0,07$ \\
\hline 10 & $45,23 \pm 0,69$ & $52,89 \pm 0,31$ & $41,64 \pm 0,44$ & $55,67 \pm 0,18$ & $46,65 \pm 0,24$ \\
\hline 11 & $44,24 \pm 0,53$ & $51,50 \pm 0,19$ & $43,09 \pm 0,02$ & $53,45 \pm 0,05$ & $43,90 \pm 0,04$ \\
\hline 12 & $45,25 \pm 0,91$ & $54,24 \pm 0,05$ & $44,06 \pm 0,00$ & $55,80 \pm 0,07$ & $45,70 \pm 0,28$ \\
\hline 13 & $41,44 \pm 0,07$ & $53,46 \pm 0,58$ & $44,17 \pm 0,60$ & $55,23 \pm 0,11$ & $45,44 \pm 0,10$ \\
\hline 14 & $44,45 \pm 0,44$ & $51,26 \pm 0,77$ & $42,01 \pm 0,63$ & $53,90 \pm 0,21$ & $44,28 \pm 0,18$ \\
\hline 15 & $45,64 \pm 0,09$ & $54,49 \pm 0,35$ & $43,68 \pm 0,22$ & $56,25 \pm 0,27$ & $46,33 \pm 0,22$ \\
\hline 16 & $44,15 \pm 0,10$ & $50,94 \pm 0,14$ & $41,92 \pm 0,16$ & $52,86 \pm 0,32$ & $44,15 \pm 0,00$ \\
\hline 17 & $45,00 \pm 0,12$ & $52,67 \pm 0,42$ & $43,37 \pm 0,07$ & $55,10 \pm 0,35$ & $46,14 \pm 0,25$ \\
\hline 18 & $45,73 \pm 0,55$ & $54,55 \pm 0,26$ & $45,20 \pm 0,17$ & $54,25 \pm 0,25$ & $45,31 \pm 0,20$ \\
\hline 19 & $41,21 \pm 1,47$ & $51,90 \pm 0,41$ & $42,84 \pm 0,20$ & $54,08 \pm 0,01$ & $43,73 \pm 0,11$ \\
\hline 20 & $45,79 \pm 0,24$ & $51,33 \pm 0,11$ & $42,62 \pm 0,03$ & $54,15 \pm 0,74$ & $45,37 \pm 0,99$ \\
\hline 21 & $43,80 \pm 0,09$ & $51,07 \pm 0,40$ & $42,34 \pm 0,77$ & $52,94 \pm 0,70$ & $43,88 \pm 0,58$ \\
\hline 22 & $42,01 \pm 0,79$ & $53,57 \pm 0,11$ & $43,34 \pm 0,66$ & $53,73 \pm 0,28$ & $42,94 \pm 0,26$ \\
\hline 23 & $43,26 \pm 1,05$ & $54,07 \pm 0,40$ & $43,48 \pm 0,83$ & $56,23 \pm 0,47$ & $46,40 \pm 0,65$ \\
\hline 24 & $42,93 \pm 0,22$ & $52,77 \pm 0,04$ & $43,20 \pm 0,02$ & $53,92 \pm 0,18$ & $44,11 \pm 0,24$ \\
\hline 25 & $44,87 \pm 0,52$ & $55,74 \pm 0,11$ & $46,07 \pm 0,09$ & $56,56 \pm 0,73$ & $47,87 \pm 0,22$ \\
\hline 26 & $44,95 \pm 0,06$ & $53,50 \pm 0,14$ & $43,04 \pm 0,36$ & $54,92 \pm 0,80$ & $45,90 \pm 1,17$ \\
\hline 27 & $44,94 \pm 1,30$ & $54,62 \pm 0,08$ & $44,26 \pm 0,11$ & $55,56 \pm 0,73$ & $46,03 \pm 0,23$ \\
\hline 28 & $43,98 \pm 0,40$ & $51,89 \pm 0,34$ & $41,79 \pm 0,04$ & $53,13 \pm 0,10$ & $43,16 \pm 0,44$ \\
\hline 29 & $44,17 \pm 1,04$ & $53,76 \pm 0,03$ & $43,52 \pm 0,09$ & $54,93 \pm 0,01$ & $45,60 \pm 0,28$ \\
\hline 30 & $44,11 \pm 0,61$ & $51,91 \pm 0,76$ & $41,49 \pm 0,41$ & $53,18 \pm 0,13$ & $43,63 \pm 0,06$ \\
\hline 31 & $43,59 \pm 0,10$ & $52,73 \pm 0,44$ & $42,37 \pm 0,11$ & $54,28 \pm 0,31$ & $45,87 \pm 0,03$ \\
\hline 32 & $45,27 \pm 0,21$ & $53,46 \pm 0,04$ & $43,46 \pm 0,25$ & $55,01 \pm 0,17$ & $44,49 \pm 0,26$ \\
\hline 33 & $43,97 \pm 0,18$ & $54,61 \pm 0,43$ & $43,25 \pm 0,01$ & $56,11 \pm 0,03$ & $47,60 \pm 1,08$ \\
\hline 34 & $46,54 \pm 0,18$ & $53,28 \pm 0,51$ & $42,43 \pm 0,58$ & $54,21 \pm 0,14$ & $44,29 \pm 0,48$ \\
\hline
\end{tabular}


Anexo E. Determinação de celulose na madeira de sessenta e quatro árvores de Eucalyptus grandis pelos métodos não-convencionais.

\begin{tabular}{|c|c|c|c|c|c|}
\hline 35 & $45,05 \pm 0,04$ & $52,45 \pm 0,27$ & $42,77 \pm 0,16$ & $54,28 \pm 0,58$ & $44,35 \pm 0,02$ \\
\hline 36 & $44,37 \pm 0,57$ & $53,04 \pm 0,47$ & $43,40 \pm 0,95$ & $54,52 \pm 0,10$ & $43,12 \pm 1,18$ \\
\hline 37 & $44,40 \pm 0,92$ & $53,30 \pm 0,36$ & $42,15 \pm 0,19$ & $58,55 \pm 0,17$ & $49,78 \pm 0,26$ \\
\hline 38 & $42,43 \pm 0,21$ & $50,77 \pm 0,13$ & $40,68 \pm 0,19$ & $54,26 \pm 0,47$ & $44,72 \pm 0,63$ \\
\hline 39 & $43,40 \pm 0,03$ & $51,86 \pm 0,18$ & $41,86 \pm 0,13$ & $54,28 \pm 0,24$ & $44,05 \pm 0,43$ \\
\hline 40 & $46,69 \pm 0,61$ & $53,97 \pm 0,04$ & $42,45 \pm 0,17$ & $56,49 \pm 0,07$ & $47,33 \pm 0,39$ \\
\hline 41 & $42,81 \pm 1,04$ & $53,74 \pm 0,05$ & $41,67 \pm 0,76$ & $56,10 \pm 0,07$ & $47,24 \pm 0,57$ \\
\hline 42 & $44,16 \pm 0,08$ & $51,96 \pm 0,18$ & $42,20 \pm 0,34$ & $54,31 \pm 0,56$ & $45,24 \pm 0,97$ \\
\hline 43 & $42,65 \pm 0,45$ & $52,58 \pm 0,23$ & $42,87 \pm 0,45$ & $54,20 \pm 0,46$ & $45,97 \pm 0,20$ \\
\hline 44 & $44,83 \pm 0,96$ & $51,18 \pm 0,32$ & $42,52 \pm 0,27$ & $55,43 \pm 0,52$ & $45,10 \pm 0,58$ \\
\hline 45 & $46,30 \pm 0,63$ & $52,35 \pm 0,48$ & $41,52 \pm 0,59$ & $57,20 \pm 0,06$ & $47,27 \pm 0,48$ \\
\hline 46 & $44,30 \pm 0,98$ & $49,81 \pm 0,93$ & $39,78 \pm 0,31$ & $55,24 \pm 0,69$ & $46,25 \pm 0,37$ \\
\hline 47 & $40,70 \pm 1,07$ & $49,50 \pm 0,25$ & $38,42 \pm 0,59$ & $55,36 \pm 0,10$ & $46,38 \pm 0,39$ \\
\hline 48 & $44,40 \pm 0,97$ & $49,98 \pm 1,37$ & $40,08 \pm 1,01$ & $54,39 \pm 0,38$ & $45,31 \pm 0,51$ \\
\hline 49 & $46,09 \pm 0,49$ & $50,82 \pm 0,10$ & $40,72 \pm 0,14$ & $55,88 \pm 0,08$ & $48,31 \pm 0,19$ \\
\hline 50 & $44,61 \pm 0,16$ & $50,02 \pm 0,27$ & $38,38 \pm 0,16$ & $55,25 \pm 0,73$ & $46,22 \pm 0,94$ \\
\hline 51 & $45,56 \pm 0,69$ & $52,06 \pm 0,47$ & $41,18 \pm 0,42$ & $56,81 \pm 0,15$ & $49,42 \pm 0,18$ \\
\hline 52 & $45,92 \pm 0,58$ & $52,42 \pm 0,10$ & $41,93 \pm 0,30$ & $55,98 \pm 0,39$ & $47,74 \pm 0,47$ \\
\hline 53 & $45,15 \pm 0,17$ & $54,33 \pm 0,27$ & $43,96 \pm 0,61$ & $56,23 \pm 0,39$ & $47,10 \pm 0,30$ \\
\hline 54 & $44,54 \pm 0,94$ & $52,23 \pm 0,81$ & $42,63 \pm 0,70$ & $54,64 \pm 0,11$ & $44,53 \pm 0,07$ \\
\hline 55 & $44,09 \pm 0,33$ & $52,02 \pm 0,03$ & $42,76 \pm 0,14$ & $55,21 \pm 0,14$ & $45,39 \pm 0,09$ \\
\hline 56 & $44,33 \pm 0,57$ & $50,83 \pm 0,21$ & $41,35 \pm 0,14$ & $55,67 \pm 0,24$ & $45,93 \pm 0,23$ \\
\hline 57 & $43,31 \pm 0,65$ & $50,60 \pm 0,58$ & $41,38 \pm 0,30$ & $54,69 \pm 0,22$ & $44,12 \pm 0,07$ \\
\hline 58 & $44,26 \pm 0,25$ & $51,77 \pm 0,58$ & $41,77 \pm 0,42$ & $52,95 \pm 0,55$ & $43,15 \pm 1,00$ \\
\hline 59 & $45,71 \pm 0,24$ & $54,81 \pm 0,23$ & $43,73 \pm 0,33$ & $56,74 \pm 0,29$ & $48,64 \pm 0,25$ \\
\hline 60 & $44,23 \pm 0,35$ & $50,92 \pm 0,82$ & $41,37 \pm 0,63$ & $53,62 \pm 0,07$ & $44,78 \pm 0,25$ \\
\hline 61 & $44,43 \pm 0,20$ & $52,99 \pm 0,48$ & $42,38 \pm 0,83$ & $55,98 \pm 0,20$ & $49,06 \pm 0,35$ \\
\hline 62 & $43,21 \pm 1,60$ & $52,01 \pm 1,03$ & $41,61 \pm 1,27$ & $54,32 \pm 0,05$ & $47,44 \pm 0,31$ \\
\hline 63 & $44,43 \pm 0,62$ & $52,38 \pm 0,78$ & $42,05 \pm 0,35$ & $55,11 \pm 0,31$ & $46,26 \pm 0,13$ \\
\hline 64 & $43,89 \pm 0,44$ & $52,57 \pm 0,67$ & $42,93 \pm 0,59$ & $55,07 \pm 0,39$ & $46,53 \pm 0,39$ \\
\hline Média & $44,23 \pm 0,55$ & $52,59 \pm 0,37$ & $42,50 \pm 0,39$ & $55,07 \pm 0,27$ & $45,76 \pm 0,40$ \\
\hline Mínimo & 40,70 & 49,50 & 38,38 & 52,86 & 42,94 \\
\hline Máximo & 47,48 & 57,13 & 46,85 & 58,55 & 49,94 \\
\hline DesvPad & 1,37 & 1,48 & 1,40 & 1,22 & 1,68 \\
\hline C.V., $\%$ & 3,10 & 2,82 & 3,30 & 2,22 & 3,67 \\
\hline
\end{tabular}


Anexo F. Determinação de $\alpha$-celulose como parâmetro de comparação para os métodos não-convencionais.

\begin{tabular}{|c|c|c|c|c|c|c|}
\hline \multirow[b]{2}{*}{ Árvore } & \multirow{2}{*}{\begin{tabular}{|c|}
$\begin{array}{c}\text { Método } \\
\text { Normatizado } \\
\%\end{array}$ \\
\\
$\alpha$-celulose
\end{tabular}} & \multicolumn{5}{|c|}{$\begin{array}{l}\text { Métodos Não-Convencionais de Determinação de Celulose na } \\
\text { Madeira, \% }\end{array}$} \\
\hline & & $\begin{array}{c}\text { Celulose } \\
\text { Seifert }\end{array}$ & $\begin{array}{l}\text { Ácido } \\
\text { Nítrico }\end{array}$ & \begin{tabular}{|c|} 
Ác. Nítrico \\
com \\
Extração \\
Alcalina
\end{tabular} & $\begin{array}{c}\text { Ácido } \\
\text { Peroxiacético }\end{array}$ & $\begin{array}{c}\text { Ác. } \\
\text { Peroxiacético } \\
\text { com Extração } \\
\text { Alcalina }\end{array}$ \\
\hline 2 & $52,19 \pm 0,32$ & $43,58 \pm 0,90$ & $53,52 \pm 0,48$ & $41,81 \pm 0,09$ & $56,20 \pm 0,41$ & $47,18 \pm 0,80$ \\
\hline 6 & $54,24 \pm 0,13$ & $47,48 \pm 0,42$ & $57,13 \pm 0,03$ & $46,85 \pm 0,55$ & $58,41 \pm 0,21$ & $49,94 \pm 0,37$ \\
\hline 10 & $51,22 \pm 0,11$ & $45,23 \pm 0,69$ & $52,89 \pm 0,31$ & $41,64 \pm 0,44$ & $55,67 \pm 0,18$ & $46,65 \pm 0,24$ \\
\hline 13 & $49,23 \pm 0,24$ & $41,44 \pm 0,07$ & $53,46 \pm 0,58$ & $44,17 \pm 0,60$ & $55,23 \pm 0,11$ & $45,44 \pm 0,10$ \\
\hline 25 & $51,22 \pm 0,00$ & \begin{tabular}{|l|}
$44,87 \pm 0,52$ \\
\end{tabular} & $55,74 \pm 0,11$ & $46,07 \pm 0,09$ & $56,56 \pm 0,73$ & $47,87 \pm 0,22$ \\
\hline 27 & $50,53 \pm 0,17$ & $44,94 \pm 1,30$ & $54,62 \pm 0,08$ & $44,26 \pm 0,11$ & $55,56 \pm 0,73$ & $46,03 \pm 0,23$ \\
\hline 33 & $51,20 \pm 0,26$ & $43,97 \pm 0,18$ & $54,61 \pm 0,43$ & $43,25 \pm 0,01$ & $56,11 \pm 0,03$ & $47,60 \pm 1,08$ \\
\hline 37 & $50,94 \pm 0,21$ & $44,40 \pm 0,92$ & $53,30 \pm 0,36$ & $42,15 \pm 0,19$ & $58,55 \pm 0,17$ & $49,78 \pm 0,26$ \\
\hline 40 & $51,21 \pm 0,04$ & $46,69 \pm 0,61$ & $53,97 \pm 0,17$ & $42,45 \pm 0,17$ & $56,49 \pm 0,07$ & $47,33 \pm 0,39$ \\
\hline 41 & $51,36 \pm 0,08$ & $42,81 \pm 1,04$ & $53,74 \pm 0,76$ & $41,67 \pm 0,76$ & $56,10 \pm 0,07$ & $47,24 \pm 0,57$ \\
\hline 45 & $51,10 \pm 0,00$ & $46,30 \pm 0,63$ & $52,35 \pm 0,59$ & $41,52 \pm 0,59$ & $57,20 \pm 0,06$ & $47,27 \pm 0,48$ \\
\hline 46 & $50,05 \pm 0,18$ & $44,30 \pm 0,98$ & $49,81 \pm 0,31$ & $39,78 \pm 0,31$ & $55,24 \pm 0,69$ & $46,25 \pm 0,37$ \\
\hline 52 & $50,08 \pm 0,21$ & $45,92 \pm 0,58$ & $52,42 \pm 0,30$ & $41,93 \pm 0,30$ & $55,98 \pm 0,39$ & $47,74 \pm 0,47$ \\
\hline 59 & $50,13 \pm 0,00$ & $45,71 \pm 0,24$ & $54,81 \pm 0,33$ & $43,73 \pm 0,33$ & $56,74 \pm 0,29$ & $48,64 \pm 0,25$ \\
\hline 61 & $50,69 \pm 0,23$ & $44,43 \pm 0,20$ & $52,99 \pm 0,83$ & $42,38 \pm 0,83$ & $55,98 \pm 0,20$ & $49,06 \pm 0,35$ \\
\hline Média & $51,03 \pm 0,15$ & $44,80 \pm 0,62$ & $53,69 \pm 0,31$ & $42,91 \pm 0,36$ & $56,40 \pm 0,29$ & $47,60 \pm 0,41$ \\
\hline Minimo & 49,23 & 41,44 & 49,81 & 39,78 & 55,23 & 45,44 \\
\hline Máximo & 54,24 & 47,48 & 57,13 & 46,85 & 58,55 & 49,94 \\
\hline DesvPad & 1,14 & 1,54 & 1,67 & 1,85 & 1,00 & 1,31 \\
\hline C.V.,\% & 2,23 & 3,44 & 3,11 & 4,31 & 1,77 & 2,74 \\
\hline
\end{tabular}

DesvPad: Desvio padrão

C.V.: Coeficiente de variação 
Anexo G. Resultados da deslignificação kraft-AQ para sessenta e quatro árvores de Eucalyptus grandis.

\begin{tabular}{|c|c|c|c|}
\hline Árvore & $\begin{array}{l}\text { Rendimento Bruto } \\
\text { Gravimétrico, \% }\end{array}$ & Número Kappa & $\begin{array}{l}\text { Teor de Lignina } \\
\text { Solubilizada, \% }\end{array}$ \\
\hline 1 & $52,74 \pm 0,90$ & $15,8 \pm 0,0$ & 95,10 \\
\hline 2 & $54,37 \pm 0,67$ & $18,9 \pm 1,2$ & 93,99 \\
\hline 3 & $51,87 \pm 1,12$ & $21,6 \pm 3,1$ & 93,96 \\
\hline 4 & $51,08 \pm 0,69$ & $17,8 \pm 0,6$ & 95,31 \\
\hline 5 & $54,55 \pm 1,76$ & $17,8 \pm 2,1$ & 94,44 \\
\hline 6 & $57,03 \pm 0,94$ & $17,3 \pm 0,1$ & 93,91 \\
\hline 7 & $53,58 \pm 0,03$ & $16,4 \pm 0,1$ & 94,86 \\
\hline 8 & $50,12 \pm 1,89$ & $16,8 \pm 0,6$ & 95,17 \\
\hline 9 & $52,45 \pm 1,34$ & $18,3 \pm 1,4$ & 94,45 \\
\hline 10 & $53,90 \pm 0,84$ & $20,4 \pm 3,5$ & 93,48 \\
\hline 11 & $51,81 \pm 1,59$ & $18,8 \pm 1,0$ & 94,42 \\
\hline 12 & $52,83 \pm 0,52$ & $17,3 \pm 1,7$ & 94,58 \\
\hline 13 & $52,88 \pm 0,79$ & $18,5 \pm 0,2$ & 94,27 \\
\hline 14 & $52,39 \pm 0,78$ & $16,4 \pm 0,8$ & 95,63 \\
\hline 15 & $54,03 \pm 0,01$ & $19,3 \pm 1,0$ & 94,49 \\
\hline 16 & $50,71 \pm 0,43$ & $18,9 \pm 0,4$ & 95,28 \\
\hline 17 & $51,60 \pm 0,59$ & $21,2 \pm 0,7$ & 94,33 \\
\hline 18 & $52,57 \pm 0,24$ & $18,2 \pm 1,3$ & 94,24 \\
\hline 19 & $51,21 \pm 0,81$ & $21,2 \pm 1,0$ & 93,70 \\
\hline 20 & $52,88 \pm 0,49$ & $20,1 \pm 0,4$ & 94,12 \\
\hline 21 & $51,60 \pm 0,58$ & $24,3 \pm 0,7$ & 93,01 \\
\hline 22 & $51,21 \pm 0,59$ & $21,8 \pm 0,6$ & 94,10 \\
\hline 23 & $53,52 \pm 0,54$ & $18,3 \pm 0,2$ & 94,86 \\
\hline 24 & $53,18 \pm 1,37$ & $24,4 \pm 1,3$ & 93,37 \\
\hline 25 & $54,81 \pm 0,93$ & $18,4 \pm 0,0$ & 93,91 \\
\hline 26 & $52,88 \pm 0,61$ & $19,8 \pm 1,2$ & 94,03 \\
\hline 27 & $54,14 \pm 0,03$ & $19,4 \pm 1,4$ & 93,81 \\
\hline 28 & $52,34 \pm 1,33$ & $23,1 \pm 2,7$ & 93,31 \\
\hline 29 & $54,14 \pm 0,85$ & $16,7 \pm 0,4$ & 94,92 \\
\hline 30 & $51,78 \pm 0,49$ & $18,4 \pm 0,5$ & 94,98 \\
\hline 31 & $54,19 \pm 0,64$ & $18,9 \pm 0,2$ & 94,06 \\
\hline 32 & $51,28 \pm 1,37$ & $17,8 \pm 1,6$ & 94,71 \\
\hline 33 & $54,43 \pm 0,12$ & $16,2 \pm 0,7$ & 94,42 \\
\hline 34 & $53,28 \pm 0,38$ & $17,4 \pm 1,3$ & 94,93 \\
\hline 35 & $52,73 \pm 1,29$ & $18,5 \pm 0,6$ & 94,74 \\
\hline 36 & $52,62 \pm 0,75$ & $17,8 \pm 1,0$ & 94,66 \\
\hline 37 & $54,89 \pm 1,08$ & $16,9 \pm 1,7$ & 94,55 \\
\hline 38 & $52,50 \pm 0,44$ & $20,6 \pm 2,3$ & 94,00 \\
\hline
\end{tabular}


Anexo G. Resultados da deslignificação kraft-AQ para sessenta e quatro árvores de Eucalyptus grandis.

\begin{tabular}{|c|c|c|c|}
\hline 39 & $51,28 \pm 0,57$ & $15,2 \pm 0,5$ & 95,49 \\
\hline 40 & $54,62 \pm 0,82$ & $15,0 \pm 0,5$ & 94,94 \\
\hline 41 & $55,02 \pm 0,23$ & $14,9 \pm 0,6$ & 95,27 \\
\hline 42 & $50,47 \pm 0,59$ & $14,3 \pm 0,2$ & 96,21 \\
\hline 43 & $53,98 \pm 1,83$ & $16,6 \pm 0,1$ & 95,01 \\
\hline 44 & $52,38 \pm 0,44$ & $15,7 \pm 0,3$ & 95,38 \\
\hline 45 & $55,64 \pm 0,28$ & $15,4 \pm 0,8$ & 94,55 \\
\hline 46 & $55,06 \pm 0,10$ & $18,3 \pm 0,1$ & 94,34 \\
\hline 47 & $53,01 \pm 1,14$ & $19,8 \pm 1,2$ & 94,06 \\
\hline 48 & $53,89 \pm 0,19$ & $18,0 \pm 0,5$ & 94,46 \\
\hline 49 & $53,52 \pm 0,39$ & $14,9 \pm 0,5$ & 95,32 \\
\hline 50 & $52,30 \pm 1,23$ & $17,1 \pm 0,8$ & 95,01 \\
\hline 51 & $52,67 \pm 0,62$ & $17,8 \pm 1,0$ & 94,47 \\
\hline 52 & $54,45 \pm 0,13$ & $18,7 \pm 0,4$ & 93,58 \\
\hline 53 & $52,70 \pm 0,92$ & $16,2 \pm 0,2$ & 95,05 \\
\hline 54 & $53,72 \pm 1,45$ & $18,7 \pm 0,6$ & 93,78 \\
\hline 55 & $53,42 \pm 0,31$ & $16,7 \pm 0,3$ & 95,01 \\
\hline 56 & $54,49 \pm 0,20$ & $18,7 \pm 2,1$ & 94,13 \\
\hline 57 & $53,46 \pm 0,24$ & $19,3 \pm 1,4$ & 93,76 \\
\hline 58 & $52,71 \pm 0,11$ & $18,5 \pm 0,9$ & 94,39 \\
\hline 59 & $55,14 \pm 0,19$ & $18,2+2,3$ & 93,57 \\
\hline 60 & $52,10 \pm 0,56$ & $16,1 \pm 1,2$ & 94,96 \\
\hline 61 & $54,60 \pm 0,20$ & $16,5 \pm 0,8$ & 94,39 \\
\hline 62 & $53,28 \pm 1,21$ & $19,4 \pm 0,7$ & 93,39 \\
\hline 63 & $52,60 \pm 0,22$ & $16,1 \pm 0,6$ & 94,87 \\
\hline 64 & $52,89 \pm 0,09$ & $19,7 \pm 1,4$ & 93,87 \\
\hline Média & $53,12 \pm 0,69$ & $18,2 \pm 0,9$ & 94,46 \\
\hline Mínimo & 50,12 & 14,3 & 93,01 \\
\hline Máximo & 57,03 & 24,4 & 96,21 \\
\hline DesvPad & 1,35 & 2,10 & 0,64 \\
\hline C.V.,\% & 2,54 & 11,80 & 0,68 \\
\hline
\end{tabular}

DesvPad: Desvio padrão

C. V.: Coeficiente de variação

Os valores relacionados no Anexo $G$ expressam o valor médio para duas determinações e seu respectivo erro padrão. 
Anexo $\mathrm{H}$. Consumo específico de madeira na deslignficação kraft-AQ para sessenta e quatro árvores de Eucalyptus grandis.

\begin{tabular}{|c|c|}
\hline Árvore & $\begin{array}{c}\text { Consumo Específico } \\
\text { de Madeira, } \mathrm{m}^{3} \text { de } \\
\text { madeira/t de celulose } \\
\text { s.e }\end{array}$ \\
\hline 1 & $4,070 \pm 0,070$ \\
\hline 2 & $3,857 \pm 0,048$ \\
\hline 3 & $3,931 \pm 0,358$ \\
\hline 4 & $4,764 \pm 0,064$ \\
\hline 5 & $4,268 \pm 0,138$ \\
\hline 6 & $3,335 \pm 0,055$ \\
\hline 7 & $4,040 \pm 0,002$ \\
\hline 8 & $4,520 \pm 0,170$ \\
\hline 9 & $4,268 \pm 0,109$ \\
\hline 10 & $3,899 \pm 0,061$ \\
\hline 11 & $4,000 \pm 0,122$ \\
\hline 12 & $3,903 \pm 0,039$ \\
\hline 13 & $4,378 \pm 0,065$ \\
\hline 14 & $4,187 \pm 0,062$ \\
\hline 15 & $4,236 \pm 0,001$ \\
\hline 16 & $4,523 \pm 0,039$ \\
\hline 17 & $4,196 \pm 0,048$ \\
\hline 18 & $4,508 \pm 0,020$ \\
\hline 19 & $4,293 \pm 0,068$ \\
\hline 20 & $4,231 \pm 0,040$ \\
\hline 21 & $3,706 \pm 0,041$ \\
\hline 22 & $4,439 \pm 0,051$ \\
\hline 23 & $3,901 \pm 0,039$ \\
\hline 24 & $3,668 \pm 0,094$ \\
\hline 25 & $3,431 \pm 0,058$ \\
\hline 26 & $3,745 \pm 0,043$ \\
\hline 27 & $3,579 \pm 0,002$ \\
\hline 28 & $4,239 \pm 0,108$ \\
\hline 29 & $4,061 \pm 0,064$ \\
\hline 30 & $4,588 \pm 0,043$ \\
\hline 31 & $4,625 \pm 0,055$ \\
\hline 32 & $4,143 \pm 0,111$ \\
\hline 33 & $4,038 \pm 0,009$ \\
\hline 34 & $4,491 \pm 0,032$ \\
\hline 35 & $4,929 \pm 0,121$ \\
\hline
\end{tabular}

\begin{tabular}{|c|c|}
\hline Árvore & $\begin{array}{c}\text { Consumo Específico } \\
\text { de Madeira, } \mathrm{m}^{3} \mathrm{de} \\
\text { madeira/t de celulose } \\
\text { s.e }\end{array}$ \\
\hline 36 & $4,963 \pm 0,071$ \\
\hline 37 & $4,199 \pm 0,083$ \\
\hline 38 & $3,864 \pm 0,033$ \\
\hline 39 & $4,621 \pm 0,051$ \\
\hline 40 & $4,412 \pm 0,066$ \\
\hline 41 & $4,103 \pm 0,017$ \\
\hline 42 & $5,068 \pm 0,059$ \\
\hline 43 & $4,067 \pm 0,138$ \\
\hline 44 & $5,091 \pm 0,043$ \\
\hline 45 & $4,048 \pm 0,021$ \\
\hline 46 & $3,760 \pm 0,007$ \\
\hline 47 & $3,876 \pm 0,083$ \\
\hline 48 & $4,604 \pm 0,016$ \\
\hline 49 & $4,828 \pm 0,035$ \\
\hline 50 & $4,429 \pm 0,104$ \\
\hline 51 & $3,923 \pm 0,046$ \\
\hline 52 & $4,193 \pm 0,010$ \\
\hline 53 & $4,374 \pm 0,076$ \\
\hline 54 & $3,833 \pm 0,104$ \\
\hline 55 & $4,169 \pm 0,024$ \\
\hline 56 & $4,152 \pm 0,015$ \\
\hline 57 & $4,232 \pm 0,019$ \\
\hline 58 & $4,662 \pm 0,010$ \\
\hline 59 & $4,287 \pm 0,014$ \\
\hline 60 & $5,188 \pm 0,056$ \\
\hline 61 & $4,435 \pm 0,016$ \\
\hline 62 & $4,127 \pm 0,094$ \\
\hline 63 & $4,391 \pm 0,018$ \\
\hline 64 & $4,192 \pm 0,008$ \\
\hline Média & $4,236 \pm 0,059$ \\
\hline Mínimo & 3,335 \\
\hline Máximo & 5,188 \\
\hline DesvPad & 0,391 \\
\hline C.V.,\% & 9,23 \\
\hline
\end{tabular}

Os valores relacionados no Anexo $\mathrm{H}$ expressam o valor médio para duas determinações e seu respectivo erro padrão. 
Anexo 1. Análise do custo total da deslignificação kraft-AQ para as sessenta e quatro árvores de Eucalyptus grandis.

\begin{tabular}{|c|c|c|c|c|}
\hline Árvore & $\begin{array}{c}\text { Densidade Básica } \\
\text { Média da Árvore, } \\
\mathrm{g} / \mathrm{cm}^{3}\end{array}$ & $\begin{array}{l}\text { Rendimento } \\
\text { da Polpação, } \\
\% \\
\end{array}$ & $\begin{array}{l}\text { Número } \\
\text { Kappa da } \\
\text { Polpa }\end{array}$ & $\begin{array}{l}\text { Custo Total da Polpação, } \\
\text { \$US/t Celulose Não- } \\
\text { Branqueada Seca }\end{array}$ \\
\hline 6 & 0,526 & 57,03 & 17,3 & 174.59 \\
\hline 25 & 0,532 & 54,81 & 18,4 & 178.36 \\
\hline 27 & 0,516 & 54,14 & 19,4 & 182.82 \\
\hline 24 & 0,513 & 53,18 & 24,4 & 185.80 \\
\hline 46 & 0,483 & 55,06 & 18,3 & 187.25 \\
\hline 21 & 0,523 & 51,60 & 24,3 & 187.75 \\
\hline 26 & 0,505 & 52,88 & 19,8 & 188.12 \\
\hline 54 & 0,486 & 53,72 & 18,7 & 189.91 \\
\hline 2 & 0,477 & 54,37 & 18,9 & 190.13 \\
\hline 38 & 0,493 & 52,50 & 20,6 & 191.41 \\
\hline 47 & 0,487 & 53,01 & 19,8 & 191.42 \\
\hline 10 & 0,476 & 53,90 & 20,4 & 191.51 \\
\hline 23 & 0,479 & 53,52 & 18,3 & 191.72 \\
\hline 12 & 0,485 & 52,83 & 17,3 & 192.21 \\
\hline 51 & 0,484 & 52,67 & 17,8 & 192.84 \\
\hline 45 & 0,444 & 55,64 & 15,4 & 194.23 \\
\hline 33 & 0,455 & 54,43 & 16,2 & 194.86 \\
\hline 11 & 0,483 & 51,81 & 18,8 & 195.38 \\
\hline 7 & 0,462 & 53,58 & 16,4 & 195.45 \\
\hline 29 & 0,455 & 54,14 & 16,7 & 195.63 \\
\hline 43 & 0,456 & 53,98 & 16,6 & 195.74 \\
\hline 41 & 0,443 & 55,02 & 14,9 & 195.95 \\
\hline 1 & 0,466 & 52,74 & 15,8 & 196.63 \\
\hline 62 & 0,455 & 53,28 & 19,4 & 197.72 \\
\hline 56 & 0,442 & 54,49 & 18,7 & 197.73 \\
\hline 37 & 0,434 & 54,89 & 16,9 & 198.56 \\
\hline 55 & 0,449 & 53,42 & 16,7 & 198.66 \\
\hline 52 & 0,438 & 54,45 & 18,7 & 198.81 \\
\hline 32 & 0,471 & 51,28 & 17,8 & 199.41 \\
\hline 64 & 0,451 & 52,89 & 19,7 & 199.64 \\
\hline 14 & 0,456 & 52,39 & 16,4 & 199.75 \\
\hline 15 & 0,437 & 54,03 & 19,3 & 200.08 \\
\hline 57 & 0,442 & 53,46 & 19,3 & 200.25 \\
\hline 5 & 0,430 & 54,55 & 17,8 & 200.41 \\
\hline 20 & 0,447 & 52,88 & 20,1 & 200.55 \\
\hline 59 & 0,423 & 55,14 & 18,2 & 200.58 \\
\hline 17 & 0,462 & 51,60 & 21,2 & 200.61 \\
\hline 28 & 0,451 & 52,34 & 23,1 & 201.18 \\
\hline
\end{tabular}


Anexo I. Análise do custo total da deslignificação kraft-AQ para a sessenta e quatro árvores de Eucalyptus grandis.

\begin{tabular}{c|c|c|c|c}
9 & 0,447 & 52,45 & 18,3 & 201.77 \\
\hline 19 & 0,455 & 51,21 & 21,2 & 203.33 \\
\hline 40 & 0,415 & 54,62 & 15,0 & 204.12 \\
\hline 53 & 0,434 & 52,70 & 16,2 & 204.21 \\
\hline 13 & 0,432 & 52,88 & 18,5 & 204.38 \\
\hline 61 & 0,413 & 54,60 & 16,5 & 204.71 \\
\hline 63 & 0,433 & 52,60 & 16,1 & 204.79 \\
\hline 3 & 0,440 & 51,87 & 21,6 & 205.05 \\
\hline 50 & 0,432 & 52,30 & 17,1 & 205.79 \\
\hline 34 & 0,418 & 53,28 & 17,4 & 206.70 \\
\hline 22 & 0,440 & 51,21 & 21,8 & 206.89 \\
\hline 18 & 0,422 & 52,57 & 18,2 & 207.83 \\
\hline 48 & 0,403 & 53,89 & 18,0 & 209.25 \\
\hline 31 & 0,399 & 54,19 & 18,9 & 209.38 \\
\hline 16 & 0,436 & 50,71 & 18,9 & 209.41 \\
\hline 8 & 0,442 & 50,12 & 16,8 & 209.59 \\
\hline 30 & 0,421 & 51,78 & 18,4 & 210.19 \\
\hline 39 & 0,422 & 51,28 & 15,2 & 211.21 \\
\hline 58 & 0,407 & 52,71 & 18,5 & 211.42 \\
\hline 4 & 0,411 & 51,08 & 17,8 & 214.77 \\
\hline 49 & 0,387 & 53,52 & 14,9 & 214.82 \\
\hline 35 & 0,385 & 52,73 & 18,5 & 217.66 \\
\hline 36 & 0,383 & 52,62 & 17,8 & 218.41 \\
\hline 44 & 0,375 & 52,38 & 15,7 & 221.80 \\
\hline 42 & 0,391 & 50,47 & 14,3 & 222.49 \\
\hline 60 & 0,370 & 52,10 & 16,1 & 224.15 \\
\hline Média & 0,447 & 53,12 & 18,2 & 200.59 \\
\hline Mínimo & $\mathbf{0 , 3 7 0}$ & 50,12 & 14,3 & $\mathbf{1 7 4 . 5 9}$ \\
\hline Máximo & $\mathbf{0 , 5 3 2}$ & $\mathbf{5 7 , 0 3}$ & $\mathbf{2 4 , 4}$ & $\mathbf{2 2 4 . 1 5}$ \\
\hline DesvPad & $\mathbf{0 , 0 3 7}$ & $\mathbf{1 , 3 5}$ & $\mathbf{2 , 1}$ & $\mathbf{1 0 , 7}$ \\
\hline C.V.\% & $\mathbf{8 , 3 2}$ & $\mathbf{2 , 5 5}$ & $\mathbf{1 1 , 8 0}$ & $\mathbf{5 0 7}$ \\
\hline C. & & & &
\end{tabular}

DesvPad: Desvio padrão

C.V.: Coeficiente de variação

As árvores assinaladas em negrito correspondem àquelas selecionadas pelos três critérios da deslignificação. 